\title{
Tick Size Regulation, Intermarket Competition and Sub-Penny Trading
}

\author{
Sabrina Buti*, \\ Barbara Rindi ${ }^{\dagger}$ \\ Yuanji Wen $\stackrel{\text { Ingrid M. Werner }}{\S}$
}

June 1, 2011

\begin{abstract}
The minimum price variation, or tick size, is at the center of the current regulatory debate as it affects competition for liquidity provision in limit order books. A reduction in the tick size is firstly shown to have a detrimental effect on the quality of illiquid stocks as it worsens both spread and depth; but it benefits liquid stocks as it reduces inside spread and increases market depth. Then we build a dual-market model and examine how competition between two public limit order books (PLB) ends up with liquidity concentration on the market with a smaller tick size. By introducing different trader type, we adapt this dual-market framework into a model with a PLB competing with another book characterized by a smaller tick size, namely Internalization Pool (IP). In this way we are able to investigate the issue of sub-penny trading that is discussed in the SEC concept release on Equity Market Structure (2010). Our findings are as follows: for illiquid low priced stocks, the quality of a PLB is dramatically worsened when broker-dealers are able to use an internalization pool (IP) to provide price improvement by a fraction of the tick size; for liquid stocks however, the introduction of an IP fosters competition and improves both spread and depth. In addition our model predicts that broker-dealers use IP more intensively for low priced liquid stocks.
\end{abstract}

\footnotetext{
${ }^{*}$ University of Toronto, Rotman School of Management, Sabrina.Buti@rotman.utoronto.ca

${ }^{\dagger}$ Bocconi University, Igier and Carefin, barbara.rindi@unibocconi.it

‡Bocconi University, yuanji.wen@phd.unibocconi.it

$\S$ Fisher College of Business, Ohio State University
} 


\title{
Tick Size Regulation, Intermarket Competition and Sub-Penny Trading
}

\begin{abstract}
The minimum price variation, or tick size, is at the center of the current regulatory debate as it affects competition for liquidity provision in limit order books. A reduction in the tick size is firstly shown to have a detrimental effect on the quality of illiquid stocks as it worsens both spread and depth; but it benefits liquid stocks as it reduces inside spread and increases market depth. Then we build a dual-market model and examine how competition between two public limit order books (PLB) ends up with liquidity concentration on the market with a smaller tick size. By introducing different trader type, we adapt this dualmarket framework into a model with a PLB competing with another book characterized by a smaller tick size, namely Internalization Pool (IP). In this way we are able to investigate the issue of sub-penny trading that is discussed in the SEC concept release on Equity Market Structure (2010). Our findings are as follows: for illiquid low priced stocks, the quality of a PLB is dramatically worsened when broker-dealers are able to use an internalization pool (IP) to provide price improvement by a fraction of the tick size; for liquid stocks however, the introduction of an IP fosters competition and improves both spread and depth. In addition our model predicts that broker-dealers use IP more intensively for low priced liquid stocks.
\end{abstract}




\section{Introduction}

The minimum price variation, or tick size, for stocks traded in financial markets is a timely issue in market design and it has been at the center of the financial regulatory debate over the last decade. When reducing the tick size, regulators have to ponder the tradeoff between the benefits of an enhanced price competition for liquidity provision (and the resulting narrower spread), and the reduced incentive to submit limit orders caused by easier undercutting.

Nevertheless, over the last ten years stock exchanges around the world have persistently reduced the minimum price variations into small magnitudes (Table 1). The most recent change in the U.S. markets occurred between 2001 and 2004, when the minimum price variation was gradually lowered to one penny. More precisely, today's quotations in National Market System (NMS) stocks must be priced in an increment of $\$ .01$, unless the quotation is less than $\$ 1.00$, in which case the increment is $\$ .0001$.

\section{[Insert Table 1 here]}

In this paper we model intermarket competition between two limit order books to investigate how the tick size should be regulated when trading platforms can compete with each other by reducing the tick size, and when some market participants can take advantage of internalization pools to undercut aggressively (by fractions of a penny) the orders posted on top of visible limit order books.

As a vast body of empirical literature ${ }^{1}$ has shown, when the tick size is reduced, spread decreases, but depth at the top of the book deteriorates; for this reason to protect displayed limit orders from the practice of stepping ahead by trivial amounts, the Sub-Penny Rule (adopted Rule 612 under Regulation NMS) was introduced. It prohibits market participants from displaying, ranking, or accepting quotations in NMS stocks that are priced at increments less than the minimum price variation.

During the last five years, however, two new elements - the development of dark markets and of fast trading facilities - have emerged and deeply affected intermarket competition. They have made Rule 612 ineffective at protecting displayed limit orders. In particular, two features of the rule must be considered. First, the Security and Exchange Commission (SEC) Rule 612 prohibits market participants from quoting prices in sub-penny, but in the belief that sub-penny trading would not be as detrimental as sub-penny quoting, it expressly allows broker-dealers to "provide price improvement to a customer order that resulted in a sub-penny execution". Second, Rule 612 prohibition of sub-penny quoting does not apply to dark markets. This means that broker-dealers can exploit dark pools to jump the queue

\footnotetext{
${ }^{1}$ See Ahn et al. (1996 and 2007), Bacidore (1997), Bourghelle and Declerck (2004), Cai et al. (2008), Griffiths et al. (1998), Lau and McInish (1995), Porter and Weaver (1997) and Ronen and Weaver (2001).
} 
by a fraction of a penny and so preempt the National Best Bid Offer (NBBO); in addition, by drawing on fast algorithmic programmes to persistently replicate trading strategies, they can make profit from the considerable amount of volume created by such price priority at negligible cost. ${ }^{2}$ It should be remarked, however, that the practice of queue jumping must not be confused with executions at the spread midpoint that take place in those dark pools designed to reduce the price impact of block trading (Buti, Rindi and Werner, 2010). Figure 1 shows in fact that over the last 10 years the proportion of queue jumping has dramatically increased compared to mid-quote trading.

\section{[Insert Figure 1 here]}

A potential negative consequence of sub-penny trading is that investors can be discouraged from providing liquidity at the top of the book; hence, within the regulatory debate on the possible solutions to the sub-penny issue, the SEC has recently proposed the Trade-At Rule $^{3}$ that would practically ban sub-penny trading by prohibiting "any trading center from executing a trade at the price of the NBBO unless the trading center was displaying that price at the time it received the incoming contra-side order." Quite the opposite is instead the proposed solution to level the playing field by reducing the minimum price increment of publicly displayed market centers to sub-pennies (BATS, 2009).

To disentangle these policy debates, it is important to clarify the effects of sub-penny trading on market quality and the factors affecting queue jumping by broker-dealers, which help us to understand how the minimum tick size regulation should interact with sub-penny trading ban.

Intuitively, on the one hand, sub-penny trading creates room for broker-dealers to make profit but meantime threatens the health of the competitive market as a whole. For a stock, a relatively small tick size fosters competition for liquidity provision and reduces brokerdealers' profits from trading against their customer orders (i.e. to internalize the order) and sub-pennying passive limit orders. Hence, a reduction in the tick size can be viewed as a way to alleviate the negative effect of sub-penny trading. On the other hand, a smaller tick size discourages liquidity providers to post limit orders on the top of the book because of being undercut more easily. Thus tick size reduction could negatively affect market depth while sub-penny trading in any case cannot improve the depth. Therefore the critical regulatory issue is to adjust the tick size to a reasonable magnitude which balances the effect on subpenny trading and the liquidity discouragement. Note that these two effects are sensitive in stock price and liquidity characteristics. Very preliminary empirical evidence (Delassus and Tyc, 2010) suggests that the practice of queue jumping could be negatively related to the stock price. ${ }^{4}$

\footnotetext{
${ }^{2}$ Jarnecic and Snape (2010) suggest that high frequency trading is negatively related to the tick size.

${ }^{3}$ SEC concept release on Equity Market Structure No. 34-61358.

${ }^{4}$ Delassus and Tyc complete sample comprises 1800 NASDAQ stocks; their sample period includes 5 consecutive trading days.
} 
Our paper provides a theoretical discussion on the regulation of the tick size when different platforms compete for liquidity provision and therefore it is also suitable to address the issue of sub-penny trading. Starting with a one-market model (Section 3 and 4), we show that the effect of a tick size reduction depends on both the liquidity of the stock and the asset value. For very illiquid stocks a reduction of the tick size discourages even further liquidity provision and worsens market quality; for liquid stocks, instead, it makes undercutting cheaper, and thus increases competition among liquidity suppliers and improves market quality. Notice however that for very liquid stocks the liquidity pressure at the best bid-offer is so intense that after the tick size reduction inside depth decreases. Clearly when the value of the tick size becomes relatively large compared to the stock price (i.e. for low priced stocks), the effects of having a finer price grid become stronger.

We then extend the framework to a dual-market model (Section 5) and find that, due to intermarket competition, liquidity concentrates on the small-tick limit order book. Traders take advantage of the finer price grid to undercut the quotes available on the large-tick market, thus draining liquidity away from it. This result is intuitively straightforward, and it explains both the existing empirical evidence on the effects of a tick size reduction and the current trend that sees stock exchanges competing to reduce the tick size.

Finally, we investigate the sub-penny trading issue (Section 6) by embedding a group of broker-dealers who can choose between trading in a lit market or in an internalization pool (IP) where they can execute their customers' orders. Competition from IP reduces liquidity demand on the public limit order book (PLB), which improves or deteriorates market quality depending on the stock characteristics. When aggressive orders are intercepted by the IP, depth on the PLB is preserved, but at the same time limit orders' execution probability decreases and consequently the incentive to provide liquidity is reduced. The net effect on market quality of the IP competition will clearly depend on the initial level of the stock liquidity. We show that for illiquid low priced stocks the availability of an internalization pool is detrimental; for liquid stocks, in contrast, it enhances price competition so that spread and depth improve. We also find that broker-dealers trade on the IP more intensively when competition for liquidity provision on the PLB is tough, so for liquid stocks; this effect becomes stronger as the tick to price ratio increases, i.e. for low priced stocks.

These results allow us to discuss both the sub-penny rule and the recently proposed Trade-At Rule. We suggest that by setting the minimum price improvement, regulators should consider both the asset value and the bid-ask spread. An adequate tick size should reduce the incentive for broker-dealers to implement sub-penny trading in illiquid and low priced stocks and also prevent the effective bid-ask spread from being held unnaturally wide. Having adjusted the minimum tick size, regulators should consider a carefully designed Trade-At Rule that addresses the issue of sub-penny trading without unfairly impacting on dark venues (BATS, 2009) and commonly used hidden mid-point orders (Buti and Rindi, 2009). One possible waiver that could be introduced is to allow sub-penny trading and quoting to take place in dark markets at the prevailing inside spread midquote. 
On the European front, our analysis sheds some light on the competition between lit and dark markets that is at the center of the regulatory debate. In the recent consultation paper of the "Review of the Market in Financial Instruments Directive", the European Commission conveys some concern on the unregulated nature of the brokers' crossing systems and proposes a new sub-regime that would regulate the activity of those internalization pools that are used by brokers to match their client's orders (European Commission, 2010). In response to this public consultation, Brandes and Domowitz (2011) outline that "all dark pools are assumed to be equal in structure from the regulatory perspective, but some are clearly less efficient than others", and present some evidence that Broker Pools' performance is worse than Multilateral Trading Facilities (MTF) pools'; they also show how dark markets' performance differs depending on the stocks' capitalization. In light of these results, our paper suggests the need for an empirical assessment of the effects that different dark markets can have on the quality of the primary markets as well as of the MTF, and therefore it draws attention to the relevance of the more transparent post trading reporting regime proposed in the same consultation paper by the European Commission.

Our model is related to three strands of the existing theoretical literature (Section 2), respectively on intermarket competition ${ }^{5}$, the optimal tick size ${ }^{6}$ and broker-dealers' internalization of order flows (Battalio and Holden, 2001), and to the best of our knowledge it is the first one that allows researchers to investigate the tick size rule within the context of intermarket competition. It also departs from existing theoretical works as it embeds sub-penny trading through an internalization pool.

\section{Literature Review}

Financial literature extensively covers the relationship between the reduction of the tick size and market quality. Empirical findings from different markets concur that after reducing the tick size, spread and depth decline and that the spread is not equally affected across stocks. ${ }^{7}$ These findings are also consistent with a recent pilot programme implemented by the major European platforms aimed at investigating the effect of a reduction of the tick size. ${ }^{8}$ Theoretically Seppi (1997) points out that as the tick size decreases, cumulative

\footnotetext{
${ }^{5}$ See, for example, Chowdhry and Nanda (1991) and Parlour and Seppi (2003).

${ }^{6}$ See Anshuman and Kalay (1998), Cordella and Foucault (1999), Foucault et al. (2005), Goettler et al. (2005), Kadan (2004) and Seppi (1997).

${ }^{7}$ See footnote 1.

${ }^{8}$ In December 2008, BATS Europe, in conjuction with Chi-X, Nasdaq OMX Europe and Turquoise, developed a proposal to standardize the tick size of the pan European trading platforms. Starting June 1, 2009, Chi-X, followed by Turquoise, BATS Europe and finally the LSE and Nasdaq OMX Europe reduced the tick size for a number of stocks. This pilot programme, aimed at studying the effect of a change in the tick size based on actual market data, showed that following the reduction of the tick size, effective spread, inside spread, inside depth and average trade size decreased (BATS, 2010).
} 
depth is minimized. Goettler, Parlour and Rajan (2005) show that by reducing the tick size regulators do not achieve a Pareto improvement but rather an increase of total investors' surplus. Kadan (2004) demonstrates that the effects of a tick size reduction on dealers and investors' welfare depends on the number of dealers active in the market, being detrimental to dealers and beneficial to investors when the number of dealers is large.

As our paper also investigates how different markets compete for the provision of liquidity by reducing the tick size, it is also related to the literature on intermarket competition that documents an improvement in market efficiency brought about by competition. ${ }^{9}$ Chowdhry and Nanda (1991) extend Kyle (1985) model to accommodate multi-market trading and show that markets with the lowest transaction costs attract liquidity. Closer to our framework Degryse et al. (2009) analyze the interaction between a dealer market and a crossing network and show that overall welfare is not necessarily enhanced by the introduction of a crossing network. Our framework substantially differs from this as we model competition between first two LOB and then a LOB and an Internalization Pool. Our model also departs from Buti, Rindi and Werner (2010) who model competition between a LOB and an Dark Pool, as it focuses on the tick size and on Internalization Pools.

Finally our model is related to the literature on broker-dealers internalization. ${ }^{10}$ Battalio and Holden (2001) extends the Glosten and Milgrom (1985) protocol to consider the practice of payment for order flows and internalization. They show that brokers make profits by exploiting their direct relationships with customers. This is consistent with the related empirical works (Chung et al. (2004a and 2004b), Hansch et al. (1999), He et al. (2006), Hendershott and Jones (2005) and Porter and Weaver (1997)).

\section{Single Market Model}

\subsection{The Market}

A market for a security is run over a trading day divided into $T$ periods: $t=1, \ldots, T$. At each period $t$ a trader arrives and can submit orders of unitary size. Following Parlour (1998), traders are rational and have the following linear preferences:

$$
U\left(C_{1}, C_{2} ; \beta\right)=C_{1}+\beta C_{2}
$$

where $C_{1}$ is the cash inflow from selling or buying the security on day 1 , while $C_{2}$ is the cash inflow from the asset payment on day 2 and is equal to $+v(-v)$ in case of a buy (sell) order. Notice that traders are risk neutral and have a personal trade-off between

\footnotetext{
${ }^{9}$ See, for example, Barclay et al. (2003), Bessembinder and Kaufman (1997), Fink et al. (2006) and Goldstein et al. (2008).

${ }^{10}$ Internalization is either the direction of order flows by a broker-dealer to an affiliated specialist, or the execution of order flows by that broker-dealer acting as a market maker.
} 
consumption in the two days equal to $\beta$ that is a patience indicator drawn from the uniform distribution $U(\beta, \bar{\beta})$ with $0 \leq \beta<1<\bar{\beta}$. A patient trader has a $\beta$ next to 1 while an eager one has extreme values of $\beta$. This is a modelling device which captures the trade-off that traders' face between waiting costs and execution costs.

Upon arrival at the market in period $t$, the trader observes the state of the book that is characterized by the number of shares available at each level of the price grid. The latter assembles two prices on the ask $\left(A_{1}, A_{2}\right)$ and two on the bid side of the market $\left(B_{1}, B_{2}\right)$, symmetrically distributed around the asset value $v$. The difference between two adjacent prices, which we name $\tau$, is equal to the minimum price increment and also corresponds to the minimum inside spread. Thus the available prices are equal to $A_{2}=v+\frac{3 \tau}{2}, A_{1}=v+\frac{\tau}{2}$, $B_{1}=v-\frac{\tau}{2}$ and $B_{2}=v-\frac{3 \tau}{2}$, and the state of the book is defined as $S_{t}=\left[Q_{t}^{A_{2}}, Q_{t}^{A_{1}}, Q_{t}^{B_{1}}, Q_{t}^{B_{2}}\right]$. As in Seppi (1997) and Parlour (1998), we assume that a trading crowd provides liquidity at the highest levels of the limit order book and prevents traders from bidding or asking prices that are too far away from the top of the book. Besides, traders are allowed to submit limit orders queuing in front of the trading crowd. In this parsimonious way, we can extend Parlour (1998) model to include two price levels where traders can submit orders, and, at the same time, keep the strategy space as small as possible. In addition we can investigate the effects of the tick size reduction on depth at different levels of the book.

Each trader can submit a unitary order that cannot be modified or cancelled thereafter; his strategy at time $t$ is defined by $H_{t}$. The market permits two types of orders: limit orders (LO) represented by +1 and market orders (MO) represented by -1 . Traders can hence submit limit orders to buy (sell) one share at different levels of the bid (ask) prices, or market orders which hit the bid (ask) prices and are executed immediately, or they can decide not to trade. More precisely, a trader's strategy space is $H=\left\{ \pm 1^{i}, 0\right\}$, where $i=A_{2}, A_{1}, B_{1}$ and $B_{2}$. The change in the LOB induced by the trader's strategy $H_{t}$ is indicated by $h_{t}$ and defined as:

$$
h_{t}=\left[h_{t}^{A_{2}}, h_{t}^{A_{1}}, h_{t}^{B_{1}}, h_{t}^{B_{2}}\right]= \begin{cases}{[ \pm 1,0,0,0]} & \text { if } H_{t}= \pm 1^{A_{2}} \\ {[0, \pm 1,0,0]} & \text { if } H_{t}= \pm 1^{A_{1}} \\ {[0,0, \pm 1,0]} & \text { if } H_{t}= \pm 1^{B_{1}} \quad \forall t=1 . . T \\ {[0,0,0, \pm 1]} & \text { if } H_{t}= \pm 1^{B_{2}} \\ {[0,0,0,0]} & \text { if } H_{t}=0\end{cases}
$$

The state of the book is hence characterized by the following dynamics:

$$
S_{t}=S_{t-1}+h_{t}, \forall t=1 . . T
$$

The expected state of the book at time $t$ is given by:

$$
E\left[S_{t \mid t-1}\right]=S_{t-1}+E\left[h_{t}\right], \forall t=1 . . T
$$

where $E\left[h_{t}^{i}\right]=\underset{\beta \in\left\{\beta: H_{t}(\beta)= \pm 1^{i}\right\}}{ } H_{t}(\beta) d \beta$ for $i=A_{2}, A_{1}, B_{1}, B_{2}$. 


\subsection{Order Submission Decision}

To optimize his order submission strategy, a trader needs to choose an order type and a price. Hence traders have to maximize their utility, which in this risk neutral setting is equivalent to maximize their payoff, considering all the strategies available to them. Market orders guarantee immediate execution but higher price opportunity cost, while limit orders enable traders to get better prices at the cost of uncertain execution. Hence in this market traders face the standard trade-off between execution cost and price opportunity cost. The payoffs of the different strategies available to traders are listed in Table 2. Market equilibrium strategies are derived in the following Section.

\section{[Insert Table 2 here]}

In Table 2 we denote by $A$ and $B$ with no subscript the best available quotes, so that for example a market buy order executed at the best available price is indicated by $-1^{A}$. Notice that $p_{t}^{*}\left(A_{k}^{N_{-k}, N_{k}} \mid S_{t}\right)$ (or $\left.p_{t}^{*}\left(B_{k}^{M_{-k}, M_{k}} \mid S_{t}\right)\right)$ with $k=1,2$ is the equilibrium execution probability, conditional on the state of the limit order book, for a limit sell (or buy) order queuing at the $N_{k}\left(M_{k}\right)$ position at the price level $A_{k}\left(B_{k}\right)$, where $N_{-k}=\sum_{d<k} N_{d}$ $\left(M_{-k}=\sum_{d<k} M_{d}\right)$ is the number of shares standing at lower price levels. ${ }^{11}$ The execution probability depends both on the price level at which the order is posted and the depth available on the limit order book. An order posted at $A_{k}$ and queueing at the $N_{k}-t h$ position, is executed against the $\left(N_{-k}+N_{k}\right)$-th market order only when $\left(N_{-k}+N_{k}-1\right)$ market orders have already hit all the $N_{-k}$ shares available at lower prices, and the $N_{k}-1$ shares available at $A_{k}$ with time priority. If $N_{-k}+N_{k}$ is larger than the number of remaining periods, additional limit orders at that price level will never be executed and $p_{t}\left(A_{k}^{N_{-k}, N_{k}} \mid S_{t}\right)=0$. Notice that the execution probability also depends on the state of the other side of the LOB: a deep LOB on the bid side increases the incentive for a seller to post limit orders as he knows that incoming buyers will be more inclined to post market orders (due to the long queue on the bid side). To facilitate the proof, when the best ask is $A_{k}$ we indicate the execution probability of a limit order queuing at $A_{k}$ by $p_{t}\left(A_{k}^{N_{k}} \mid S_{t}\right)$ instead of using $p_{t}\left(A_{k}^{0, N_{k}} \mid S_{t}\right)$ and the execution probability of the order standing first by $p_{t}\left(A_{k} \mid S_{t}\right)$ instead of using $p_{t}\left(A_{k}^{0,1} \mid S_{t}\right)$.

\subsection{Market Equilibrium}

Traders use information from the state of the limit order book to rationally compute different orders' execution probabilities, and then compare the expected payoffs from each order type to choose the optimal strategy consistent with their own $\beta .{ }^{12}$ The model allows

\footnotetext{
${ }^{11}$ Equilibrium values are indicated with a star superscript.

${ }^{12}$ Notice that, differently from Parlour (1998), we do not assume that traders are ex-ante buyers or sellers but rather endogenously solve for the trader's decision to buy or to sell the asset.
} 
us to compute cutoff values for $\beta$ from which we derive the probabilities of the equilibrium trading strategies; equilibrium is found by backward induction. At time $T$, the execution probability for limit orders is zero, hence traders will only submit market orders or decide not to trade. It can be easily shown that traders' equilibrium strategies are:

$$
H_{T}^{*}\left(\beta, S_{T-1}\right)=\left\{\begin{array}{cl}
-1^{B} & \text { if } \beta \in\left[\beta, \frac{B}{v}\right) \\
0 & \text { if } \beta \in\left[\frac{\bar{B}}{v}, \frac{A}{v}\right) \\
-1^{A} & \text { if } \beta \in\left[\frac{A}{v}, \bar{\beta}\right]
\end{array}\right.
$$

where the best ask and bid prices are equal to $A=A_{1,2}\left(B=B_{1,2}\right)$ depending on the state of the LOB. By using these equilibrium strategies together with the distribution of $\beta$, we can calculate the equilibrium execution probabilities at the best quotes for limit orders submitted at $T-1$ :

$$
\begin{aligned}
& p_{T-1}^{*}\left(A \mid S_{T-1}\right)=\int_{\beta \in\left\{\beta: H_{T}^{*} \mid S_{T-1}=-1^{A}\right\}} 1 d \beta=\frac{\bar{\beta} v-A}{(\bar{\beta}-\underline{\beta}) v} \\
& p_{T-1}^{*}\left(B \mid S_{T-1}\right)= \\
& \int_{\beta \in\left\{\beta: H_{T}^{*} \mid S_{T-1}=-1^{B}\right\}} 1 d \beta=\frac{B-\underline{\beta} v}{(\bar{\beta}-\underline{\beta}) v}
\end{aligned}
$$

These execution probabilities are the dynamic link between period $T$ and $T-1$. Notice that a trader arriving at $T-1$ can choose between a market and a limit order, and his choice is driven by his $\beta$ value. The following Lemma holds: ${ }^{13}$

Lemma 1 If at time $t \neq T$ at least one limit order strategy has positive execution probability, then there will always exist a $\beta$ value for which a limit order is optimally selected by the incoming trader.

As an example, if we solve the trader's maximization problem at $T-1$ after substituting the equilibrium execution probabilities at $T$ given by (4) and (5) for the case $p_{T-1}^{*}\left(A_{k}^{N_{-k}, N_{k}} \mid S_{T-1}\right) \neq 0$ and $p_{T-1}^{*}\left(B_{k}^{M_{-k}, M_{k}} \mid S_{T-1}\right) \neq 0$, we obtain the following optimal strategies:

$$
H_{T-1}^{*}\left(\beta, S_{T-2}\right)= \begin{cases}-1^{B} & \text { if } \beta \in\left[\beta, \beta_{1, T-1}\right) \\ +1^{A_{k}} & \text { if } \beta \in\left[\bar{\beta}_{1, T-1}, \beta_{3, T-1}\right) \\ +1^{B_{k}} & \text { if } \beta \in\left[\beta_{3, T-1}, \beta_{5, T-1}\right) \\ -1^{A} & \text { if } \beta \in\left[\beta_{5, T-1}, \bar{\beta}\right]\end{cases}
$$

\footnotetext{
${ }^{13}$ All the proofs are presented in the Appendix.
} 
where $\beta_{1, T-1}=\frac{B}{v}-\frac{p_{T-1}^{*}\left(A_{k} \mid S_{T-1}\right)}{1-p_{T-1}^{*}\left(A_{k} \mid S_{T-1}\right)} \cdot \frac{A_{k}-B}{v}, \beta_{3, T-1}=\frac{p_{T-1}^{*}\left(A_{k} \mid S_{T-1}\right) A_{k}+p_{T-1}^{*}\left(B_{k} \mid S_{T-1}\right) B_{k}}{p_{T-1}^{*}\left(A_{k} \mid S_{T-1}\right)+p_{T-1}^{*}\left(B_{k} \mid S_{T-1}\right)} \cdot \frac{1}{v}$, and $\beta_{5, T-1}=\frac{A}{v}+\frac{p_{T-1}^{*}\left(B_{k} \mid S_{T-1}\right)}{1-p_{T-1}^{*}\left(B_{k} \mid S_{T-1}\right)} \cdot \frac{A-B_{k}}{v}$. Notice that $p_{T-1}^{*}\left(A_{k}^{N_{-k}, N_{k}} \mid S_{T-1}\right) \neq 0$ only when $N_{-k}=0$ and $N_{k}=1$ : a limit order posted at $T-1$ has a positive execution probability only if it undercuts all the orders resident on the LOB and gains execution priority, as only one trader can still arrive at the market at $T$. Moreover, the larger the limit order execution probability, $p_{T-1}^{*}\left(A_{k} \mid S_{T-1}\right)$, the smaller is the threshold between market sell orders and limit sell orders, $\beta_{1}$, and the more likely it is for traders to submit limit rather than market orders. More generally, if execution probabilities at time $t$ are such that waiting costs are lower than execution costs, traders will submit limit orders. If instead execution probabilities are low, they will choose market orders. Notice also that the optimal price at which a trader will submit a limit order is the result of a trade-off between price risk and execution risk: a more competitive price implies a higher execution probability due to both the lower risk of being undercut by incoming traders and the greater attractiveness of the order for traders on the opposite side. However this is obtained at the cost of lower revenues once the order is executed. This trade-off crucially depends on the relative tick size $\frac{\tau}{v}$, as shown in the following Lemma:

Lemma 2 At each time $t \neq T$ traders' aggressiveness in the provision of liquidity is positively related to the value of $\frac{\tau}{v}$.

From the equilibrium strategies at $T-1$, we can derive the execution probabilities for limit orders submitted at $T-2$ and therefore we can compute the corresponding equilibrium strategies. We can then derive the execution probabilities of limit orders submitted in previous periods, compare the payoffs of different strategies, and finally compute equilibrium strategies back to period $t=1$. Traders' equilibrium strategies shape the equilibrium books $S_{1: T}$. The equilibrium is defined as follows:

Definition 1 Given an initial book $S_{0}$, a dynamic equilibrium is a set of order submission decisions $\left\{H_{t}^{*}\right\}$ and states of the limit order book $\left\{S_{t}\right\}$, for $t \in[1, T]$, such that at each period the trader maximizes his payoff $U(\cdot)$ (Table 2) according to his Bayesian belief over the execution probabilities $p^{*}(\cdot)$, i.e.

$$
\begin{array}{ll}
\left\{H_{t}^{*}:=\arg \max U\left(\cdot \mid S_{t-1}, p_{t-1}^{*}\right)\right\} & \forall t[1, T] \\
\left\{S_{t}:=S_{t-1}+h_{t}^{*}\right\} & \forall t[1, T]
\end{array}
$$

where $h_{t}^{*}$ is defined by $(1)$

\section{Tick Size Reduction and Market Quality}

To investigate the effects of a change in the tick size on traders' strategies and, as a result, on market quality, we start from the single market framework and then, in the next 
Section, we add intermarket competition by allowing agents to trade in a parallel LOB with a different tick size. This allows us to discuss in Section 6 how the tick size changes undertaken both in the US and in Europe during the last decade have interacted with the development of fast and dark trading facilities. We can finally compare the different recent proposals on equity market structure put forward both in US and in Europe by the SEC and the Committee of European Securities Regulators (CESR).

We start with the market characterized by a large tick size (LM) that we already presented in Section 3 and then we compare the resulting equilibrium trading strategies with those obtained when, all else equal, the tick size is reduced from $\tau$ to $\frac{1}{3} \tau$. Both price grids are shown in Table 3: on the LM market the price grid is still $P^{L M}=\left\{A_{2}, A_{1}, B_{1}, B_{2}\right\}$, while on the small tick market (SM) it has 5 levels on both the ask and the bid side, $a_{l}$ and $b_{l}$, where $l=1, . ., 5$. Notice that for the SM the dynamics and expected state of the book are still characterized by equations (2) and (3) respectively, the main difference being that both $S_{t}^{S M}$ and $h_{t}^{S M}$ now consist of ten components instead of four. Notice also that the trader's strategy space is much richer thanks to the finer price grid, $H^{S M}=\left\{ \pm 1^{j}, 0\right\}$ with $j=\left\{a_{1: 5}, b_{1: 5}\right\}$.

\section{[Insert Table 3 here]}

To compare the two markets, we build standard indicators of market quality using traders' equilibrium strategies. Depth is measured by the number of shares available on the LOB at different price levels. More precisely, for the LM we define average depth at price $i$ as $D P_{t}^{i, L M}=E\left[Q_{t}^{i}\right]$, where $i=\left\{A_{1: 2}, B_{1: 2}\right\}$, and average depth at the best quotes, i.e. the inside depth, as $D P I_{t}^{L M}=E\left[Q_{t}^{A}+Q_{t}^{B}\right]$; total depth is measured by the sum of average depth at all price levels, $D P T_{t}^{L M}=\sum_{i} E\left[Q_{t}^{i}\right]$. Average spread is the expected difference between the best ask and bid prices, $S P_{t}^{L M}=E[A-B]$. Volume is measured by the number of orders executed, while liquidity provision is obtained by considering the number of limit orders submitted. As at each period only one trader arrives at the market who submits only one order of unitary size, expected volume, $V L_{t}$, and liquidity provision, $L P_{t}$, are computed as the probability that this trader will submit a market order or a limit order at all price levels:

$$
\begin{aligned}
V L_{t}^{L M} & =E\left[\sum_{i} \int_{\beta \in\left\{\beta: H_{t} \mid S_{t-1}=-1^{i}\right\}} 1 d \beta\right] \\
L P_{t}^{L M} & =E\left[\sum_{i} \int_{\beta \in\left\{\beta: H_{t} \mid S_{t-1}=+1^{i}\right\}} 1 d \beta\right]
\end{aligned}
$$

Indicators of market quality for the SM are computed in a similar way, but using $j=$ $\left\{a_{1: 5}, b_{1: 5}\right\}$. To illustrate the effects of a tick size reduction on different groups of stocks (liquid versus illiquid), we use the initial state of the book as a proxy for liquidity and consider there cases: an empty book for illiquid stocks, a book with either one or two units on 
the first (second) level of the LM (SM) price grid for liquid stocks. The following Proposition summarizes the effects of a tick size change on both traders' strategies and market quality:

Proposition 1 When the tick size is reduced, changes induced on traders' order submission strategies and market quality depend on the initial state of the book.

- For liquid stocks

- liquidity provision increases and spread and depth improve;

- trading volume decreases;

- for very liquid stocks the effects are the same except for inside depth that worsens.

- For illiquid stocks

- the results are the opposite: liquidity provision decreases and spread, depth and inside depth deteriorate.

- All the above effects become stronger for low priced stocks.

\section{[Insert Tables 4,5 and 6 here]}

Tables 4 and 5 report results at $T-2$ for orders submission strategies and market quality for both the large and the small tick size regimes under two different opening states of the limit order book: with 1 share on $A_{1}\left(a_{2}\right)$ and $B_{1}\left(b_{2}\right)\left(S_{T-3}=[01 \mid 10]=[00010 \mid 01000]\right)$, and with 2 shares $\left(S_{T-3}=[02 \mid 20]=[00020 \mid 02000]\right)$. By considering books that differ in market depth, we can offer insights on how the effects of a tick size change on market quality can be influenced by liquidity. Consider first the regime under which the book opens at $T-2$ with only 1 share on both $A_{1}\left(a_{2}\right)$ and $B_{1}\left(b_{2}\right)$ and notice that when the tick size is smaller (the price grid is finer), undercutting is cheaper and competition for the provision of liquidity becomes more intense so that in equilibrium traders switch from market to limit orders that they post to the new best price levels $\left(a_{1}\right.$ and $\left.b_{1}\right)$. The result is that depth increases -both total and at the inside spread-, spread narrows and trading volume decreases (e.g. for $v=1$, from .8994 to .7666). Notice that these effects become stronger as the stock price decreases: for example when $v$ is equal to 1 following a reduction in the tick size, spread decreases by .02 , whereas it only narrows by .0004 when $v$ is equal to 50. Clearly, when the value of the tick size becomes relatively small compared to the stock price, the benefit of having a finer price grid decreases, and the probability that traders switch from market to limit orders posted at $a_{1}$ and $b_{1}$ becomes smaller.

Consider then the regime where the book opens full at $A_{1}\left(a_{2}\right)$ and $B_{1}\left(b_{2}\right)$ (Table 5) and notice that, compared to the previous case, the tick size reduction produces effects that are 
more intense and of the same direction except for depth at the inside spread, that decreases rather than increases. When at $T-2$ the book opens full at $A_{1}\left(a_{2}\right)$ and $B_{1}\left(b_{2}\right)$, in the large tick size protocol there is no room for limit orders and traders are forced either to use market orders or to refrain from trading; hence when the tick size is reduced, traders move even more aggressively than before to the top of the book (the probability of observing a limit order at $a_{1}\left(b_{1}\right)$ increases to .1167) and hence aggregate depth increases; however, depth at the top of the book decreases due to the fact that before the reduction of the tick size the liquidity pressure at the best bid and offer was very intense.

We can therefore conclude that the reduction of the tick size improves liquidity as it narrows the inside spread and increases total depth, but its effect on inside depth depends on the state of the book. If we believe that the regime with a deeper book is a good proxy for very liquid stocks, we can then suggest that for these stocks a tick size reduction can actually decrease depth at the inside spread. For illiquid stocks, however, that we proxy by the empty book, the effect of a tick size reduction is to worsen the inside spread as well. Indeed Table 6 shows that when the book opens empty, the inside spread widens and depth decreases. The reason being that traders do not have enough incentive to undercut aggressively by posting limit orders on the new top of the book: the higher execution probability they would obtain is in fact not large enough to compensate the lower execution price. Notice that, even in this case, when the stock price increases, the reduction of the tick size tends to produce effects that gradually drop off.

The results obtained so far are consistent with most of the existing empirical evidence on tick size reduction ${ }^{14}$ showing that when the tick size is reduced, inside spread decreases but depth not necessarily improves. The results are also consistent with Bourghelle and Declerck (2004) who investigate the effects of a reduction of the tick size and show that, as one moves to less liquid stocks, the percentage spread increases and the quoted depth decreases.

The results from Proposition 1 also show that the effect of the tick size reduction is stronger the lower priced securities are. Indeed, a relevant issue put forward by the most recent regulatory debate concerns the relation between tick size and stock price. It has been suggested that the tick size value established uniformly for all NMS stocks is not adequate for low priced stocks. More precisely, it is being observed that the current tick size is relatively too large for securities priced below $\$ 20$ (BATS, 2009). Delassus and Tyc (2010) also suggest that for stocks between $\$ 1$ and $\$ 5$ the relatively high value of the minimum price change is playing a role in keeping the relative spread artificially wide. Our model captures this effect and explains how a wider tick size increases the bid-ask spread and, even more importantly, how this effect gets stronger as the price of the security decreases.

\footnotetext{
${ }^{14}$ See Ahn et al. (1996), Bacidore (1997), Harris(1994), and Porter and Weaver (1997).
} 
Both Table 4 and Table 5 report equilibrium order submission probabilities and indicators of market quality for different stock prices and show that all the effects of a tick size reduction tend to lessen as the ratio between the tick size and the stock price decreases. In particular the positive effect that a reduction of the tick size produces on the inside spread steadily decreases with the increase in the stock price. Hence we can suggest that when the stock price is too small relative to the tick size, the inside spread is kept unnaturally wide so that, by curtailing the tick size, regulators can effectively reduce the spread. When instead the tick size is small relative to the stock price, a reduction of the tick size have marginal positive effects on market quality. This result bears important policy implications in that it suggests that what regulators should seek is not an unlimited reduction in the tick size, but rather an optimal ratio between the security price and the minimum price variation. We have shown that by increasing this ratio, the effect of a reduction of the tick size produces a smaller and smaller effect on the inside spread, and that for the most liquid stocks it can also reduce inside depth. We can then conjecture that the optimal tick to price ratio should be achieved by reducing the tick size down to the point where a further reduction does not produce any additional effect on the inside spread.

\section{Dual-Market Model: Intermarket Competition}

In this Section we extend the previous framework where we compare two markets with different tick size, by allowing these same markets to compete with each other: traders arriving at each period $t$ can now choose not only their order type and aggressiveness, but also the trading venue where to submit their orders. Thus the strategy space expands into $H=\left\{H^{S M}, H^{L M}\right\}$, where $H^{L M}=\left\{ \pm 1^{i}, 0\right\}$ with $i=\left\{A_{1: 2}, B_{1: 2}\right\}$, and $H^{S M}=\left\{ \pm 1^{j}, 0\right\}$ with $j=\left\{a_{1: 5}, b_{1: 5}\right\}$. We also assume that if the two trading venues offer the same payoff, a trader will randomize his order submission and post his order to one of the two markets with equal probability. We indicate the number of shares available at each price level by $N_{1: 2}\left(n_{1: 5}\right)$ and $M_{1: 2}\left(m_{1: 5}\right)$ respectively for the ask and the bid side of the LM (SM). The dual-market model is solved by backward induction as the single market model, the following Lemma characterizes the equilibrium:

Lemma 3 When the two markets open with the same depth at the common price levels, they have the same expected book dynamics at those same price levels.

Intuitively, let's assume that one book is thinner than the other one at the common price levels. This implies that incoming traders have an incentive to submit limit orders at those price levels on the thinner book because of the higher execution probability. As a result, liquidity builds up in the thinner book up to the point in which limit order execution probabilities are equal in the two trading venues. So in equilibrium the two books should always have equal depth at the common price levels. Notice that, compared with the equilibrium 
strategies in the single market model, here traders need to consider the potential competition in liquidity provision coming from the other market. Hence they will take advantage of the finer price grid in the SM to undercut aggressively the quotes available on the LM, submitting orders at the price levels just below the common ones. For example a seller will submit orders on $a_{4}$, to avoid the competition from the trading crowd standing on the other market at $A_{2}$ or, if more impatient, on $a_{1}$ as no undercutting by incoming traders is possible at that price level. This aggressive liquidity supply is observed especially when competition is fierce, i.e. for liquid and/or low priced stocks. The following Proposition summarizes the main findings in the dual-market model.

Proposition 2 When two trading venues with different tick size compete, no matter how liquid the markets and how priced the securities are, liquidity provision concentrates on the small tick size market as traders undercut orders standing on the large tick market.

Competition for liquidity provision between markets with different tick size induces traders to submit limit orders exclusively to the small tick size market with the result that in the large tick market depth and inside spread deteriorate. Why do traders move to the new trading platform? Because when the tick size is smaller they have a better chance to fine tune the trade-off between execution risk and price risk, and more aggressive liquidity suppliers can submit their orders to the new inside quotes. Notice that, as in the single market case, this effect lessens significantly when the asset value increases from $v=1$ to $v=10$, and that it is stronger for more liquid stocks, i.e. when the book opens with 1 or more units posted at $A_{1}\left(a_{2}\right)$ and $B_{1}\left(b_{2}\right) .{ }^{15}$ The intuition here is the same as before: when the tick to price ratio decreases, any incentive from a tick size reduction becomes smaller and traders' advantage to undercut existing quotes decreases. However, by comparing the single market protocol with the dual market one, it can be noticed that market interaction fosters competition for liquidity provision so that the probability to observe orders posted to the top of the book is higher in the case with intermarket competition. And this effect -once againbecomes stronger for liquid stocks. In fact, even if limit orders move to the SM, depth on the LM still attract liquidity demanders so that the execution probability of limit orders posted at the same price level on the SM is smaller than in the single market case. Clearly this is due to the assumption that traders randomize their market orders when expected profits from the two markets are the same, and it explains -for example- why in the dual market model traders post their orders to $a_{4}$ rather than $a_{5}$ as at $a_{5}$ the trading crowd is active on both markets an hence the execution probability of limit orders posted to this price level is halved compared to the single market case. Noticeably our three-period model does not capture the whole real dynamic interaction between the two markets, as presumably the LM

\footnotetext{
${ }^{15}$ Notice that having 1 or more shares on $A_{1}\left(a_{2}\right)$ and $B_{1}\left(b_{2}\right)$ is indifferent as, when traders can choose between two trading venues, depth at each price level is the result of the sum of the shares posted in the two markets - traders in fact can submit their market orders to both and obtain the same execution price.
} 
would shut down as soon as the trading crowd were moved to the SM; however, our model markedly shows how the adjustment process starts and in which direction the equilibrium would converge had we assumed an "endogenous" rather than exogenous trading crowd.

These results are consistent with the empirical findings by Oppenheimer et al. (2003) who analyze the impact of US decimalization on the Canadian stocks and find that spread and inside depth decline by a greater amount in the US than in Canada. Similarly, Lin et al. (2009) look at the effect of US decimalization on stocks cross-listed on Euronext and NYSE and find that the NYSE proportion of trading of French firms declines markedly in the post-decimalization period. Our results also provide insights to investigate the effects of competition between MTFs/ECNs and regulated markets. Consistently with Proposition 2, Bias et al. (2003) find that limit orders posted by traders to Island ECN undercut NASDAQ quotes. Similarly Hengelbrock and Theissen (2009) find that competition fostered by the entry of Turquoise led to a decrease in the inside spread.

Our model suggests a further interesting extension that can be tested empirically: the effects of competition among markets with different tick size regimes can greatly differ depending on both the firm's price to tick ratio, and on liquidity. As far as liquidity is concerned, market capitalization is frequently used to sort stocks; more fiddly can instead result the selection of groups of stocks with a high degree of price variability as market cap is generally related with firm price. Our results suggest that by solving this issue empirical researchers should be able to bolster ${ }^{16}$ the preliminary results obtained so far (e.g. Gomber and Pierron, 2010) on the effects of fragmentation on market quality.

\section{Sub-Penny Trading and Internalization Pool}

In this Section, we extend the dual-market model to investigate sub-penny trading. This practice is carried out by those broker-dealers who can access internalization pools (IP) to compete on price with the liquidity posted to the top of the book by limit order traders. IP are a special type of dark pools, that were initially designed to internalize order flows for cost-saving purposes (Degryse et al. 2009). Rosenblatt breakdown (Table 8) shows that volume made on IP has steadily increased over the last three years and that, for example, in August 2010 it attracted $8.55 \%$ of the consolidated US equity volume -the rest being drawn by public crossing networks, exchange and consortium based pools- scoring an increase of $25 \%$ over the previous year. One of the main features that characterizes IP is that they are controlled by broker-dealers and hence contain proprietary order flows. In practice broker dealers can use IP to internalize orders and execute them at sub-penny quotes. How is this possible? Rule 612 does not allow market participants to quote prices in sub-penny on lit markets, but it indeed allows broker-dealers to execute customers' orders at quotes that price improve even by only a fraction of the tick size (which in US markets is equal to 1 penny

\footnotetext{
${ }^{16}$ See FESE (2010) comments on this issue.
} 
for stocks priced above $\$ 1$ ). This is precisely what broker-dealers can achieve by posting sub-penny quotes in their internalization pools. Assume, for example, that the best bid and ask prices on a public limit order book are equal to $\$ 50.62$ and $\$ 50.70$ respectively; then a broker-dealer can post a limit order to sell at $\$ 50.6999$ and a limit order to buy at $\$ 50.6201$ so that when an investor sends a market buy order for -say- 500 shares he/she sells short $\$ 25,349.95$, and when another investor sends a market sell order for a further 500 shares, he can cover his short position by buying in front of the displayed bid for $\$ 25,310.05$. With this round trip transaction the broker-dealer captures the bid-ask spread and earns a profit of $\$ 39.90$, whereas the two investors save together $\$ 0.1$ as their orders are executed at a $\$ 0.01 / 100$ better than the price quoted on the lit market.

Given that the volume intermediated at sub-penny is steadily increasing (Figure 1), and that the estimated percentage of share volume in NMS stocks intermediated by broker-dealers accounted up to $17.5 \%$ in September 2009 (SEC, 2010), regulators are worried about the ultimate effects of sub-penny trading on market quality. Does this practice foster competition for the provision of liquidity and improve market quality, or it only allows highly sophisticated dealers to generate considerable returns from using internalization pools to step in front of the NBBO? As the better prices available in the IP intercept market orders sent to the public limit order book (PLB same as previous LM), liquidity demand decreases. This generates two opposite effects on the quality of the PLB. On the one hand when fewer market orders hit the top of the PLB, depth decreases by a lesser amount, thus holding the spread tighter. On the other hand, however, the reduction of market orders lessens the execution probability of limit orders and hence the incentive for traders to post depth to the top of the PLB, resulting in lower market depth and wider spread. The changing pattern of market orders, which move from the PLB to the IP, is affected by the state of the PLB as well as by the relative tick size of the stock considered. Indeed agents' choice between market and limit orders hinges on the trade-off between price risk and execution risk, which are both influenced by these stocks idiosyncratic features. To discuss all these effects, we adapt our previous dual market model to embed sub-penny trading. The resulting framework allows us to draw conclusions on competition between PLB and IP.

\section{[Insert Table 8 here]}

We assume that at each trading period one individual out of two groups of traders arrives at the market: with probability $\alpha$ the incoming trader is a broker-dealer and with the complementary probability he is a regular trader. While a regular trader can only post his orders to the PLB, the incoming broker-dealer can use both the PLB and the IP with a smaller tick size where he can undercut orders posted by other traders on the top of the PLB. So we assume as before that two markets compete with each other, one of which with a smaller tick size; however, differently from before, we assume that only a fraction $\alpha$ of the investors' population can trade on the small tick market. Furthermore, we assume that 
consistently with the very nature of real IP, the small tick market does not have a trading crowd that closes the book at $A_{2}$ and $B_{2}$. Finally, while only broker-dealers can post limit orders to the IP, all traders can take advantage of the liquidity offered by both trading platforms, which is consistent with the existence of a smart order routing technology ${ }^{17}$ that allows all investors to simultaneously access multiple sources of liquidity (Butler, 2010). The degree of access to IP volume affects the visibility of this trading platform by regular traders. We will first assume perfect inference and then extend the model to include partial inference and Bayesian learning. The effect of this extension is that the information structure of the game changes: broker-dealers directly observe both markets as they are allowed to submit orders in both; yet the other traders observe only the PLB, and have to make inference on the state of the IP.

The US market provides the National Best Bid Offer (NBBO) and hence allows traders to search for the best execution on a consolidated limit order book. Accordingly we assume that traders can employ smart order routers to search the best quotes on the consolidated limit order book (PLB\&IP): if the resulting inference is perfect, then investors' market orders will always get the best execution even though they do not necessarily observe the IP. If instead not all of them have access to sophisticated liquidity aggregators, then their overall inference will be based on their gradual learning process.

We therefore consider two cases: the benchmark (PLB), where only one trading platform is available to all traders, and the PLB\&IP framework, where an IP competes with the PLB. The latter case further differentiates into visible and invisible, depending on the transparency of the IP market. Notice that to introduce a certain degree of uncertainty on the state of the IP, we assume that at $T-2$ the IP opens either empty or with one unit on the first level of the book with equal probability. The following Proposition summarizes the results obtained under both the assumptions of perfect foresight and Bayesian inference.

Proposition 3 When an Internalization Pool is added to a Public Limit Order Book that allows broker-dealers to sub-penny existing liquidity on the PLB, traders' order submission strategies and market quality change as follows.

- For illiquid stocks market quality, measured by depth and inside spread, deteriorates as liquidity provision decreases. The effects are stronger for low priced stocks and when the IP market is invisible for regular traders.

- For liquid stocks, the effect of sub-penny trading is to foster price competition so that in the PLB spread and depth improve, yet liquidity provision worsens. The effects are stronger for high priced stocks and weaker when the IP market is invisible for regular traders.

\footnotetext{
${ }^{17}$ Examples are ITG Dark Aggregator and Smartrade Liquidity Aggregator.
} 
- IP is used more intensively by broker dealers when the stock is both liquid and low priced.

The effect of sub-penny trading on market quality is detrimental for illiquid stocks, whereas it is beneficial for the liquid ones; the former effect is stronger for low priced stocks, the opposite holding for the latter. Tables 9 and 10 provide the results for $\alpha=10 \%$. Table 9 is focused on the case with an empty opening book at $T-2$, that we assume to proxy illiquid stocks, while Table 10 shows results for a book that opens with one share on $A_{1}\left(a_{2}\right)$ which should offer intuitions for more liquid stocks. Starting from Table 9, notice that comparing the two market protocols, with and without an IP, both depth and limit orders decrease when the IP is added to the PLB. When traders perceive the potential competition from broker-dealers they react by supplying less aggressive liquidity to the book. Furthermore, this effect generally outweighs the reduction in market orders resulting from their interception by the IP and the inside spread worsens. Notice that all these effects get weaker as the stock price increases: when the tick to price ratio becomes very small, the profitability of liquidity provision, and hence of undercutting, declines so that IP competition becomes less relevant. A similar intuition explains why these effects become stronger when traders cannot observe the IP book: the uncertainty on the IP depth and on the actual level of competition makes them even more reluctant to post limit orders on the PLB.

For more liquid stocks (Table 10) the main effect of sub-penny trading is to foster price competition: when the market opens with some depth on the PLB the effect on market quality is positive as both spread and depth improve. These improvements on the PLB are due to a reduction of the market orders executed in this venue: when the IP platform is introduced, agents allowed to trade on both markets submit limit orders to the IP at $a_{1}$ to undercut the existing depth at $A_{1}$ and intercept incoming market orders away from the PLB. The resulting reduction of liquidity demand on the PLB improves spread and depth. However, the switch of orders from PLB to IP implies that liquidity provision and volume worsen on the public venue, as documented respectively by the reduction in limit and market orders submissions. Notice that in this case, when the stock price increases, the effects on the PLB of IP competition become stronger as they hinge on the deviation of market orders away from the PLB. As market orders become more profitable and are hence more largely used, the overall effect is magnified. When the IP market becomes opaque and uncertainty increases for regular traders, they move from limit to market orders thus reducing the positive effect of IP on market quality.

Finally, by comparing traders' equilibrium strategies for illiquid and liquid stocks (Table 9 and 10) we observe that broker-dealers post orders to the IP more intensively when competition for liquidity provision on the PLB in more fierce, i.e. for liquid stocks; this effect is stronger for low priced stocks where providing liquidity is more convenient than taking liquidity, due to the larger tick to price ratio.

Which conclusions can we draw from these results? We show that sub-penny trading is 
detrimental for market quality when it takes place in illiquid stocks, especially low priced, whereas it benefits market quality for liquid ones. The existing preliminary empirical evidence (Delassus and Tyc, 2010) shows that as the stock value decreases, the percentage of sub-penny trading via internalization pool increases. This evidence combined with our theoretical results supports the SEC concern about sub-penny trading that was recently discussed in the April 2010 Concept Release on Equity Market Structure.

\section{[Insert Tables 9 and 10 here]}

\section{Empirical implication}

A number of interesting elements can be observed from the computed equilibrium strategies of our model, that are conducive to ready testable empirical consequences. From traders' equilibrium order submission strategies it emerges that traders' behavior is crucially dependent on the liquidity of the limit order book and on the price of the stock considered, and that this is true both within the context of a single market framework and with intermarket competition.

Starting with the single market protocol which is not exposed to the competition from other trading venues, when the tick size is reduced in a market characterized by a deep book, traders find it more convenient to undercut existing depth, thus enhancing competition for the provision of liquidity and hence improving both inside spread and depth. The opposite occurs and liquidity worsens when the tick size reduction takes place in a shallow market where the increased execution probability from aggressive undercutting does not compensate traders for the reduced execution price that they get by posting orders nearer to the BBO. Furthermore, for both liquid and shallow markets the effects of a reduction in the tick size hinges on another element that is the price to tick size ratio, as results show that they gradually drop off with the increase in the company's price.

These model's prediction can be directly tested by selecting dates corresponding to tick size reductions for different sample stocks, by grouping these stocks both in terms of liquidity and of firm's price, and by applying an event study methodology to investigate market quality before and after the tick size reduction. An empirical issue is therefore to adequately select a sample of stocks embedding a certain degree of variability in liquidity and firm price.

The optimal equilibrium strategies resulting from competition between two markets with different tick size provides similar intuitions: they show that market players tend to move to the trading platform with the smaller tick size and that market interaction fosters competition for the provision of liquidity entailing an improvement in depth and inside spread. However, results differ conditional on the stock's characteristics, getting much stronger for liquid and low priced stocks. 
As a result, relating order submission strategies, state of the book and other stocks' characteristics offer a rich map of empirical links between different order types, liquidity provision and volume; these implications can provide guidelines to the most recent empirical investigations aimed at assessing the effects of the increased market competition and fragmentation that followed the MIFID implementation. According to our results, such an empirical assessment should be conducted by controlling for the firms' distinguishing features as the intermarket competition enhanced by the MIFID can indeed result into fragmentation between markets with different tick size regimes.

In addition to providing model support for intermarket competition between venues with different tick sizes, we also offer a wide range of testable implications derived from competition between a primary market and an internalization pool. The endogenous strategic interaction between regular traders and more sophisticated broker-dealers having access to dark crossing systems implies distinctive empirical patterns for liquidity supply and liquidity demand. More precisely, the changing liquidity attitude of regular traders exposed to the competition of an internalization pool has empirical predictions for the dynamics of order flows that still depend on firms' idiosyncratic features. In deep markets IP competition attracts market orders away from the primary market thus preserving and ultimately enhancing liquidity; in illiquid markets IP competition overall deters liquidity provision thus worsening market quality. While the effect on liquid stocks is amplified when the stock price increases, the opposite holds for illiquid stocks. These theoretical findings are directly testable both cross sectionally by adequately selecting once more firms with different degree of liquidity and price levels, or by using time series of order data to verify whether an increase in market depth in the primary market engages a positive feedback from the internalization pool, whereas a draining of depth results in further reduction in liquidity provision. A final ready testable empirical implication of our model is the prediction that broker-dealers will use IP more intensively when the stock is both liquid and low priced.

\section{Policy Discussion and Conclusions}

In light of the growing interest for tick size regulation and its effects in a global fragmented environment, this paper extends the existing literature on tick size and intermarket competition in a number of directions.

First of all, it discusses the effects of a reduction in the tick size within the context of a limit order book and shows that such effects depend on the liquidity of the stock and its underlying asset value. In this respect, we show that the market quality of illiquid stocks worsens with a reduction of the tick size, while it improves for liquid stocks. We also show that the effect is relevant for low priced stocks, whereas it vanishes as the value of the security increases. These results, that are consistent with most of the existing empirical evidence, suggest that the objective of the tick size regulation should not be an indefinite reduction 
of the tick size, but rather the definition of a minimum price change that is consistent with the stock's main attributes and should be related to liquidity and asset value.

This paper also extends previous literature on tick size to include intermarket competition and shows that when two limit order books compete on price by reducing their tick size, liquidity concentrates on the smaller-tick market, which is consistent with the prevailing tendency of exchanges to competitively reduce their minimum price variation.

This extension constitutes the building block that allows us to investigate the issue of sub-penny trading, which is one of the main concerns expressed by the SEC in the April 2010 concept release on Equity Market Structure. Our model suggests that sub-penny trading undertaken by broker-dealers in their internalization pools can have dramatic effects on the quality of illiquid and low priced stocks, but that it is beneficial to the quality of the market for liquid stocks. The popularity of sub-penny trading, substantiated by the brokerdealers' internalization activity that accounts for up to $17.5 \%$ of the US equity share volume, induced the SEC to outline (SEC, 2010) the concept of a Trade-At Rule according to which, for example, "a trading center that was not displaying the NBBO at the time it received an incoming marketable order could either: (1) execute the order with significant price improvement (such as the minimum allowable quoting increment, generally one cent); or (2) route ISOs to fully displayed size of NBBO quotations and then execute the balance of the order at the NBBO price."

This rule would have the benefit of prohibiting broker-dealers to step in front of the NBBO by a fraction of a penny, thus avoiding the practice of pre-emptying the public limit order book; ${ }^{18}$ however, it would have a detrimental effect on those public crossing networks -dark pools- that are designed to trade blocks and generally execute at the spread midpoint; similarly, such rule would negatively affect totally undisclosed orders that are allowed by several exchanges to be pegged at the spread midpoint. A possible solution that we suggest -but that our model does not tackle- is to introduce the Trade-At Rule together with a waiver that allows sub-penny quoting and trading at the spread midpoint in dark venues. Future extensions of our model could aim at discussing this proposal.

Finally, our analysis suggests that future empirical work should focus on the effect of high frequency trading on market quality during the second half of the last decade. Existing preliminary evidence shows that, starting from 2005, sub-penny trading swamped in US markets and because this practice is tightly linked to algorithmic and fast trading programmes, it would be interesting to verify whether Hendershott et al. (2010) positive results on the effects of high frequency trading on liquidity would still hold for most recent time periods.

\footnotetext{
${ }^{18}$ Notice that this proposal is consistent with the even more recent concerns raised after the turmoil of May 6, 2010 by market professionals who believe the idea of depth-of-book protection should be revisited (Chapman, 2010).
} 


\section{Appendix}

\section{A Proof of Lemma 1}

Proof. At any period $t \neq T$, a trader selects his optimal strategy $H_{t}^{*}$ by comparing the payoffs of all the strategies described in Table $2, H_{t}=\left\{-1^{B},+1^{A_{k}},+1^{B_{k}},-1^{A}, 0\right\}$. Assume that $p_{t}^{*}\left(A_{k}^{N_{-k}, N_{k}}\right)>0$ where in order to simplify the notation in this proof we omit to write that all the execution probabilities are conditional on $S_{t}$. We compute the threshold $\beta_{-1^{B}, 0}$ between $H_{t}=-1^{B}$ and $H_{t}=0$ by equalizing the profits from the two strategies: $B-\beta v=0$, and we obtain $\beta_{-1^{B}, 0}=\frac{B}{v}$. Similarly we compute the threshold between $H_{t}=-1^{B}$ and $H_{t}=+1^{A_{k}}$ and obtain $\beta_{-1^{B}, 1^{A_{k}}}=\frac{B}{v}-\frac{p_{t}^{*}\left(A_{k}^{N-k}, N_{k}\right.}{1-p_{t}^{*}\left(A_{k}^{N_{k}, N_{k}}\right)} \cdot \frac{A_{k}-B}{v}$. Notice that under the assumption that $p_{t}^{*}\left(A_{k}^{N_{-k}, N_{k}}\right)>0$, then $\beta_{-1^{B}, 1^{A_{k}}}<\beta_{-1^{B}, 0}$ and hence there always exists

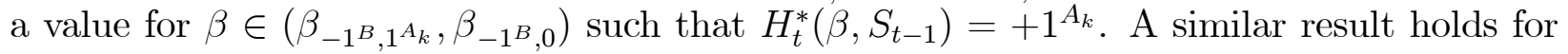
the bid side. Clearly, traders' equilibrium $\beta$-thresholds and hence strategies crucially depend on the state of the book that traders face when arriving at the market, as these affect the execution probabilities of their limit orders. Hence we can have four possible scenarios. When there is room for limit orders on both sides of the market, equilibrium traders' strategies for $t \neq T$ are:

$$
H_{t}^{*}\left(\beta, S_{t-1}\right)=\left\{\begin{array}{ll}
-1^{B} & \text { if } \beta \in\left[\beta, \beta_{1}\right) \\
+1^{A_{k}} & \text { if } \beta \in\left[\bar{\beta}_{1}, \beta_{3}\right) \\
+1^{B_{k}} & \text { if } \beta \in\left[\beta_{3}, \beta_{5}\right) \\
-1^{A} & \text { if } \beta \in\left[\beta_{5}, \bar{\beta}\right]
\end{array} \text { if } p_{t}^{*}\left(A_{k}^{N_{-k}, N_{k}}\right) \neq 0 \& p_{t}^{*}\left(B_{k}^{M_{-k}, M_{k}}\right) \neq 0\right.
$$

where $\beta_{1}=\frac{B}{v}-\frac{p_{t}^{*}\left(A_{k}^{N_{-k}, N_{k}}\right)}{1-p_{t}^{*}\left(A_{k}^{N}-N_{k}, N_{k}\right)} \cdot \frac{A_{k}-B}{v}, \beta_{3}=\frac{p_{t}^{*}\left(A_{k}^{N_{-}, N_{k}}\right) A_{k}+p_{t}\left(B_{k}^{M_{-k}, M_{k}}\right) B_{k}}{p_{t}^{*}\left(A_{k}^{N_{-}, N_{k}}\right)+p_{t}\left(B_{k}^{M}-k, M_{k}\right)} \cdot \frac{1}{v}$ and $\beta_{5}=\frac{A}{v}+$ $\frac{p_{t}^{*}\left(B_{k}^{M_{-k}, M_{k}}\right)}{1-p_{t}^{*}\left(B_{k}^{M_{-}, M_{k}}\right)} \cdot \frac{A-B_{k}}{v}$. When instead the book open full either on the ask or on the bid side, the equilibrium strategies are respectively:

$$
\begin{aligned}
& H_{t}^{*}\left(\beta, S_{t-1}\right)=\left\{\begin{array}{cl}
-1^{B} & \text { if } \beta \in\left[\beta, \beta_{1}\right) \\
0 & \text { if } \beta \in\left[\bar{\beta}_{1}, \beta_{4}\right) \\
+1^{B_{k}} & \text { if } \beta \in\left[\beta_{4}, \beta_{5}\right) \\
-1^{A} & \text { if } \beta \in\left[\beta_{5}, \bar{\beta}\right]
\end{array} \text { if } p_{t}^{*}\left(A_{k}^{N_{-k}, N_{k}}\right)=0 \& p_{t}^{*}\left(B_{k}^{M_{-k}, M_{k}}\right) \neq 0\right. \\
& H_{t}^{*}\left(\beta, S_{t-1}\right)=\left\{\begin{array}{cl}
-1^{B} & \text { if } \beta \in\left[\beta, \beta_{1}\right) \\
+1^{A_{k}} & \text { if } \beta \in\left[\bar{\beta}_{1}, \beta_{2}\right) \\
0 & \text { if } \beta \in\left[\beta_{2}, \beta_{5}\right) \\
-1^{A} & \text { if } \beta \in\left[\beta_{5}, \bar{\beta}\right]
\end{array} \text { if } p_{t}^{*}\left(A_{k}^{N_{-k}, N_{k}}\right) \neq 0 \& p_{t}^{*}\left(B_{k}^{M_{-k}, M_{k}}\right)=0\right.
\end{aligned}
$$


where $\beta_{2}=\frac{A_{k}}{v}$ and $\beta_{4}=\frac{B_{k}}{v}$.Finally, when the book is full on both sides, equilibrium strategies are:

$$
H_{t}^{*}\left(\beta, S_{t-1}\right)=\left\{\begin{array}{cl}
-1^{B} & \text { if } \beta \in\left[\beta, \beta_{1}\right) \\
0 & \text { if } \beta \in\left[\bar{\beta}_{1}, \beta_{5}\right) \quad \text { if } p_{t}^{*}\left(A_{k}^{N_{-k}, N_{k}}\right)=0 \& p_{t}^{*}\left(B_{k}^{M_{-k}, M_{k}}\right)=0 \\
-1^{A} & \text { if } \beta \in\left[\beta_{5}, \bar{\beta}\right]
\end{array}\right.
$$

Notice that if $p_{t}^{*}\left(A_{k}^{N_{-k}, N_{k}}\right)=p_{t}^{*}\left(B_{k}^{M_{-k}, M_{k}}\right)=0, H_{t}^{*}\left(\beta, S_{t-1}\right)=H_{T}^{*}\left(\beta, S_{t-1}\right)$.

\section{B Proof of Lemma 2}

Proof. As an example, we consider the ask side in period $T-1$; the other cases can be derived in a similar way. At $T-1$ limit orders have positive execution probability on both $A_{1}$ and $A_{2}$ only when the book opens empty on both sides, $S_{T-1}=[0,0,0,0]$. In this case traders can optimally select their level of price aggressiveness. Profits from the two available limit order strategies are:

$$
\begin{array}{lll}
H_{T-1}=+1^{A_{2}} & :\left(A_{2}-\beta v\right) \cdot p_{T-1}^{*}\left(A_{2} \mid[1000]\right)=\left(A_{2}-\beta v\right) \cdot \frac{\bar{\beta} v-A_{2}}{(\bar{\beta}-\underline{\beta}) v} \\
H_{T-1}=+1^{A_{1}} & : \quad\left(A_{1}-\beta v\right) \cdot p_{T-1}^{*}\left(A_{1} \mid[0100]\right)=\left(A_{1}-\beta v\right) \cdot \frac{\bar{\beta} v-A_{1}}{(\bar{\beta}-\underline{\beta}) v}
\end{array}
$$

A limit order at $A_{1}$ is optimal if $\exists \beta$ such that $\left(A_{2}-\beta v\right) \cdot p_{T-1}^{*}\left(A_{1} \mid[0100]\right)>\max \left\{B_{2}-\beta v\right.$, $\left.\left(A_{1}-\beta v\right) \cdot p_{T-1}^{*}\left(A_{2} \mid[1000]\right)\right\}$; in this case that the threshold between $H_{T-1}=-1^{B}$ and $H_{T-1}=+1^{A_{1}}$ is smaller than the threshold between $H_{T-1}=-1^{B}$ and $H_{T-1}=+1^{A_{2}}$. More

precisely, as $\beta_{-1^{B}, 1^{A_{k}}}=\left.\beta_{1}\right|_{B=B_{2}, A_{k}}=\frac{B_{2}}{v}-\frac{p_{T-1}^{*}\left(A_{k} \mid S_{t}\right)}{1-p_{T-1}^{*}\left(A_{k} \mid S_{t}\right)} \cdot \frac{A_{k}-B_{2}}{v}$, in order for $\beta_{-1^{B}, 1^{A_{1}}}<$ $\beta_{-1^{B}, 1^{A_{2}}}$ the lower selling price (by one tick, $\tau$ ) must be compensated by a higher execution probability. As $p_{T-1}^{*}\left(A_{1} \mid[0100]\right)-p_{T-1}^{*}\left(A_{2} \mid[1000]\right)=\frac{\bar{\beta} v-A_{1}}{(\bar{\beta}-\beta) v}-\frac{\bar{\beta} v-A_{2}}{(\bar{\beta}-\beta) v}=\frac{\tau}{(\bar{\beta}-\beta) v}$ is an increasing function of the relative tick size, for $H_{T-1}=+1^{A_{1}}$ to be an optimal strategy, $\frac{\tau}{v}$ must be larger than $\frac{\widehat{\tau}}{v}$, where $\frac{\widehat{\tau}}{v}$ solves $\left(A_{1}-\beta v\right) \cdot \frac{\bar{\beta} v-A_{1}}{(\bar{\beta}-\underline{\beta}) v}-\left(A_{2}-\beta v\right) \cdot \frac{\bar{\beta} v-A_{2}}{(\bar{\beta}-\underline{\beta}) v}=0$.

\section{Proof of Proposition 1}

Proof. 1) Illiquid stocks: starting book at $T-2$ is [0000]

(1.1) Consider a LM where at $T-2$ traders' strategy space is $\left\{-1^{B},+1^{A_{2}},+1^{A_{1}},+1^{B_{1}},+1^{B_{2}},-1^{A}, 0\right\}$; each strategy corresponds to an opening book at $T-1$ equal to [0000], [1000], [0100], [0010], [0001] and [0000] respectively. Let's consider -as an example- the book that opens at $T-1$ with one share on $A_{2},[1000]$. Traders' strategy space is $\left\{-1^{B},+1^{A_{1}},+1^{B_{1}},+1^{B_{2}},-1^{A}, 0\right\}$ and the corresponding payoffs are: 


\begin{tabular}{llll|}
\hline$H_{T-1}=-1^{B}$ & $:$ & $B_{2}-\beta v$ \\
$H_{T-1}=+1^{A_{1}}$ & $:$ & $\left(A_{1}-\beta v\right) \cdot p_{T-1}^{*}\left(A_{1} \mid[1100]\right)$ \\
$H_{T-1}=+1^{B_{1}}$ & $:$ & $\left(\beta v-B_{1}\right) \cdot p_{T-1}^{*}\left(B_{1} \mid[1010]\right)$ \\
$H_{T-1}=+1^{B_{2}}$ & $:$ & $\left(\beta v-B_{2}\right) \cdot p_{T-1}^{*}\left(B_{2} \mid[1001]\right)$ \\
$H_{T-1}=-1^{A}$ & $:$ & $\beta v-A_{2}$ \\
$H_{T-1}=0$ & $:$ & 0 \\
\hline
\end{tabular}

where the execution probabilities are given by (4) and (5), presented in Section 3.3. After comparing these payoffs, we obtain the equilibrium strategies at $T-1$ that depend on the relative tick size $\frac{\tau}{v}$, as shown in Lemma 2. For the time being we assume that the relative tick size is such (small enough) that traders are not aggressive and post limit orders at higher levels of the book when available. The equilibrium strategies at $T-1$ are given by formula (6):

$$
H_{T-1}^{* L M}(\beta,[1000])= \begin{cases}-1^{B} & \text { if } \beta \in\left[\beta,\left.\beta_{1, T-1}\right|_{A_{1}, B=B_{2}}\right) \\ +1^{A_{1}} & \text { if } \beta \in\left[\left.\bar{\beta}_{1, T-1}\right|_{A_{1}, B=B_{2}},\left.\beta_{3, T-1}\right|_{A_{1}, B_{2}}\right) \\ +1^{B_{2}} & \text { if } \beta \in\left[\left.\beta_{3, T-1}\right|_{A_{1}, B_{2}},\left.\beta_{5, T-1}\right|_{A=A_{2}, B_{2}}\right) \\ -1^{A} & \text { if } \beta \in\left[\left.\beta_{5, T-1}\right|_{A=A_{2}, B_{2}}, \bar{\beta}\right]\end{cases}
$$

where $\left.\beta_{1, T-1}\right|_{A_{1}, B=B_{2}}=\frac{B_{2}}{v}-\frac{p_{T-1}^{*}\left(A_{1} \mid[1100]\right)}{1-p_{T-1}^{*}\left(A_{1} \mid[1100]\right)} \cdot \frac{A_{1}-B_{2}}{v},\left.\beta_{3, T-1}\right|_{A_{1}, B_{2}}=\frac{p_{T-1}^{*}\left(A_{1} \mid[1100]\right) A_{1}+p_{T-1}^{*}\left(B_{2} \mid[1001]\right) B_{2}}{p_{T-1}^{*}\left(A_{1} \mid[1100]\right)+p_{T-1}^{*}\left(B_{2} \mid[1001]\right)}$. $\frac{1}{v}$ and $\left.\beta_{5, T-1}\right|_{A=A_{2}, B_{2}}=\frac{A_{2}}{v}+\frac{p_{T-1}^{*}\left(B_{2} \mid[1001]\right)}{1-p_{T-1}^{*}\left(B_{2} \mid[1001]\right)} \cdot \frac{A_{2}-B_{2}}{v}$. This allows us to compute the execution probability of the strategy $H_{T-2}=+1^{A_{2}}$ that produces at $T-1$ the book that we are considering, i.e. [1000]:

$$
\begin{aligned}
p_{T-2}^{*}\left(A_{2} \mid[1000]\right)= & \frac{\bar{\beta}-\left.\beta_{5, T-1}\right|_{A=A_{2}, B_{2}}}{\bar{\beta}-\underline{\beta}}+\frac{\left.\beta_{5, T-1}\right|_{A=A_{2}, B_{2}}-\left.\beta_{3, T-1}\right|_{A_{1}, B_{2}}}{\bar{\beta}-\underline{\beta}} \cdot p_{T-1}^{*}\left(A_{2} \mid[1001]\right) \\
& +\frac{\beta_{1, T-1} \mid A_{1}, B=B_{2}-\underline{\beta}}{\bar{\beta}-\underline{\beta}} \cdot p_{T-1}^{*}\left(A_{2} \mid[1000]\right)
\end{aligned}
$$

The first term on the RHS of this equation represents the probability of being executed at $T-1$, while the other two terms stand for the probability of being executed during the last period $T$. Similarly, we are able to get the execution probabilities at $T-2$ for the other order types, that produce respectively the opening books [0000],[0100],[0010] and [0001] at $T-1$. We can then replicate the procedure used at $T-1$ to compare all possible trader's payoffs at $T-2$ : 


\begin{tabular}{|lll|}
$H_{T-2}=-1^{B}$ & $:$ & $B_{2}-\beta v$ \\
$H_{T-2}=+1^{A_{2}}$ & $:$ & $\left(A_{2}-\beta v\right) \cdot p_{T-2}^{*}\left(A_{2} \mid[1000]\right)$ \\
$H_{T-2}=+1^{A_{1}}$ & $:$ & $\left(A_{1}-\beta v\right) \cdot p_{T-2}^{*}\left(A_{1} \mid[0100]\right)$ \\
$H_{T-2}=+1^{B_{1}}$ & $:$ & $\left(\beta v-B_{1}\right) \cdot p_{T-2}^{*}\left(B_{1} \mid[0010]\right)$ \\
$H_{T-2}=+1^{B_{2}}$ & $:$ & $\left(\beta v-B_{2}\right) \cdot p_{T-2}^{*}\left(B_{2} \mid[0001]\right)$ \\
$H_{T-2}=-1^{A}$ & $:$ & $\beta v-A_{2}$ \\
$H_{T-2}=0$ & $:$ & 0 \\
\hline
\end{tabular}

Hence equilibrium strategies at $T-2$ are:

$$
H_{T-2}^{* L M}(\beta,[0000])= \begin{cases}-1^{B} & \text { if } \beta \in\left[\beta,\left.\beta_{1, T-2}\right|_{A_{2}, B=B_{2}}\right) \\ +1^{A_{2}} & \text { if } \beta \in[\bar{\beta} \\ \left.+\left.1_{1, T-2}\right|_{A_{2}, B=B_{2}},\left.\beta_{3, T-2}\right|_{A_{2}, B_{2}}\right) & \text { if } \beta \in\left[\left.\beta_{3, T-2}\right|_{A_{2}, B_{2}},\left.\beta_{5, T-2}\right|_{A=A_{2}, B_{2}}\right) \\ -1^{A} & \text { if } \beta \in\left[\left.\beta_{5, T-2}\right|_{A=A_{2}, B_{2}}, \bar{\beta}\right]\end{cases}
$$

where $\left.\beta_{1, T-2}\right|_{A_{2}, B=B_{2}}=\frac{B}{v}-\frac{p_{T-2}^{*}\left(A_{2} \mid[1000]\right)}{1-p_{T-2}^{*}\left(A_{2} \mid[1000]\right)} \cdot \frac{A_{2}-B}{v},\left.\beta_{3, T-2}\right|_{A_{2}, B_{2}}=\frac{p_{T-2}^{*}\left(A_{2} \mid[1000]\right) A_{2}+p_{T-2}^{*}\left(B_{2}[[0001]) B_{2}\right.}{p_{T-2}^{*}\left(A_{2} \mid[1000]\right)+p_{T-2}^{*}\left(B_{2} \mid[0001]\right)}$. $\frac{1}{v},\left.\beta_{5, T-2}\right|_{A=A_{2}, B_{2}}=\frac{A}{v}+\frac{p_{T-2}^{*}\left(B_{2} \mid[0001]\right)}{1-p_{T-2}^{*}\left(B_{2} \mid[0001]\right)} \cdot \frac{A-B_{2}}{v}$.

When instead $\frac{\tau}{v}$ is large, submitting limit orders on the first level of the book becomes also an optimal strategy. We present directly the equilibrium strategies at $T-2$, where formula (7a) is modified as follows:

$$
H_{T-2}^{* L M}(\beta,[0000])= \begin{cases}-1^{B} & \text { if } \beta \in\left[\beta,\left.\beta_{1, T-2}\right|_{A_{1}, B=B_{2}}\right) \\ +1^{A_{1}} & \text { if } \beta \in\left[\left.\beta_{1, T-2}\right|_{A_{1}, B=B_{2}},\left.\beta_{6, T-2}\right|_{A_{1}, A_{2}}\right) \\ +1^{A_{2}} & \text { if } \beta \in\left[\left.\beta_{6, T-2}\right|_{A_{1}, A_{2}},\left.\beta_{3, T-2}\right|_{A_{2}, B_{2}}\right) \\ +1^{B_{2}} & \text { if } \beta \in\left[\left.\beta_{3, T-2}\right|_{A_{2}, B_{2}},\left.\beta_{7, T-2}\right|_{B_{1}, B_{2}}\right) \\ +1^{B_{1}} & \text { if } \beta \in\left[\left.\beta_{7, T-2}\right|_{B_{1}, B_{2}},\left.\beta_{5, T-2}\right|_{A=A_{2}, B_{1}}\right) \\ -1^{A} & \text { if } \beta \in\left[\left.\beta_{5, T-2}\right|_{A=A_{2}, B_{1}}, \bar{\beta}\right]\end{cases}
$$

where $\left.\beta_{6, T-2}\right|_{A_{1}, A_{2}}=\frac{p_{T-2}^{*}\left(A_{1} \mid[0100]\right) A_{1}-p_{T-2}^{*}\left(A_{2} \mid[1000]\right) A_{2}}{p_{T-2}^{*}\left(A_{1} \mid[0100]\right)-p_{T-2}^{*}\left(A_{2} \mid[1000]\right)} \cdot \frac{1}{v},\left.\beta_{7, T-2}\right|_{B_{1}, B_{2}}=\frac{p_{T-2}^{*}\left(B_{1} \mid[0010]\right) B_{1}-p_{T-2}^{*}\left(B_{2} \mid[0001]\right) B_{2}}{p_{T-2}^{*}\left(B_{1} \mid[0010]\right)-p_{T-2}^{*}\left(B_{2} \mid[0001]\right)}$. $\frac{1}{v}$.

(1.2) We solve the same problem in the small-tick market (SM) where traders can select among five price levels both on the ask and the bid side to post their limit orders, so that $a_{l}=v+\frac{\tau}{6}(2 l-1)$ and $b_{l}=v-\frac{\tau}{6}(2 l-1)$ for $l=1, . ., 5$, and $A_{1}=a_{2}, A_{2}=a_{5}, B_{1}=b_{2}$ and $B_{2}=b_{5}$. As the methodology is similar to the one for case 1.1, we directly present the equilibrium strategies at $T-2$ for the case with an empty book, that we indicate with $S_{t}=[0]$, and a small relative tick size value, $\frac{\tau}{v}$ :

$$
H_{T-2}^{* S M}(\beta,[0])= \begin{cases}-1^{b} & \text { if } \beta \in\left[\beta,\left.\beta_{1, T-2}\right|_{a_{5}, b=b_{5}}\right) \\ +1^{a_{5}} & \text { if } \beta \in\left[\left.\beta \beta_{1, T-2}\right|_{a_{5}, b=b_{5}},\left.\beta_{3, T-2}\right|_{a_{5}, b_{5}}\right) \\ +1^{b_{5}} & \text { if } \beta \in\left[\left.\beta_{3, T-2}\right|_{a_{5}, b_{5}},\left.\beta_{5, T-2}\right|_{a=a_{5}, b_{5}}\right) \\ -1^{a} & \text { if } \beta \in\left[\left.\beta_{5, T-2}\right|_{a=a_{5}, b_{5}}, \beta\right]\end{cases}
$$


When $\frac{\tau}{v}$ is large, equilibrium strategies at $T-2$ modify as follows:

$$
H_{T-2}^{* S M}(\beta,[0])= \begin{cases}-1^{b} & \text { if } \beta \in\left[\beta,\left.\beta_{1, T-2}\right|_{a_{1}, b=b_{5}}\right) \\ +1^{a_{1}} & \text { if } \beta \in\left[\left.\bar{\beta}_{1, T-2}\right|_{a_{1}, b=b_{5}},\left.\beta_{6, T-2}\right|_{a_{1}, a_{5}}\right) \\ +1^{a_{5}} & \text { if } \beta \in\left[\left.\beta_{6, T-2}\right|_{a_{1}, a_{5}},\left.\beta_{3, T-2}\right|_{a_{5}, b_{5}}\right) \\ +1^{b_{5}} & \text { if } \beta \in\left[\left.\beta_{3, T-2}\right|_{a_{5}, b_{5}},\left.\beta_{7, T-2}\right|_{b_{1}, b_{5}}\right) \\ +1^{b_{1}} & \text { if } \beta \in\left[\left.\beta_{7, T-2}\right|_{b_{1}, b_{5}},\left.\beta_{5, T-2}\right|_{a=a_{5}, b_{1}}\right) \\ -1^{a} & \text { if } \beta \in\left[\left.\beta_{5, T-2}\right|_{a=a_{5}, b_{1}}, \bar{\beta}\right]\end{cases}
$$

(1.3) As defined in Section 4, liquidity provision and executed volume at $T-2$ are determined by the probability that in this trading round the incoming trader submits a limit order or a market order respectively. To compare LM and SM in terms of these measures, it is sufficient to compare the thresholds that make the trader indifferent between submitting a market order and the most attractive among the available limit order strategies:

$$
\begin{gathered}
\left.\widehat{\beta}_{5, T-2}^{L M}\right|_{A=A_{2}, B_{k}}=\left.\max _{B_{k}} \beta_{5, T-2}\right|_{A=A_{2}, B_{k}}=\max _{B_{k}}\left\{\frac{A_{2}}{v}+\frac{p_{T-1}^{*}\left(B_{k} \mid S_{T-1}\right)}{1-p_{T-1}^{*}\left(B_{k} \mid S_{T-1}\right)} \cdot \frac{A_{2}-B_{k}}{v}\right\} \\
\left.\widehat{\beta}_{5, T-2}^{S M}\right|_{a=a_{5}, b_{l}}=\left.\max _{b_{l}} \beta_{5, T-2}\right|_{a=a_{5}, b_{l}}=\max _{b_{l}}\left\{\frac{a_{5}}{v}+\frac{p_{T-1}^{*}\left(b_{l} \mid S_{T-1}\right)}{1-p_{T-1}^{*}\left(b_{l} \mid S_{T-1}\right)} \cdot \frac{a_{5}-b_{l}}{v}\right\}
\end{gathered}
$$

After substituting the execution probabilities computed in (1.1) and (1.2), we find that the probability of a market buy order is larger for the small tick market: $\left.\widehat{\beta}_{5, T-2}^{S M}\right|_{a=a_{5}, b_{l}}<$ $\left.\widehat{\beta}_{5, T-2}^{L M}\right|_{A=A_{2}, B_{k}}$. A similar result holds for a market sell order: $\left.\widehat{\beta}_{1, T-2}^{S M}\right|_{a_{l}, b=b_{5}}>\left.\widehat{\beta}_{1, T-2}^{L M}\right|_{A_{k}, B=B_{2}}$. Consequently volume is higher in the small tick market:

$$
V L_{T-2}^{S M}=\frac{\bar{\beta}-\left.\widehat{\beta}_{5, T-2}^{S M}\right|_{a=a_{5}, b_{l}}}{\bar{\beta}-\underline{\beta}}+\frac{\left.\widehat{\beta}_{1, T-2}^{S M}\right|_{a_{l}, b=b_{5}}-\underline{\beta}}{\bar{\beta}-\underline{\beta}}>\frac{\bar{\beta}-\left.\widehat{\beta}_{5, T-2}^{L M}\right|_{A=A_{2}, B_{k}}}{\bar{\beta}-\underline{\beta}}+\frac{\left.\widehat{\beta}_{1, T-2}^{L M}\right|_{A_{k}, B=B_{2}}-\underline{\beta}}{\bar{\beta}-\underline{\beta}}=V L_{T-2}^{L M}
$$

Notice that when the book starts empty at $T-2$, no trading $\left(H_{T-2}=0\right)$ is never optimal and hence in this single market model the submission probabilities of market and limit orders are complements. Thus, as $V L_{T-2}^{L M}<V L_{T-2}^{S M}, L P_{T-2}^{L M}>L P_{T-2}^{S M}$. Notice also that, as the book starts empty so that there is no depth already available, inside depth coincides with total depth and also with liquidity provision, $D P I_{T-2}=D P T_{T-2}=L P_{T-2}$, where:

$$
L P_{T-2}=\frac{\widehat{\beta}_{5, T-2}-\widehat{\beta}_{1, T-2}}{\bar{\beta}-\underline{\beta}}
$$

As a consequence, also total and internal depth are lower in a small tick market: $D P I_{T-2}^{L M}=$ $D P T_{T-2}^{L M}>D P I_{T-2}^{S M}=D P T_{T-2}^{S M}$. Finally, in order to compute the spread, we need to differentiate two cases depending on the value of $\frac{\tau}{v}$. When $\frac{\tau}{v}$ is large, we obtain:

$$
\begin{aligned}
S P_{T-2}^{L M} & =E[A-B]=3 \tau-\left(\frac{\left.\beta_{6, T-2}\right|_{A_{1}, A_{2}}-\left.\beta_{1, T-2}\right|_{A_{2}, B=B_{2}}}{\bar{\beta}-\underline{\beta}}+\frac{\left.\beta_{5, T-2}\right|_{A=A_{2}, B_{2}}-\left.\beta_{7, T-2}\right|_{B_{1}, B_{2}}}{\bar{\beta}-\underline{\beta}}\right) \cdot \tau \\
& <3 \tau-\left(\frac{\left.\beta_{6, T-2}\right|_{a_{1}, a_{5}}-\left.\beta_{1, T-2}\right|_{a_{1}, b=b_{5}}}{\bar{\beta}-\underline{\beta}}+\frac{\left.\beta_{5, T-2}\right|_{a=a_{5}, b_{1}}-\left.\beta_{7, T-2}\right|_{b_{1}, b_{5}}}{\bar{\beta}-\underline{\beta}}\right) \cdot \frac{4 \tau}{3}=S P_{T-2}^{S M}
\end{aligned}
$$


where, for example, $\frac{\beta_{6, T-2}\left|A_{1}, A_{2}-\beta_{1, T-2}\right|_{A_{2}, B=B_{2}}}{\bar{\beta}-\beta}$ is the probability of a limit sell order posted at $A_{1}$ and $\frac{\left.\beta_{5, T-2}\right|_{A=A_{2}, B_{2}}-\left.\beta_{7, T-2}\right|_{B_{1}, B_{2}}}{\bar{\beta}-\beta}$ is the probability of a limit buy order posted at $B_{1}$. When instead $\frac{\tau}{v}$ is small and traders in equilibrium post limit orders only at $A_{2}=a_{5}$ and $B_{2}=b_{5}$, we obtain that $S P_{T-2}^{L M}=S P_{T-2}^{S M}=3 \tau$. So the spread never decreases after a tick size reduction, and it increases for stocks with large relative tick size.

2) Liquid stocks: starting book at $T-2$ is [0110]

(2.1) Consider again LM. The traders' strategy space at $T-2$ is the same as in case (1) and the possible opening books at $T-1$ are: [0100], [0010], [0210], [0120], [0110], [1110] and [0111]. As an example, we consider the case where $H_{T-2}=+1^{A_{1}}$ so that the book opens at $T-1$ as [0210]; in this case the incoming trader never gets execution priority for limit orders and therefore his strategy space is $\left\{-1^{B},-1^{A}, 0\right\}$; his corresponding payoffs are:

$$
\begin{array}{lll|}
H_{T-1}=-1^{B} & : & B_{2}-\beta v \\
H_{T-1}=-1^{A} & : & \beta v-A_{2} \\
H_{T-1}=0 & : & 0 \\
\hline
\end{array}
$$

By comparing these payoffs, it is then straightforward to compute his equilibrium strategies, obtained by using $(7 \mathrm{~d})$ :

$$
H_{T-1}^{* L M}(\beta,[0210])=\left\{\begin{array}{cl}
-1^{B} & \text { if } \beta \in\left[\beta,\left.\beta_{1, T-1}\right|_{B=B_{1}}\right) \\
0 & \text { if } \beta \in\left[\left.\bar{\beta}_{1, T-1}\right|_{B=B_{1}},\left.\beta_{5, T-1}\right|_{A=A_{1}}\right) \\
-1^{A} & \text { if } \beta \in\left[\left.\beta_{5, T-1}\right|_{A=A_{1}}, \bar{\beta}\right]
\end{array}\right.
$$

where $\left.\beta_{1, T-1}\right|_{B=B_{1}}=\frac{B_{1}}{v}$ and $\left.\beta_{5, T-1}\right|_{A=A_{1}}=\frac{A_{1}}{v}$. We can then compute the execution probabilities of the order submitted at $T-2$ as:

$$
p_{T-2}^{*}(A \mid[0210])=\frac{\bar{\beta}-\left.\beta_{5, T-1}\right|_{A=A_{1}}}{\bar{\beta}-\underline{\beta}}
$$

Following the same methodology, we are able to obtain the execution probabilities for all possible strategies at $T-2$. We can finally compute the strategies' payoffs in the same period:

\begin{tabular}{|lll|}
\hline$H_{T-2}=-1^{B}$ & $:$ & $B_{1}-\beta v$ \\
$H_{T-2}=+1^{A_{2}}$ & $:$ & $\left(A_{2}-\beta v\right) \cdot p_{T-2}^{*}\left(A_{2}^{1,1} \mid[1110]\right)$ \\
$H_{T-2}=+1^{A_{1}}$ & $:$ & $\left(A_{1}-\beta v\right) \cdot p_{T-2}^{*}\left(A_{1}^{2} \mid[0210]\right)$ \\
$H_{T-2}=+1^{B_{1}}$ & $:$ & $\left(\beta v-B_{1}\right) \cdot p_{T-2}^{*}\left(B_{1}^{2} \mid[0120]\right)$ \\
$H_{T-2}=+1^{B_{2}}$ & $:$ & $\left(\beta v-B_{2}\right) \cdot p_{T-2}^{*}\left(B_{2}^{1,1} \mid[0111]\right)$ \\
$H_{T-2}=-1^{A}$ & $:$ & $\beta v-A_{1}$ \\
$H_{T-2}=0$ & $:$ & 0 \\
\hline
\end{tabular}


where $p_{T-2}^{*}\left(A_{2}^{1,1} \mid[1110]\right)=\left.\frac{\bar{\beta}-\left.\beta_{5, T-1}\right|_{A=A_{1}, B_{1}}}{\bar{\beta}-\underline{\beta}} \cdot p_{T-1}^{*}(A)\right|_{A=A_{2}}, p_{T-2}^{*}\left(A_{1}^{2} \mid[0210]=\frac{\bar{\beta}-\left.\beta_{5, T-1}\right|_{A=A_{1}, B_{1}}}{\bar{\beta}-\underline{\beta}}\right.$. $\left.p_{T-1}^{*}(A)\right|_{A=A_{1}}, p_{T-2}^{*}\left(B_{1}^{2} \mid[0120]\right)=\left.\frac{\left.\bar{\beta}_{1, T-1}\right|_{A=A_{1}, B_{1}}-\underline{\beta}}{\bar{\beta}-\underline{\beta}} \cdot p_{T-1}^{*}(B)\right|_{B=B_{1}}$ and $p_{T-2}^{*}\left(B_{2}^{1,1} \mid[0111]\right)=$ $\left.\frac{\left.\beta_{1, T-1}\right|_{A=A_{1}, B_{1}-\underline{\beta}}}{\bar{\beta}-\beta} \cdot p_{T-1}^{*}(B)\right|_{B=B_{2}}$. By comparing these payoffs we obtain the following equilibrium strategies:

$$
H_{T-2}^{* L M}(\beta,[0110])= \begin{cases}-1^{B} & \text { if } \beta \in\left[\beta,\left.\beta_{1, T-2}\right|_{A_{2}, B=B_{1}}\right) \\ +1^{A_{2}} & \text { if } \beta \in\left[\left.\beta_{1, T-2}\right|_{A_{2}, B=B_{1}},\left.\beta_{3, T-2}\right|_{A_{2}, B_{2}}\right) \\ +1^{B_{2}} & \text { if } \beta \in\left[\left.\beta_{3, T-2}\right|_{A_{2}, B_{2}},\left.\beta_{5, T-2}\right|_{A=A_{1}, B_{2}}\right) \\ -1^{A} & \text { if } \beta \in\left[\left.\beta_{5, T-2}\right|_{A=A_{1}, B_{2}}, \bar{\beta}\right]\end{cases}
$$

where $\left.\beta_{1, T-2}\right|_{A_{2}, B=B_{1}}=\frac{B_{1}}{v}-\frac{p_{T-2}^{*}\left(A_{2}^{1,1} \mid[1110]\right)}{1-p_{T-2}^{*}\left(A_{2}^{1,1} \mid[1110]\right)} \cdot \frac{A_{2}-B_{1}}{v},\left.\beta_{3, T-2}\right|_{A_{2}, B_{2}}=\frac{p_{T-2}^{*}\left(A_{2}^{1,1} \mid[1110]\right) A_{2}+p_{T-2}^{*}\left(B_{2}^{1,1} \mid[0111]\right) B_{2}}{p_{T-2}^{*}\left(A_{2}^{1,1} \mid[1110]\right)-p_{T-2}^{*}\left(B_{2}^{1,1} \mid[0111]\right)}$. $\frac{1}{v}$, and $\left.\beta_{5, T-2}\right|_{A=A_{1}, B_{2}}=\frac{A_{1}}{v}+\frac{p_{T-2}^{*}\left(B_{2}^{1,1} \mid[0111]\right)}{1-p_{T-2}^{*}\left(B_{2}^{1,1} \mid[0111]\right)} \cdot \frac{A_{1}-B_{2}}{v}$.

(2.2) We solve the same problem in SM. Notice that in this case where at $T-2$ one share is available at $a_{2}$ and $b_{2}$, thanks to the finer price grid traders have room for undercutting the best quotes by submitting limit orders at $a_{1}$ and $b_{1}$. As the procedure to get to the equilibrium strategies is the same as in the previous case, we present directly the results. Notice that we indicate by $\left[Q^{a_{2}}=1, Q^{b_{2}}=1\right]$ the book that opens at $T-1$ with one unit on both $a_{2}$ and $b_{2}$.

$$
H_{T-2}^{* S M}\left(\beta,\left[Q^{a_{2}}=1, Q^{b_{2}}=1\right]\right)= \begin{cases}-1^{b} & \text { if } \beta \in\left[\beta, \beta 1, T-2||_{a_{1}, b=b_{2}}\right) \\ +1^{a_{1}} & \text { if } \beta \in\left[\left.\bar{\beta}_{1, T-2}\right|_{a_{1}, b=b_{2}},\left.\beta_{6, T-2}\right|_{a_{1}, a_{5}}\right) \\ +1^{a_{5}} & \text { if } \beta \in\left[\left.\beta_{6, T-2}\right|_{a_{1}, a_{5}},\left.\beta_{3, T-2}\right|_{a_{5}, b_{5}}\right) \\ +1^{b_{5}} & \text { if } \beta \in\left[\left.\beta_{3, T-2}\right|_{a_{5}, b_{5}},\left.\beta_{7, T-2}\right|_{b_{1}, b_{5}}\right) \\ +1^{b_{1}} & \text { if } \beta \in\left[\left.\beta_{7, T-2}\right|_{b_{1}, b_{5}},\left.\beta_{5, T-2}\right|_{a=a_{2}, b_{1}}\right) \\ -1^{a} & \text { if } \beta \in\left[\left.\beta_{5, T-2}\right|_{a=a_{2}, b_{1}}, \bar{\beta}\right]\end{cases}
$$

(2.3) Similarly to (1.3), we compare the indicators of market quality by using the probabilities of observing different order types. Notice from the equilibrium strategies presented in (2.2) that here $\left.\widehat{\beta}_{5, T-2}^{S M}\right|_{a=a_{5}, b_{l}}=\left.\beta_{5, T-2}\right|_{a=a_{2}, b_{1}}$ and $\left.\widehat{\beta}_{5, T-2}^{L M}\right|_{A=A_{1}, B_{k}}=\left.\beta_{5, T-2}\right|_{A=A_{1}, B_{2}}$. After substituting for the optimal execution probabilities we find that $\left.\beta_{5, T-2}\right|_{A=A_{1}, B_{2}}<$ $\left.\beta_{5, T-2}\right|_{a=a_{2}, b_{1}}$ and $\left.\beta_{1, T-2}\right|_{A_{2}, B=B_{1}}>\left.\beta_{1, T-2}\right|_{a_{1}, b=b_{2}}$, so that:

$$
V L_{T-2}^{S M}=\frac{\bar{\beta}-\left.\beta_{5, T-2}\right|_{a=a_{2}, b_{1}}}{\bar{\beta}-\underline{\beta}}+\frac{\left.\beta_{1, T-2}\right|_{a_{1}, b=b_{2}}-\underline{\beta}}{\bar{\beta}-\underline{\beta}}<\frac{\bar{\beta}-\left.\beta_{5, T-2}\right|_{A=A_{1}, B_{2}}}{\bar{\beta}-\underline{\beta}}+\frac{\left.\beta_{1, T-2}\right|_{A_{2}, B=B_{1}}-\underline{\beta}}{\bar{\beta}-\underline{\beta}}=V L_{T-2}^{L M}
$$

Given that $H_{T-2}=0$ cannot occur in equilibrium and that as a consequence the probability of limit and market orders are complements, $V L_{T-2}^{L M}>V L_{T-2}^{S M}$ implies that $L P_{T-2}^{L M}<L P_{T-2}^{S M}$. 
The other market indicators for LM are computed as follows:

$$
\begin{aligned}
D P I_{T-2}^{L M} & =2-1 \cdot\left(\frac{\left.\beta_{1, T-2}\right|_{A_{2}, B=B_{1}}-\underline{\beta}}{\bar{\beta}-\underline{\beta}}+\frac{\bar{\beta}-\left.\beta_{5, T-2}\right|_{A=A_{1}, B_{2}}}{\bar{\beta}-\underline{\beta}}\right)=2-V L_{T-2}^{L M}=1+L P_{T-2}^{L M} \\
D P T_{T-2}^{L M} & =2+L P_{T-2}^{L M}-V L_{T-2}^{L M}=1+2 \cdot L P_{T-2}^{L M} \\
S P_{T-2}^{L M} & =L P_{T-2}^{L M} \cdot(\tau)+V L_{T-2}^{L M} \cdot(2 \tau)=\left(2-L P_{T-2}^{L M}\right) \tau
\end{aligned}
$$

Following the same methodology, we compute market indicators for the small tick case, where $D P I_{T-2}^{S M}=1+L P_{T-2}^{S M}, D P T_{T-2}^{S M}=1+2 \cdot L P_{T-2}^{S M}$ and

$$
\begin{aligned}
S P_{T-2}^{S M} & =\operatorname{Pr}\left(H_{T-2}^{* S M}=+1^{a_{2}},+1^{b_{2}}\right) \cdot(\tau)+\operatorname{Pr}\left(H_{T-2}^{* S M}=+1^{a_{1}},+1^{b_{1}}\right) \cdot\left(\frac{2 \tau}{3}\right)+V L_{T-2}^{L M} . \\
& =L P_{T-2}^{L M} \cdot(\tau)-\operatorname{Pr}\left(H_{T-2}^{* S M}=+1^{a_{1}},+1^{b_{1}}\right) \cdot \frac{\tau}{3}+V L_{T-2}^{L M} \cdot(2 \tau) \\
& <\left(2-L P_{T-2}^{S M}\right) \tau
\end{aligned}
$$

so that $D P I_{T-2}^{L M}<D P I_{T-2}^{S M}, D P T_{T-2}^{L M}<D P T_{T-2}^{S M}$ and $S P_{T-2}^{L M}>S P_{T-2}^{S M}$.

3) Highly liquid stocks: starting book at $T-2$ is [0220]

At $T-2$ traders' strategy space in a LM is now $\left\{-1^{B},-1^{A}, 0\right\}$ and the corresponding opening books at $T-1$ [0210], [0120], and [0220]. As the stock is very liquid, limit orders at $T-1$ never get executed except for the small tick market where traders can undercut existing liquidity by posting limit orders at $A_{1}$ and $B_{1}$. The equilibrium trading strategies at $T-2$ are:

$$
\begin{gathered}
H_{T-2}^{* L M}(\beta,[0220])=\left\{\begin{array}{cl}
-1^{B} & \text { if } \beta \in\left[\underline{\beta},\left.\beta_{1, T-2}\right|_{A_{1}, B=B_{1}}\right) \\
0 & \text { if } \beta \in\left[\left.\bar{\beta}_{1, T-2}\right|_{A_{1}, B=B_{1}},\left.\beta_{5, T-2}\right|_{A=A_{1}, B_{1}}\right) \\
-1^{A} & \text { if } \beta \in\left[\left.\beta_{5, T-2}\right|_{A=A_{1}, B_{1}}, \bar{\beta}\right]
\end{array}\right. \\
H_{T-2}^{* S M}\left(\beta,\left[Q^{a_{2}}=2, Q^{b_{2}}=2\right]\right)=\left\{\begin{array}{cl}
-1^{b} & \text { if } \beta \in\left[\beta,\left.\beta_{1, T-2}\right|_{a_{1}, b=b_{2}}\right) \\
+1^{a_{1}} & \text { if } \beta \in\left[\left.\bar{\beta}_{1, T-2}\right|_{a_{1}, b=b_{2}},\left.\beta_{3, T-2}\right|_{a_{1}, b_{1}}\right) \\
+1^{b_{1}} & \text { if } \beta \in\left[\left.\beta_{3, T-2}\right|_{a_{1}, b_{1}},\left.\beta_{5, T-2}\right|_{a=a_{2}, b_{1}}\right) \\
-1^{a} & \text { if } \beta \in\left[\left.\beta_{5, T-2}\right|_{a=a_{2}, b_{1}}, \bar{\beta}\right]
\end{array}\right.
\end{gathered}
$$

clearly, liquidity provision is positive only in the SM market so that $L P_{T-2}^{S M}>L P_{T-2}^{L M}=0$, thus $D P T_{T-2}^{S M}>D P T_{T-2}^{L M}$ and $S P_{T-2}^{S M}<S P_{T-2}^{L M}$. Comparing the thresholds for market orders we obtain:

$$
\left.\widehat{\beta}_{1, T-2}^{S M}\right|_{a_{1}, b=b_{2}}=\min \left\{\frac{b_{2}}{v}, \frac{b_{2}}{v}-\frac{p_{T-2}^{*}(\cdot) \mid a_{1}}{1-\left.p_{T-2}^{*}(\cdot)\right|_{a_{1}}} \cdot \frac{a_{1}-b_{2}}{v}\right\}<\frac{B_{1}}{v}=\left.\widehat{\beta}_{1, T-2}^{L M}\right|_{A_{1}, B=B_{1}}
$$

so that $V L_{T-2}^{S M}<V L_{T-2}^{L M}$. Finally, $D P I_{T-2}^{S M}=3<3 V L_{T-2}^{L M}+4\left(1-V L_{T-2}^{L M}\right)=D P I_{T-2}^{L M}$. 


\section{Proof of Lemma 3}

Proof. Assume that the two markets have the same initial depth at the common price levels, so that $S_{0}^{A_{2}}=S_{0}^{a_{5}}, S_{0}^{A_{1}}=S_{0}^{a_{2}}, S_{0}^{B_{2}}=S_{0}^{b_{5}}$, and $S_{0}^{B_{1}}=S_{0}^{b_{2}}$. Consider an incoming seller who can submit either a market order or a limit order or refrain from trading. If he opts for a market order, he faces two cases: either the best ask price is different from the two common price levels $\left(A \neq A_{2} \neq A_{1}\right)$, or it is one of those two $\left(A=A_{2}\right.$ or $\left.A_{1}\right)$. In the first case the market order will only change depth at the best ask price level and not at the common ones; in the second one the trader will randomize between the two trading venues as they both offer liquidity at the best ask and hence expected depth at the two common price levels will change equally. For this reason, we obtain that: $E\left[S_{1}^{A_{2}}\right]=E\left[S_{1}^{a_{5}}\right]$ and $E\left[S_{1}^{A_{1}}\right]=E\left[S_{1}^{a_{2}}\right]$. If instead the trader opts for a limit order, either he submits his order to a price level that is not common to the two markets, in which case the Lemma trivially holds, or if he decides to submit a limit order at one of the two common price levels (i.e. $A_{2}=a_{5}$ and $A_{1}=a_{2}$ ), he will optimally randomize between them so that expected depth will still be the same. For this case, consider as an example $A_{1}=a_{2}$ and notice that profits from the two limit order strategies are indeed the same:

$\begin{array}{lll}H_{1}=+1^{A_{1}} & :\left(A_{1}-\beta v\right) \cdot p_{1}^{*}\left(A_{1}^{n_{1}, n_{2}+N_{1}+1} \mid S_{0}\right) \\ H_{1}=+1^{a_{2}} & :\left(a_{2}-\beta v\right) \cdot p_{1}^{*}\left(a_{2}^{n_{1}, n_{2}+N_{1}+1} \mid S_{0}\right)\end{array}$

For this reason the incoming trader will randomize between the two trading venues:

$$
E\left[h_{1}^{A_{1}}\right]=E\left[h_{1}^{a_{2}}\right]=\frac{1}{2} \int_{\beta \in\left\{\beta: H_{t}(\beta)=1^{A_{1}, 1^{a}}\right\}} H_{t}(\beta) d \beta
$$

From equation (3), this implies that $E\left[S_{1}^{A_{1}}\right]=E\left[S_{1}^{a_{2}}\right]$. A similar result is obtained for $A_{2}=a_{5}$. Finally, if the trader decides not to trade, then no change is observed on the depth associated to the two common price levels, and the Lemma will hold. As the same argument can be applied to the bid side and holds recursively for $t \geq 2$, we obtain that when $S_{0}^{A_{2}}=S_{0}^{a_{5}}, S_{0}^{A_{1}}=S_{0}^{a_{2}}, S_{0}^{B_{2}}=S_{0}^{b_{5}}$, and $S_{0}^{B_{1}}=S_{0}^{b_{2}}$, then $\forall t \in[1, T] \quad E\left[S_{t}^{A_{2}}\right]=E\left[S_{t}^{a_{5}}\right]$, $E\left[S_{t}^{A_{1}}\right]=E\left[S_{t}^{a_{2}}\right], E\left[S_{t}^{B_{2}}\right]=E\left[S_{t}^{b_{5}}\right]$ and $E\left[S_{t}^{B_{1}}\right]=E\left[S_{t}^{b_{2}}\right]$.

\section{E Proof of Proposition 2}

Proof. Lemma 3 tells us that, if the two markets have the same initial depth at the common price levels, they should always have the same expected depth at those price levels. So in order to prove that liquidity provision concentrates on the SM, it is sufficient to show that traders optimally submit limit orders at price levels that are not common to the two trading 
venues. Consider hence a LM and a SM with the same initial depth at their common price levels and for simplicity with $S_{0}^{a_{j}}=0$ for $j=1,3,4$. If, contrary to Proposition 2, depth does not concentrate on SM, it means that traders post their orders only to the common price levels, i.e. $S_{t}^{a_{j}}=0, \forall t$. Assume that until the beginning of period $t$ it has never been indeed optimal to submit a limit order at any of the non-common price levels, so that $S_{t-1}^{a_{j}}=0$ for $j=1,3,4$. As an example, consider the payoffs of a seller who arrives at $t$ and wants to submit a limit order. Define the payoff's difference between undercutting at $a_{1}$ and queuing at $a_{2}$ as:

$$
f\left(n_{2}\right)=\left(a_{1}-\beta v\right) \cdot p_{t}^{*}\left(a_{1} \mid S_{t}^{L M}, S_{t}^{S M}\right)-\left(a_{2}-\beta v\right) \cdot p_{t}^{*}\left(a_{2}^{2 n_{2}+1} \mid S_{t}^{L M}, S_{t}^{S M}\right)
$$

Notice that if the book is full at $a_{2}$ (or $A_{1}$ )(i.e. $2 n_{2} \geqslant T-t$ ), queuing at $a_{2}$ implies a zero execution probability. Hence we obtain: $f\left(n_{2}\right)=\left(a_{1}-\beta v\right) \cdot p_{t}^{*}\left(a_{1} \mid S_{t}^{L M}, S_{t}^{S M}\right)>$ $0 \Rightarrow H_{t}=+1^{a_{1}} \succ H_{t}=+1^{a_{2}}$. If instead queuing has a non zero execution probability, $p_{t}^{*}\left(a_{2}^{2 n_{2}+1} \mid S_{t-1}^{L M}, S_{t-1}^{S M}\right)>0$, then, as $\partial f\left(n_{2}\right) / \partial n_{2}>0, \exists \bar{n}_{2}$ such that $H_{t}=+1^{a_{1}} \succ H_{t}=+1^{a_{2}}$ for $n_{2}>\bar{n}_{2}$. A similar result holds when comparing $H_{t}=+1^{a_{1}}$ and $H_{t}=+1^{a_{5}}$, where $\bar{n}_{5}<\bar{n}_{2}$. Thus, as the book gets deeper at the common prices, there always exists a critical number of shares above which $H_{t}=+1^{a_{1}}$ is preferred to $H_{t}=+1^{a_{2}},+1^{a_{5}}$. Moreover, taking into account that in the case considered here the book is empty (at $t$ ) at non common price levels, and hence $H_{t}=+1^{a_{1}}$ has always positive execution probability for $t \neq T$, it can be shown that for certain ranges of $\beta$, a limit order at $a_{1}$ is preferable to a market order or not trade. That is, $\exists \beta \in\left(\beta_{-1^{B}, 1^{a_{1}}}, \beta_{-1^{B}, 0}\right)$ s.t $H_{t}^{*}\left(\beta, S_{t-1}^{L M}, S_{t-1}^{S M}\right)=+1^{a_{1}}$ (see proof of Lemma 2). Similar results can be obtained for the bid side. We can hence conclude that when the two markets compete, liquidity concentrates on the SM.

\section{F $\quad$ Proof of Proposition 3}

Proof. Broker-dealers (BD) can choose the market where to submit limit orders, while regular traders (RT) can only submit them to the PLB. A smart router allows all market orders to spot the best price between the two markets. We distinguish two cases depending on whether the IP is visible or invisible to regular traders. In the first case, RT can fully observe the state of the IP, while in the second one they cannot observe the IP and hence they infer the IP state from the order flow arriving to the PLB. We also assume that the IP opens at $T-2$ with equal probability either empty -that we indicate with [0]- or with one unit on the first level -that we indicate with [1]. We provide a proof for liquid stocks, i.e. when the starting PLB at $T-2$ is [01|10]. The proof for illiquid stocks follows a similar procedure and is available from the authors upon request.

1) Liquid stocks, visible IP: starting book at $T-2$ is [0110]\&[0] or [0110]\&[1] 
When RT can observe the state of the IP, they use different trading strategies depending on the initial realization of the IP state. So we first solve the two cases separately (i.e. $[0110] \&[0]$ and $[0110] \&[1])$, and then, in order to obtain market quality indicators that are comparable with the invisible IP case, we average them out.

(1.1) When the opening book is $[0110] \&[0]$, at $T-2$ trader's strategy space, considering both BD and RT, is $\left\{-1^{B},+1^{i},+1^{j},-1^{A}, 0\right\}$ with $i=A_{1: 2}$ and $B_{1: 2}, j=a_{1: 5}$ and $b_{1: 5}$. Therefore at the beginning of $T-1$ there are 17 possible states of the books: one share added on the i-th level of the PLB and no shares added on the IP (4 cases), one share added on the j-th level of the IP and no shares added on the PLB (10 cases), one share taken away from the PLB (2 cases) or no trading (1 case). Conditional on each case, the optimal equilibrium strategy for different types of traders can be obtained. Notice that at $T$, as all traders can observe the best available price, the equilibrium strategies of RT and BD coincide (market order only). As a result the orders' execution probabilities at $T-1$ are independent of traders' type incoming at $T$, so that for example: $p_{T-1}^{* R T}\left(A_{k} \mid S_{T-1}^{P L B}, S_{T-1}^{I P}\right)=p_{T-1}^{* B D}\left(A_{k} \mid S_{T-1}^{P L B}, S_{T-1}^{I P}\right)=$ $p_{T-1}^{*}\left(A_{k} \mid S_{T-1}^{P L B}, S_{T-1}^{I P}\right)$. An example for the case [1110]\&[0], is provided below.

If a RT arrives at $T-1$, he will face the following payoffs:

$$
\begin{array}{lll|}
H_{T-1}=-1^{B} & : & B_{1}-\beta v \\
H_{T-1}=-1^{A} & : & \beta v-A_{1} \\
H_{T-1}=0 & : & 0 \\
\hline
\end{array}
$$

Trader's equilibrium strategies at $T-1$ are easily obtained:

$$
H_{T-1}^{* R T}(\beta,[1110] \&[0])= \begin{cases}-1^{B} & \text { if } \beta \in\left[\beta,\left.\beta_{1, T-1}^{R T}\right|_{B=B_{1}}\right) \\ 0 & \text { if } \beta \in\left[\left.\beta_{1, T-1}^{R T}\right|_{B=B_{1}},\left.\beta_{5, T-1}^{R T}\right|_{A=A_{1}}\right) \\ -1^{A} & \text { if } \beta \in\left[\left.\beta_{5, T-1}^{R T}\right|_{A=A_{1}}, \bar{\beta}\right]\end{cases}
$$

By using the optimal $\beta$ thresholds associated with these strategies, we can compute the execution probability of the strategy $H_{T-2}=+1^{A_{2}}$ in case a RT arrives at $T-1$ :

$$
p_{T-2}^{* R T}\left(A_{2} \mid[1110] \&[0]\right)=\left.\frac{\bar{\beta}-\left.\beta_{5, T-1}^{R T}\right|_{A=A_{1}}}{\bar{\beta}-\underline{\beta}} \cdot p_{T-1}^{*}(A)\right|_{A=A_{2}}
$$

If instead a BD arrives at $T-1$, he will face the following payoffs:

$$
\begin{array}{lll}
H_{T-1}=-1^{B} & : & B_{1}-\beta v \\
H_{T-1}=+1^{a_{l}} & : & \left(a_{l}-\beta v\right) \cdot p_{T-1}^{*}\left(a_{l} \mid S_{T-1}^{P L B}, S_{T-1}^{I P}\right) \\
H_{T-1}=+1^{b_{l}} & : & \left(\beta v-b_{l}\right) \cdot p_{T-1}^{*}\left(b_{l} \mid S_{T-1}^{P L}, S_{T-1}^{I P}\right) \\
H_{T-1}=-1^{A} & : & \beta v-A_{1} \\
H_{T-1}=0 & : & 0
\end{array}
$$

After substituting the execution probabilities at $T$, trader's equilibrium strategies at $T-1$ are obtained: 


$$
H_{T-1}^{* B D}(\beta,[1110] \&[0])= \begin{cases}-1^{B} & \text { if } \beta \in\left[\beta,\left.\beta_{1, T-1}^{B D}\right|_{a_{1}, B=B_{1}}\right) \\ +1^{a_{1}} & \text { if } \beta \in\left[\left.\beta_{1, T-1}^{B D}\right|_{a_{1}, B=B_{1}},\left.\beta_{2, T-1}^{B D}\right|_{a_{1}, a_{2}}\right) \\ +1^{a_{2}} & \text { if } \beta \in\left[\left.\beta_{2, T-1}^{B D}\right|_{a_{1}, a_{2}},\left.\beta_{3, T-1}^{B D}\right|_{a_{2}, b_{2}}\right) \\ +1^{b_{2}} & \text { if } \beta \in\left[\left.\beta_{3, T-1}^{B D}\right|_{a_{2}, b_{2}},\left.\beta_{4, T-1}^{B D}\right|_{b_{1}, b_{2}}\right) \\ +1^{b_{1}} & \text { if } \beta \in\left[\left.\beta_{4, T-1}^{B D}\right|_{b_{1}, b_{2}},\left.\beta_{5, T-1}^{B D}\right|_{A=A_{1}, b_{1}}\right) \\ -1^{A} & \text { if } \beta \in\left[\left.\beta_{5, T-1}^{B D}\right|_{A=A_{1}, b_{1}}, \bar{\beta}\right]\end{cases}
$$

So, when a $\mathrm{BD}$ arrives at $T-1$, the execution probability of the limit order posted at $A_{2}$ is:

$$
p_{T-2}^{* B D}\left(A_{2} \mid[1110] \&[0]\right)=\left.\frac{\bar{\beta}-\left.\beta_{5, T-1}^{B D}\right|_{A=A_{1}, b_{1}}}{\bar{\beta}-\underline{\beta}} \cdot p_{T-1}^{*}(A)\right|_{A=A_{2}}
$$

We can hence compute the total execution probability of the limit order posted on $A_{2}$ at $T-2$ as:

$$
p_{T-2}^{*}\left(A_{2} \mid[0110] \&[0]\right)=\alpha p_{T-2}^{* B D}\left(A_{2} \mid[1110] \&[0]\right)+(1-\alpha) p_{T-2}^{* R T}\left(A_{2} \mid[1110] \&[0]\right)
$$

Similarly, we can compute the equilibrium strategies for all the other possible states of the book at $T-1$ and in this way obtain the execution probabilities of the different order types available at $T-2$ to a BD and a RT.

(i) At $T-2$, if a RT arrives, his strategy space is $\left\{-1^{B},+1^{A_{2}},+1^{A_{1}},+1^{B_{1}},+1^{B_{2}},-1^{A}, 0\right\}$. His payoffs are:

$\begin{array}{lll}H_{T-2}=-1^{B} & : & B_{2}-\beta v \\ H_{T-2}=+1^{A_{i}} & : & \left(A_{i}-\beta v\right) \cdot p_{T-2}^{*}\left(A_{i} \mid[0110] \&[0]\right) \\ H_{T-2}=+1^{B_{i}} & : & \left(\beta v-B_{i}\right) \cdot p_{T-2}^{*}\left(B_{i} \mid[0110] \&[0]\right) \\ H_{T-2}=-1^{A} & : & \beta v-A_{2} \\ H_{T-2}=0 & : & 0\end{array}$

where, for example, $p_{T-2}^{*}\left(A_{1} \mid[0110] \&[0]\right)=\alpha p_{T-2}^{* R T}\left(A_{1} \mid[0210] \&[0]\right)+(1-\alpha) p_{T-2}^{* B D}\left(A_{1} \mid[0210] \&[0]\right)$. By comparing these payoffs, we have:

$$
H_{T-2}^{* R T}(\beta,[0110] \&[0])= \begin{cases}-1^{B} & \text { if } \beta \in\left[\beta,\left.\beta_{1, T-2}^{R T}\right|_{A_{2}, B=B_{1}}\right) \\ +1^{A_{2}} & \text { if } \beta \in\left[\left.\beta_{1, T-2}^{R T}\right|_{A_{2}, B=B_{1}},\left.\beta_{3, T-2}^{R T}\right|_{A_{2}, B_{2}}\right) \\ +1^{B_{2}} & \text { if } \beta \in\left[\left.\beta_{3, T-2}^{R T}\right|_{A_{2}, B_{2}},\left.\beta_{5, T-2}^{R T}\right|_{A=A_{1}, B_{2}}\right) \\ -1^{A} & \text { if } \beta \in\left[\left.\beta_{5, T-2}^{R T}\right|_{A=A_{1}, B_{2}}, \beta\right]\end{cases}
$$

(ii) At $T-2$, if a $\mathrm{BD}$ arrives, he has to decide where to trade. Thus his strategy space is $\left\{-1^{B},+1^{i},+1^{j},-1^{A}, 0\right\}$ with $i=A_{1: 2}$ and $B_{1: 2}, j=a_{1: 5}$ and $b_{1: 5}$. His payoffs are: 


\begin{tabular}{lll|}
$H_{T-2}=-1^{B}$ & $:$ & $B_{2}-\beta v$ \\
$H_{T-2}=+1^{A_{i}}$ & $:$ & $\left(A_{i}-\beta v\right) \cdot p_{T-2}^{*}\left(A_{i} \mid[0110] \&[0]\right)$ \\
$H_{T-2}=+1^{a_{l}}$ & $:$ & $\left(a_{l}-\beta v\right) \cdot p_{T-2}^{*}\left(a_{l} \mid[0110] \&[0]\right)$ \\
$H_{T-2}=+1^{b_{l}}$ & $:$ & $\left(\beta v-b_{l}\right) \cdot p_{T-2}^{*}\left(b_{l} \mid[0110] \&[0]\right)$ \\
$H_{T-2}=+1^{B_{i}}$ & $:$ & $\left(\beta v-B_{i}\right) \cdot p_{T-2}^{*}\left(B_{i} \mid[0110] \&[0]\right)$ \\
$H_{T-2}=-1^{A}$ & $:$ & $\beta v-A_{2}$ \\
$H_{T-2}=0$ & $:$ & 0
\end{tabular}

where for example $p_{T-2}^{*}\left(a_{l} \mid[0110] \&[0]\right)=\alpha p_{T-2}^{* B D}\left(a_{l} \mid[0110] \& Q^{a_{l}}=1\right)+(1-\alpha) p_{T-2}^{* R T}\left(a_{l} \mid[0110] \& Q^{a_{l}}=1\right)$. Notice that if he submits a limit order to the PLB, his execution probabilities are the same as for a RT. His equilibrium strategies are:

$$
H_{T-2}^{* B D}(\beta,[0110] \&[0])= \begin{cases}-1^{B} & \text { if } \beta \in\left[\beta,\left.\beta_{1, T-2}^{B D}\right|_{a_{1}, B=B_{1}}\right) \\ +1^{a_{1}} & \text { if } \beta \in\left[\bar{\beta} B D-,\left.\left.\right|_{1,2}\right|_{a_{1}, B=B_{1}},\left.\beta_{2, T-2}^{B D}\right|_{a_{1}, a_{2}}\right) \\ +1^{a_{2}} & \text { if } \beta \in\left[\left.\beta_{2, T-2}^{B D}\right|_{a_{1}, a_{2}},\left.\beta_{2, T-2}^{B D}\right|_{a_{2}, A_{2}}\right) \\ +1^{A_{2}} & \text { if } \beta \in\left[\left.\beta_{2, T-2}^{B D}\right|_{a_{2}, A_{2}},\left.\beta_{3, T-2}^{B D}\right|_{A_{2}, B_{2}}\right) \\ +1^{B_{2}} & \text { if } \beta \in\left[\left.\beta_{3, T-2}^{B D}\right|_{A_{2}, B_{2}},\left.\beta_{4, T-2}^{B D}\right|_{B_{2}, b_{2}}\right) \\ +1^{b_{2}} & \text { if } \beta \in\left[\left.\beta_{4, T-2}^{B D}\right|_{B_{2}, b_{2}},\left.\beta_{4, T-2}^{B D}\right|_{b_{2}, b_{1}}\right) \\ +1^{b_{1}} & \text { if } \beta \in\left[\left.\beta_{4, T-2}^{B D}\right|_{b_{2}, b_{1}},\left.\beta_{5, T-2}^{B D}\right|_{A=A_{1}, b_{1}}\right) \\ -1^{A} & \text { if } \beta \in\left[\left.\beta_{5, T-2}^{B D}\right|_{A=A_{1}, b_{1}}, \bar{\beta}\right]\end{cases}
$$

(iii) At $T-2$ expected volume on the PLB is:

$$
\begin{gathered}
V L_{T-2}^{P L B}([0110] \&[0])=\alpha\left[\operatorname{Pr}\left(H_{T-2}^{* B D}=-1^{A_{1}}\right)+\operatorname{Pr}\left(H_{T-2}^{* B D}=-1^{B_{1}}\right)\right]+(1-\alpha)\left[\operatorname{Pr}\left(H_{T-2}^{* R T}=-1^{A_{1}}\right)+\operatorname{Pr}\left(H_{T-2}^{* R T}=-1^{B_{1}}\right)\right] \\
=\alpha\left(\frac{\beta_{1, T-2}^{B D} \mid a_{1}, B=B_{1}-\underline{\beta}}{\bar{\beta}-\underline{\beta}}+\frac{\bar{\beta}-\left.\beta_{5, T-2}^{B D}\right|_{A=A_{1}, b_{1}}}{\bar{\beta}-\underline{\beta}}\right)+(1-\alpha)\left(\frac{\left.\beta_{1, T-2}^{R T}\right|_{A_{2}, B=B_{1}}-\underline{\beta}}{\bar{\beta}-\underline{\beta}}+\frac{\bar{\beta}-\left.\beta_{5, T-2}^{R T}\right|_{A=A_{1}, B_{2}}}{\bar{\beta}-\underline{\beta}}\right)
\end{gathered}
$$

As, being empty, there is no volume executed in the IP, we obtain that:

$$
L P_{T-2}^{P L B}([0110] \&[0])=1-V L_{T-2}^{P L B}([0110] \&[0])-L P_{T-2}^{I P}([0110] \&[0])
$$

By taking into account that the book opens as [0110], we can also compute the other market indicators for the PLB from the optimal order submission strategies at $T-2$ :

$$
\begin{aligned}
D P I_{T-2}^{P L B}([0110] \&[0]) & =2-V L_{T-2}^{P L B}([0110] \&[0]) \\
D P T_{T-2}^{P L B}([0110] \&[0]) & =2+L P_{T-2}^{P L B}([0110] \&[0])-V L_{T-2}^{P L B}([0110] \&[0]) \\
S P_{T-2}^{P L B}([0110] \&[0]) & =\tau\left\{L P_{T-2}^{P L B}([0110] \&[0])+L P_{T-2}^{I P}([0110] \&[0])\right\}+2 \tau V L_{T-2}^{P L B}([0110] \&[0])
\end{aligned}
$$

(1.2) When the opening book is [01|10]\&[1], by following the same methodology we can derive the equilibrium strategies at $T-2$ for a $\mathrm{RT}$ and a $\mathrm{BD}$ respectively:

$$
H_{T-2}^{* R T}(\beta,[01 \mid 10] \&[1])= \begin{cases}-1^{b} & \text { if } \beta \in\left[\beta,\left.\beta_{1, T-2}^{R T}\right|_{B=b_{1}}\right) \\ 0 & \text { if } \beta \in\left[\left.\bar{\beta}_{1, T-2}^{R T}\right|_{B=b_{1}},\left.\beta_{5, T-2}^{R T}\right|_{A=a_{1}}\right) \\ -1^{a} & \text { if } \beta \in\left[\left.\beta_{5, T-2}^{R T}\right|_{A=a_{1}}, \bar{\beta}\right]\end{cases}
$$




$$
H_{T-2}^{* B D}(\beta,[01 \mid 10] \&[1])= \begin{cases}-1^{b} & \text { if } \beta \in\left[\beta,\left.\beta_{1, T-2}^{B D}\right|_{a_{1}, B=b_{1}}\right) \\ +1^{a_{1}} & \text { if } \beta \in\left[\left.\bar{\beta}_{1, T-2}^{B D}\right|_{a_{1}, B=b_{1}},\left.\beta_{3, T-2}^{B D}\right|_{a_{1}, b_{1}}\right) \\ +1^{b_{1}} & \text { if } \beta \in\left[\left.\beta_{3, T-2}^{B D}\right|_{a_{1}, b_{1}},\left.\beta_{5, T-2}^{B D}\right|_{A=a_{1}, b_{1}}\right) \\ -1^{a} & \text { if } \beta \in\left[\left.\beta_{5, T-2}^{B D}\right|_{A=a_{1}, b_{1}}, \bar{\beta}\right]\end{cases}
$$

From these equilibrium strategies we obtain the market quality indicators for this case: $V L_{T-2}^{P L B}([0110] \&[1]), D P I_{T-2}^{P L B}([0110] \&[1]), D P T_{T-2}^{P L B}([0110] \&[1])$ and $S P_{T-2}^{P L B}([0110] \&[1])$.

(1.3) Market quality indicators for the visible IP case (V) are computed as the average of those obtained in (1.1) and (1.2), so that for example:

$$
V L_{T-2}^{P L B, V}=\frac{V L_{T-2}^{P L B}([0110] \&[0])}{2}+\frac{V L_{T-2}^{P L B}([0110] \&[1])}{2}
$$

To analyze the changes in the PLB after the introduction of an IP, we compare these market indicators with those in (2.3) of proof of Proposition 1. We first analyze separately the two cases, and start with [0110]\&[0]. Notice that if there were no broker-dealers in the market $(\alpha=0)$, the single market case would coincide with this PLB\&IP case. When $\alpha$ is positive, instead, limit orders submitted at $T-2$ have a lower execution probability in the PLB\&IP case, as they are more frequently undercut due to the presence of BD. It follows that both BD and RT submit market orders with a higher probability. From Proposition 1 we know that:

$$
V L_{T-2}^{L M}=\frac{\left.\widehat{\beta}_{1, T-2}^{L M}\right|_{A_{k}, B=B_{1}}-\underline{\beta}}{\bar{\beta}-\underline{\beta}}+\frac{\bar{\beta}-\left.\widehat{\beta}_{5, T-2}^{L M}\right|_{A=A_{1}, B_{k}}}{\bar{\beta}-\underline{\beta}}
$$

So we obtain that:

$$
\begin{aligned}
& \left.\beta_{1, T-2}^{R T}\right|_{A_{2}, B=B_{1}}>\left.\beta_{1, T-2}^{B D}\right|_{a_{1}, B=B_{1}}>\left.\widehat{\beta}_{1, T-2}^{L M}\right|_{A_{k}, B=B_{1}} \\
& \left.\beta_{5, T-2}^{R T}\right|_{A=A_{1}, B_{2}}<\left.\beta_{5, T-2}^{B D}\right|_{A=A_{1}, b_{1}}<\left.\widehat{\beta}_{5, T-2}^{L M}\right|_{A=A_{1}, B_{k}}
\end{aligned}
$$

This implies that $V L_{T-2}^{P L B}([0110] \&[0])>V L_{T-2}^{L M}$. It is then simple to show that:

$$
\begin{aligned}
L P_{T-2}^{P L B}([0110] \&[0]) & \leq 1-V L_{T-2}^{P L B}([0110] \&[0])<1-V L_{T-2}^{L M}=L P_{T-2}^{L M} \\
D P I_{T-2}^{P L B}([0110] \&[0]) & >D P I_{T-2}^{L M} \\
D P T_{T-2}^{P L B}([0110] \&[0]) & >D P T_{T-2}^{L M} \\
S P_{T-2}^{P L B}([0110] \&[0]) & <S P_{T-2}^{L M}
\end{aligned}
$$

Let's consider now [0110]\&[1]: in this case all incoming market orders at $T-2$ are executed in the IP due to the better price available, so that $V L_{T-2}^{P L B}([0110] \&[1])=0$. Moreover, also limit orders will be submitted only to the IP as orders posted on the PLB have a zero execution probability, so that $L P_{T-2}^{P L B}([0110] \&[1])=0$ and $S P_{T-2}^{P L B}([0110] \&[1])=\tau$.

Once we average over the two cases, [0110]\&[0] and [0110]\&[1], we hence obtain $V L_{T-2}^{P L B, V}<$ $V L_{T-2}^{L M}, L P_{T-2}^{P L B, V}<L P_{T-2}^{L M}, D P I_{T-2}^{P L B, V}>D P T_{T-2}^{L M}, S P_{T-2}^{P L B, V}<S P_{T-2}^{L M}$. 
2) Liquid stocks, invisible IP: starting book at $T-2$ is [01|10]\&[0] or [01|10]\&[1]

We provide only a sketch of the proof as the model is solved by backward induction as for case (1). The only difference is that now RT do not observe the IP and can only make inferences on its state. For BD nothing changes, as they still observe the IP. So we will focus on RT and refer to case (1) for BD. Consider again as an example the PLB that opens as [1110] at $T-1$. If a RT arrives, he will infer the state of the IP from the observed PLB. Clearly, the state of the IP is unchanged compared to $T-2$, as the submission of a limit order on the PLB implies that no order has been submitted there. Moreover, the RT knows that $H_{T-2}=+1^{A_{2}}$ is never an equilibrium strategy for a broker-dealer if the state of the IP is [1], as the order would have a zero execution probability. So he will update the probabilities associated to $I P=[0]$ and $I P=[1]$ from $1 / 2$ to:

$$
\begin{gathered}
\operatorname{Pr}\left\{S_{T-2}^{I P}=[0] \mid S_{T-2}^{P L B}=[11 \mid 10]\right\}=\frac{\frac{1}{2}\left[\alpha \operatorname{Pr}\left(H_{T-2}^{* R T}=+1^{A_{2}}\right)+(1-\alpha) \operatorname{Pr}\left(H_{T-2}^{* B D}=+1^{A_{2}}\right)\right]}{\frac{1}{2} \alpha \operatorname{Pr}\left(H_{T-2}^{* R T}=+1^{A_{2}}\right)+(1-\alpha) \operatorname{Pr}\left(H_{T-2}^{* B D}=+1^{A_{2}}\right)}>\frac{1}{2} \\
\operatorname{Pr}\left\{S_{T-2}^{I P}=[1] \mid S_{T-2}^{P L B}=[11 \mid 10]\right\}=\frac{\frac{1}{2}(1-\alpha) \operatorname{Pr}\left(H_{T-2}^{* B D}=+1^{A_{2}}\right)}{\frac{1}{2} \alpha \operatorname{Pr}\left(H_{T-2}^{* R T}=+1^{A_{2}}\right)+(1-\alpha) \operatorname{Pr}\left(H_{T-2}^{* B D}=+1^{A_{2}}\right)}<\frac{1}{2}
\end{gathered}
$$

To select his optimal trading strategy, he will then compute his expected payoffs using the Bayesian updated probabilities. For example:

$$
H_{T-1}=-1^{B}: B_{1} \operatorname{Pr}\left\{S_{T-2}^{I P}=[0] \mid[11 \mid 10]\right\}+b_{1} \operatorname{Pr}\left\{S_{T-2}^{I P}=[1] \mid[11 \mid 10]\right\}-\beta v
$$

A similar reasoning applies to a $\mathrm{RT}$ arriving at $T$, his strategies payoff are:

$$
\begin{array}{lll}
H_{T}=-1^{B} & : & E\left(B \mid S_{T-1}, h_{T-1}, h_{T-2}\right)-\beta v \\
H_{T}=-1^{A} & : & \beta v-E\left(A \mid S_{T-1}, h_{T-1}, h_{T-2}\right) \\
H_{T}=0 & : & 0
\end{array}
$$

where $E\left(B \mid S_{T-1}, h_{T-1}, h_{T-2}\right)$ is for example the expected execution price of a market sell order given the actual state of the book and the order submissions observed in the previous periods. Notice that, differently from (1.1), here RT and BD strategies do not coincide at $T$.

Finally, to analyze the changes in the PLB after the introduction of an IP, we compare the obtained market indicators with those in (2.3) of proof of Proposition 1 and with those computed for a visible IP in (1). We find that an opaque IP makes the trader more inclined to submit markets order and less inclined to provide liquidity. So IP invisibility slightly weakens the positive market quality effects created by the introduction of an IP:

$$
\begin{aligned}
D P I_{T-2}^{P L B, V} & >D P I_{T-2}^{P L B, I}>D P I_{T-2}^{L M} \\
D P T_{T-2}^{P L B, V} & >D P T_{T-2}^{P L B, I}>D P T_{T-2}^{L M} \\
S P_{T-2}^{P L B, V} & <S P_{T-2}^{P L, I}<S P_{T-2}^{L M}
\end{aligned}
$$




\section{References}

Ahn, H., C. Q. Cao, and H. Choe. 1996. Tick Size, Spread, and Volume. Journal of Financial Intermediation 5:2-22.

Ahn, H., J. Cai, K. Chan, and Y. Hamao. 2007. Tick Size Change and Liquidity Provision on the Tokyo Stock Exchange. Journal of Japanese and International Economies 21:173-194.

Anshuman, R. V., and A. Kalay. 1998. Market Making with Discrete Prices. Review of Financial Studies 11:81-109.

Bacidore, J., R. Battalio, and R. H. Jennings. 2003. Order Submission Strategies, Liquidity Supply and Trading in Pennies on the New York Stock Exchange. Journal of Financial Markets 6:337-362.

Bacidore, J.. 1997. The Impact of Decimalization on Market Quality: an Empirical Investigation of the Toronto Stock Exchange. Journal of Financial Interemediation 6:92-120.

Barclay, M. J., T. Hendershott, and D. T. McCormick. 2003. Competition among Trading Venues: Information and Trading on Electronic Communications Networks. Journal of Finance 58:2637-2665.

BATS. 2009. Pan European Tick Size Pilot: An analysis of results.

Battalio, R., and C. W. Holden. 2001. A Simple Model of Payment for Order Flow, Internalization, and Total Trading Cost. Journal of Financial Markets 4:33-71.

Bessembinder, H., and H. M. Kaufman. 1997. A Cross-exchange Comparison of Execution Costs and Information Flow for NYSE-listed Stocks. Journal of Financial Economics 46:293319 .

Biais, B., C. Bisiere, and C. Spatt. 2003. Imperfect competition in financial markets: ISLAND vs NASDAQ, Working Paper, Carnegie Mellon University.

Bourghelle, D., and F. Declerck. 2004. Why Markets Should not Necessarily Reduce the Tick Size. Journal of Banking and Finance 28:373-398.

Brandes, Y. and I. Domowitz, 2011. ATSs in Europe: Post-MIFID Performance. ITG Working Paper.

Buti, S., B. Rindi, and I. M. Werner. 2010. Dark Pool Trading Strategies, Ohio State University Working Paper.

Buti, S., and B. Rindi. 2009. Hidden Orders and Optimal Submission Strategies in a Dynamic Limit Order Market, Working Paper.

Butler G. (2010). Liquidity Aggregation: What Institutional Investors Need to Know, ITG Working Paper.

Cai, J., Hamao Y., and R. Y. K. Ho. 2008. Tick Size Change and Liquidity Provision for Japanese Stock Trading Near 1000. Japan and the World Economy 20:19-39.

Chapman, P., 2010. Consider Depth-of-Book Protection, Nasdaq Says. Traders Magazine Online News

Chowdry, B., and V. Nardia. 1991. Multi-Market Trading and Market Liquidity. Review of Financial Studies 4:483-511. 
Chung, K. H., C. Chuwonganant, and D.T. McCormick. 2004a. Order Preferencing and Market quality on NASDAQ Before and After Decimalization. Journal of Financial Economics 71:581-612.

Chung, K. H., C. Charoenwong, and D.K. Ding. 2004b. Penny Pricing and the Components of Spread and Depth Changes. Journal of Banking and Finance 28:2981-3007.

Cordella, T., and T. Foucault. 1999. Minimum Price Variations, Time Priority and Quote Dynamics. Journal of Financial Intermediation 8:141-173.

Degryse, H., M.Van Achter and G. Wuyts, 2008. Shedding Light on Dark Liquidity Pools, TILEC Discussion Paper No. 2008-039.

Degryse, H., M. Van Achter, G. Wuyts. 2009. Dynamic order submission strategies with competition between a dealer market and a crossing network. Journal of Financial Economics 91:319-338.

Delassus R., and S. Tyc. 2010. Subpenny trading in US equity markets. BNP Paribas Working Paper.

European Commission 2010. Review of the Market for Financial Instrument Directive (MIFID). Public Consulation Paper, December 8..

Federation of European Securities Exchanges (FESE), 2011. Response of the FESE to the European Commission Public Consultation on the Review of the Markets in Financial Instruments Directive (MIFID).

Fink, J., K. E. Fink, and J. P. Weston. 2006. Competition on the Nasdaq and the Growth of Electronic Communication Networks. Journal of Banking and Finance 30:2537-2559.

Foucault, T., O. Kadan, and E. Kandel. 2005. Limit Order Book as A Market for Liquidity. Review of Financial Studies 18:1171-1217.

Glosten, L. and P. Milgrom. 1985. Bid, Ask and Transaction Prices in a Specialist Market with Heterogeneously Informed Traders. Journal of Financial Economics 14:71-100.

Goettler, R. L., C. Parlour, and U. Rajan. 2005. Equilibrium in a Dynamic Limit Order Market. Journal of Finance 60:2149-2190.

Goldstein, M. A., A. V. Shiklko, B. F. Van Ness, and R. A. Van Ness. 2008. Competition in the market for NASDAQ securities. Journal of Financial Markets 11:113-143.

Gomper, S., and Pierron, 2010. MIFID: Spirit and Reality of a European Financial Market Directive. Working Paper.

Griffiths, M. D., B. F. Smith, D. A. S. Turnbull, and R. W. White. 1998. The Role of Tick Size in Upstairs Trading and Downstairs Trading. Journal of Financial Intermediation 7:393-417.

Hansch, O., N. Y. Naik, and S. Viswanathan. 1999. Preferencing, Internalization, Best Execution and Dealer Profits. Journal of Finance. 54(5):1799-1828

Harris, L. 1994. Minimum Price Variations, Discrete Bid-ask Spreads and Quotation Sizes. Review of Financial Studies 7:149-178.

He, C., E. Odders-White, and M. Ready. 2006. The Impact of Preferencing on Execution Quality. Journal of Financial Markets 9:246-273. 
Hendershott, T., C. Jones, and A.J. Menkveld. 2010. Does algorithmic trading improve liquidity?. forthcoming in Journal of Finance.

Hendershott, and T., C. Jones. 2005. Trade-Through Prohibitions and Market Quality. Journal of Financial Markets 8:1-23.

Hengelbrock, J., and E. Theissen. 2009. Fourteen at One Blow: The Market Entry of Turquoise. Working paper.

Jarnecic, E., and M. R. Snape. 2010. An Empirical Analysis of High Frequency Trading on the London Stock Exchange. Working Paper.

Kadan, O. 2004. So, Who Gains from a Small Tick Size?. Journal of Financial Intermediation 15:32-66.

Kyle, A. S. 1985. Continuous Auctions and Insider Trading. Econometrica 53:1315-1335.

Lau, S. T., and T. McInish. 1995. Reducing Tick Size on the Stock Exchange of Singapore. Pacific- Basin Finance Journal 3:485-496.

Lin, B.-X., D. Michayluk, H. R. Oppenheimer, and S. Sabherwal. 2009. French and U.S. trading of cross-listed stocks around the period of U.S. decimalization: Volume, spreads, and depth effects. International Review of Financial Analysis 18:223-231.

Oppenheimer, H. R., S. Sabherwal. 2003. The Competitive Effects of US Decimalization: Evidence from the US-listed Canadian stocks, Journal of Banking and Finance 27:1883-1910. Parlour, C. 1998. Price Dynamics in Limit Order Markets. Review of Financial Studies 11(4):789-816

Parlour, C., and D. Seppi. 2003. Liquidity-based Competition for Order Flow. Review of Financial Studies 16(2):301-343

Porter, D. C., and D. G. Weaver. 1997. Tick Size and Market Quality. Financial Management 26:5-26.

Ronen, T. and D. G. Weaver. 2001. Teenes' Anyone?. Journal of Financial Markets 4:231260.

Seppi, D. J. 1997. Liquidity Provision with Limit Orders and a Strategic Specialist. Review of Financial Studies 10:103-150.

U.S.Securities and Exchange Commission. 1997. Report on the Practice of Preferencing. U.S.Securities and Exchange Commission. 2005. Rule 612.

U.S.Securities and Exchange Commission. 2010. Concept Release on Equity Market Structure. 


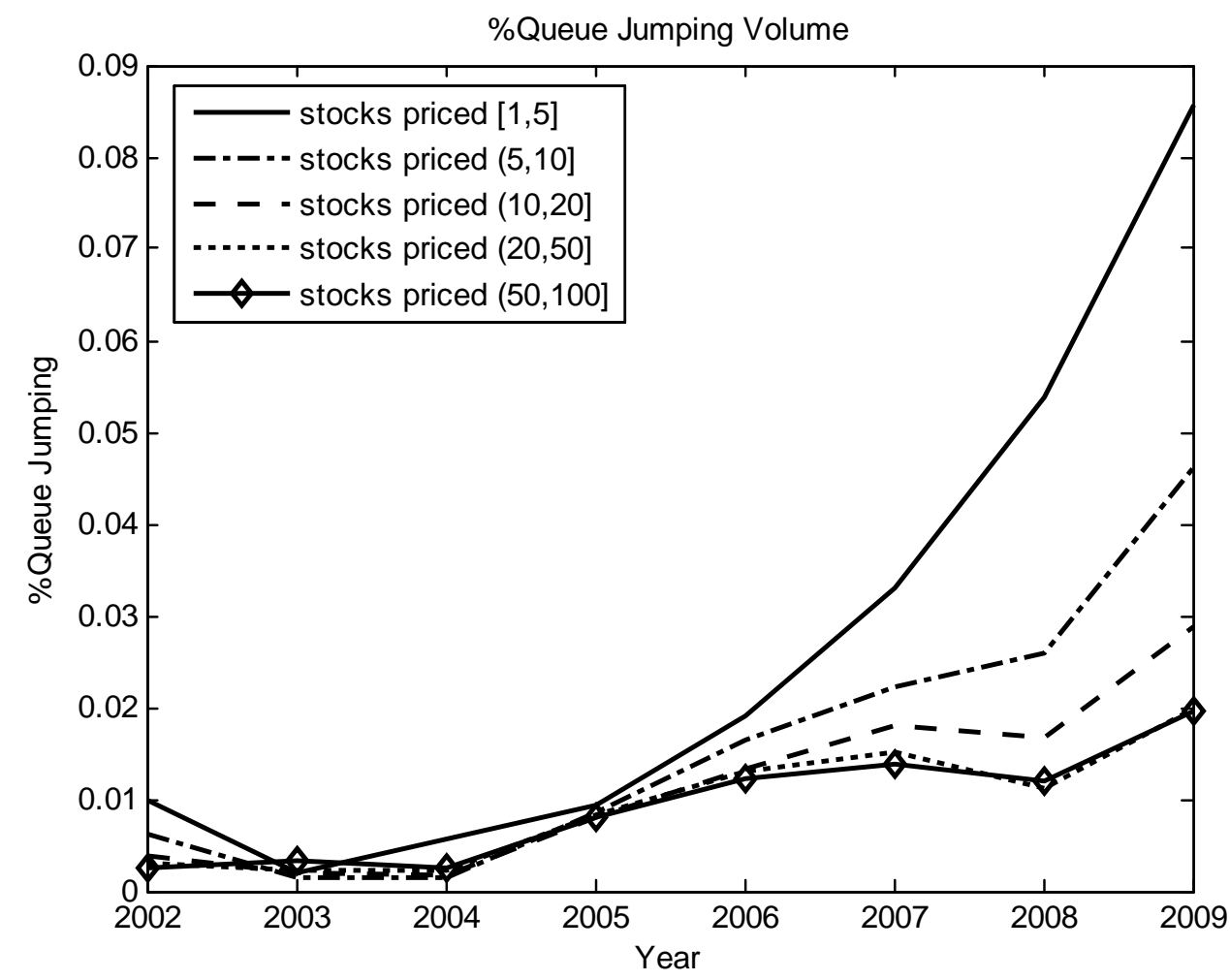

Figure 1: NASDAQ Stocks: Queue Jumping. This Figure shows the evolution of sub-penny trading over the last 10 years for different priced NASDAQ stocks. Weekly statistics are from Delassus and Tyc (2010), who use daily data from Thomson Reuters tick-by-tick hystorical. 


\begin{tabular}{|c|c|c|c|}
\hline \multicolumn{4}{|c|}{ Table 1 Tick Size Reductions } \\
\hline \multirow[t]{2}{*}{ Country } & \multicolumn{2}{|r|}{ Market } & \multirow[t]{2}{*}{ Change time } \\
\hline & Abbr. & Full name & \\
\hline \multirow[t]{3}{*}{ US } & AMEX & American Stock Exchange & 1992,1997 \\
\hline & NYSE & New York Stock Exchange & $1992,1997,2001$ \\
\hline & NASDAQ & & $1991,1997,2001$ \\
\hline Canada & TSE & Toronto Stock Exchange & 1996 \\
\hline France & $\mathrm{EuP}$ & Euronext Paris & 1999 \\
\hline HK & HKSE & Hong Kong Stock Exchange & 1994 \\
\hline Singapore & SES & Stock Exchange of Singapore & 1994 \\
\hline Japan & TySE & Tokyo Stock Exchange & 1998 \\
\hline Indonesia & ISE & Indonesia Stock Exchange & 2001-2007 \\
\hline Thailand & SET & Stock Exchange of Thailand & 2001 \\
\hline
\end{tabular}

Table 1: Tick Size Reductions. This Table reports examples of tick size reductions which took place in some major exchages over the past two decades.

\begin{tabular}{||l|l|l|}
\hline \hline \multicolumn{3}{||l|}{ Table 2 Order Submission Strategy Space } \\
\hline \hline Strategy & $H$ & $U(\cdot)$ \\
\hline Market Sell Order & $-1^{B}$ & $B-\beta v$ \\
\hline Limit Sell Order & $1^{A_{k}}$ & $p_{t}^{*}\left(A_{k}^{N_{-k}, N_{k}} \mid S_{t}\right) \cdot\left(A_{k}-\beta v\right)$ \\
\hline No Trade & 0 & 0 \\
\hline Limit Buy Order & $1^{B_{k}}$ & $p_{t}^{*}\left(B_{k}^{M_{-k}, M_{k}} \mid S_{t}\right) \cdot\left(\beta v-B_{k}\right)$ \\
\hline Market Buy Order & $-1^{A}$ & $\beta v-A$ \\
\hline
\end{tabular}

Table 2: Order Submission Strategy Space. This Table reports in column 3 the payoffs $(U(\cdot))$ of the order strategies $\left(H_{t}\right)$ listed in column 2. 


\begin{tabular}{||c|c|c|}
\hline \hline \multicolumn{3}{|c|}{ Table 3 Price Grid } \\
\hline \hline Large Tick & Price & Small Tick \\
\hline$A_{2}$ & $v+\frac{9}{6} \tau$ & $a_{5}$ \\
\hline & $v+\frac{7}{6} \tau$ & $a_{4}$ \\
\hline & $v+\frac{5}{6} \tau$ & $a_{3}$ \\
\hline$A_{1}$ & $v+\frac{3}{6} \tau$ & $a_{2}$ \\
\hline & $v+\frac{1}{6} \tau$ & $a_{1}$ \\
\hline \hline & $v-\frac{1}{6} \tau$ & $b_{1}$ \\
\hline & $v-\frac{3}{6} \tau$ & $b_{2}$ \\
\hline$B_{1}$ & $v-\frac{5}{6} \tau$ & $b_{3}$ \\
\hline & $v-\frac{7}{6} \tau$ & $b_{4}$ \\
\hline & $v-\frac{9}{6} \tau$ & $b_{5}$ \\
\hline$B_{2}$ & & \\
\hline
\end{tabular}

Table 3: Price Grid. This Table shows price levels in different markets, where $v$ indicates the asset value and $\tau$ the tick size. A large tick market has a coarse price grid while a small tick market has a fine price grid. 


\begin{tabular}{|c|c|c|c|c|c|c|c|c|c|c|c|c|c|c|c|c|c|c|}
\hline & & 180 & $\stackrel{\leftrightarrow}{\sim}$ & 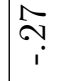 & 0 & $\underset{i}{\vec{J}}$ & $\stackrel{\curvearrowright}{\sim}$ & 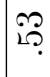 & 它. & 1 & 1 & 0 & 1 & 10 & 0 & 1 & & $\hat{o}_{i}$ \\
\hline & 8 & $\stackrel{ }{\circ}$ & 苞 & קִ & 0 & ন্ & חֶּ & $\begin{array}{l}0 \\
\stackrel{0}{0} \\
i\end{array}$ & דִּ & & 1 & 0 & 1 & 10 & 0 & 1 & & 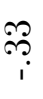 \\
\hline & $\frac{x}{y}$ & 100 & 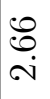 & $\begin{array}{l}\hat{\sigma} \\
\hat{\sigma} \\
i \\
i\end{array}$ & 0 & $\underset{i}{\stackrel{0}{7}}$ & $\begin{array}{l}1 \\
\mathscr{v} \\
\mathcal{v}\end{array}$ & ڤִ & ?. & ' & 1 & 0 & 1 & 10 & 0 & 1 & & $\underbrace{\infty}_{i}$ \\
\hline 8 & & -1 & $\begin{array}{l}\infty \\
\stackrel{\infty}{*} \\
\stackrel{\infty}{\sim}\end{array}$ & 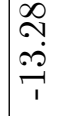 & 0 & $\begin{array}{l}8 \\
\dot{0} \\
\stackrel{i}{i}\end{array}$ & $\mid \begin{array}{l}\infty \\
\sim \\
\sim \\
\sim \\
\sim\end{array}$ & 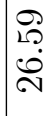 & 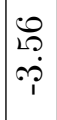 & I & I & 0 & 1 & 10 & 0 & 1 & 1 & $\begin{array}{l}6 \\
10 \\
0 \\
9\end{array}$ \\
\hline \begin{tabular}{|l}
0 \\
0 \\
8 \\
8 \\
0 \\
\end{tabular} & $\begin{array}{c}\mathrm{F}-\mathrm{m} \\
11\end{array}$ & 10 & $\begin{array}{l}8 \\
\stackrel{2}{8} \\
8 \\
0\end{array}$ & $\begin{array}{l}\circ \\
\not 2 \\
\mathscr{2} \\
\mathscr{\rho}\end{array}$ & 0 & $\stackrel{\vec{S}}{\stackrel{\partial}{二}}$ & ن & $\begin{array}{l}8 \\
0 \\
0 \\
0 \\
-1\end{array}$ & .20 & 0 & 0.0 & 0 & 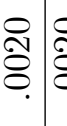 & 尺ิ & 0 & 0 & 0 & $\begin{array}{l}\stackrel{2}{8} \\
8 \\
8\end{array}$ \\
\hline $\mid \begin{array}{l}\| \\
\frac{\sigma}{\underline{\Xi}} \\
\bar{\sigma}\end{array}$ & 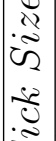 & $\stackrel{ }{二}$ & 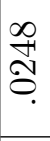 & 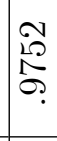 & 0 & 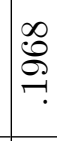 & 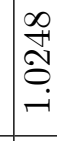 & 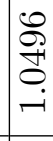 & $\begin{array}{l}\vec{~} \\
\stackrel{\Xi}{\delta}\end{array}$ & 0 & 0 & 0 & \begin{tabular}{c|c}
8 & \\
0 & \\
&
\end{tabular} & $\left|\begin{array}{c}0 \\
0 \\
0\end{array}\right|$ & $\circ c$ & 0 & 0 & $\stackrel{\Xi}{\Xi}$ \\
\hline $\mid \begin{array}{c}11 \\
T \\
1\end{array}$ & 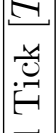 & 10 & 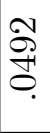 & $\begin{array}{l}1 \\
0 \\
20 \\
\text { o. }\end{array}$ & 0 & $\begin{array}{l}\stackrel{\sim}{\mathscr{\sigma}} \\
\stackrel{\mathscr{\sigma}}{\longrightarrow}\end{array}$ & 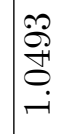 & $\begin{array}{l}0 \\
\infty \\
\infty \\
0 \\
- \\
-\end{array}$ & 递 & 0 & 0 & 0 & 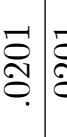 & $\begin{array}{c}\overrightarrow{0} \\
\stackrel{0}{0}\end{array}$ & 0 & 0 & & $\frac{12}{8}$ \\
\hline$\left[\begin{array}{c}-1 \\
0 \\
11\end{array}\right.$ & $\begin{array}{c}\stackrel{\widetilde{\Xi}}{\Xi} \\
\text { की }\end{array}$ & $\neg$ & $\begin{array}{l}\stackrel{H}{\mathscr{m}} \\
\stackrel{\sim}{\sim}\end{array}$ & $\begin{array}{l}0 \\
8 \\
0 \\
1\end{array}$ & 0 & $\stackrel{\mathscr{\partial}}{\mathscr{0}}$ & مै & 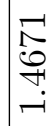 & 站 & 0 & 0.0 & 0 & 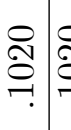 & 尺ิ & 00 & 0 & 0 & $\frac{N}{7}$ \\
\hline 80 & $F$ & 28 & $\stackrel{\vartheta}{8}$ & $\begin{array}{l}\frac{1}{N} \\
\text { S } \\
\text { S }\end{array}$ & 0 & 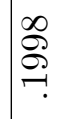 & 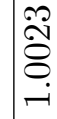 & 年 & $\frac{1}{8}$ & T & ' & 0 & 1 & 1 & 0 & ' & & $\frac{2}{\overrightarrow{8}}$ \\
\hline $\begin{array}{l}\vec{U} \\
\tilde{N}\end{array} \mid$ & 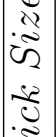 & $\stackrel{0}{-1}$ & $\underset{\exists}{\vec{\sigma}}$ & $\begin{array}{l}20 \\
20 \\
20 \\
0\end{array}$ & 0 & 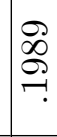 & 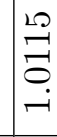 & 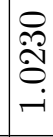 & ?. & 1 & 10 & 0 & 1 & 10 & 0 & 1 & & $\stackrel{10}{8}$ \\
\hline 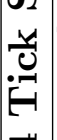 & 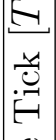 & 20 & $\begin{array}{l}\stackrel{0}{N} \\
\text { Iิ } \\
0\end{array}$ & $\frac{N}{\stackrel{N}{N}}$ & D & 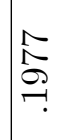 & 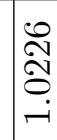 & & & ' & 1 & 0 & 1 & 10 & 0 & ' & 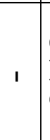 & $\stackrel{\circ}{\circ}$ \\
\hline$\frac{6}{6}$ & 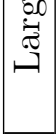 & -1 & 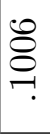 & $\begin{array}{l}\vec{S} \\
\stackrel{2}{D} \\
\infty\end{array}$ & & $\begin{array}{l}\mathscr{\mathscr { D }} \\
\stackrel{\infty}{-}\end{array}$ & 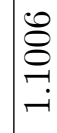 & 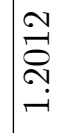 & $\begin{array}{l}9 \\
20 \\
20 \\
2\end{array}$ & I & ' & 0 & 1 & 10 & 0 & ' & & $\begin{array}{l}\text { ஜ̊ } \\
0\end{array}$ \\
\hline & & 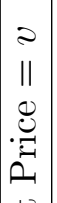 & $\begin{array}{l}\vec{A} \\
\| \\
\ddot{0} \\
\overrightarrow{0} \\
\dot{0}\end{array}$ & 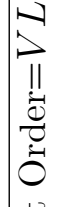 & 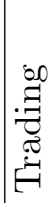 & 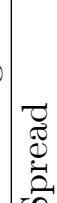 & 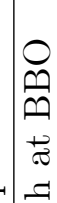 & $\frac{\tau}{\frac{\pi}{3}}$ & 章 & ठే & $\mathscr{\theta}$ & $\begin{array}{c}8 \\
\| \\
\| \\
\vec{T}\end{array}$ & $\vec{\sigma}$ & 5 & $\begin{array}{c}\tilde{s} \\
11 \\
\infty-1\end{array}$ & & $\sigma^{+1}$ & R \\
\hline & & $\mid \begin{array}{l}0 \\
w \\
0 \\
2 \\
⿱ 乛 龰 \\
\end{array}$ & 可 & 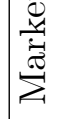 & Z & & $\stackrel{\tilde{\theta}}{0}$ & 4 & & & & & & 을 & $\dot{0}$ & & & \\
\hline
\end{tabular}

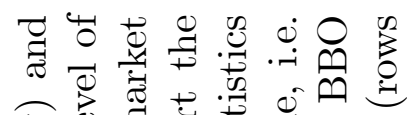

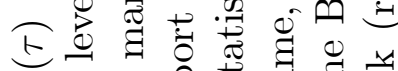

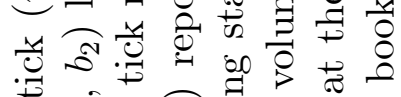

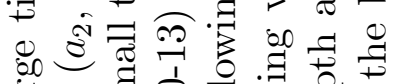

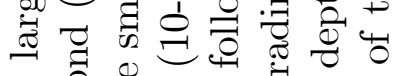
过

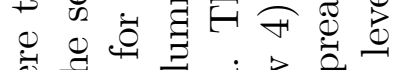

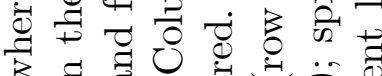

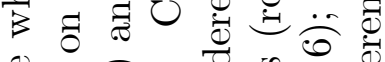

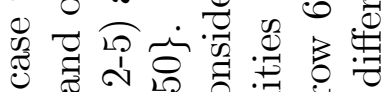
( ) Фิ бี Э

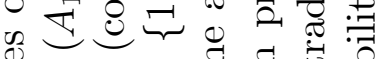

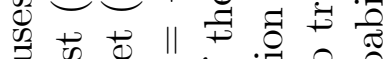

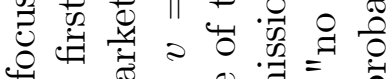
○ छ क 元 0000 워 0

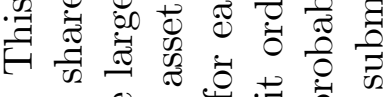

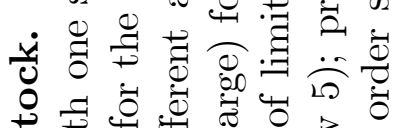

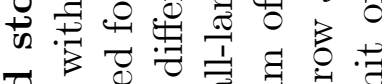

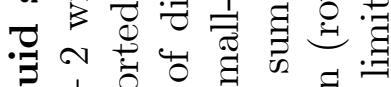

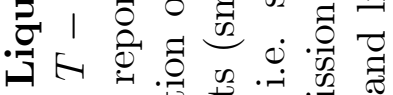

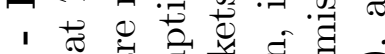
¿ $\infty$ की

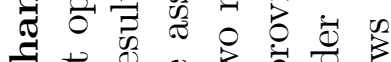

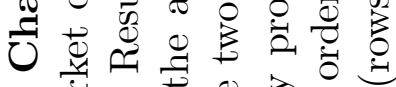

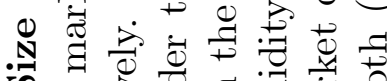

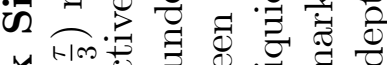
순 से

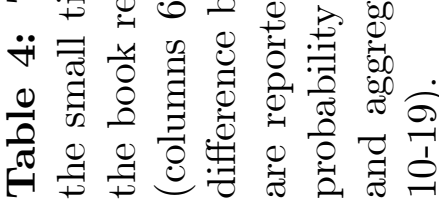




\begin{tabular}{|c|c|c|c|c|c|c|c|c|c|c|c|c|c|c|c|c|c|c|}
\hline & & 10 & म? & $\underset{i}{\stackrel{8}{1}}$ & $\underset{i}{\stackrel{0}{\rightarrow}}$ & $\mathscr{J}_{i}$ & $\stackrel{?}{\rightarrow}$ & 8 & 0 & ' & 1 & 0 & 1 & 1 & 0 & 1 & & 0 \\
\hline & 8 & $\stackrel{ }{=}$ & $\begin{array}{l}\infty \\
\stackrel{\infty}{+} \\
\stackrel{\sim}{+}\end{array}$ & $\mid$\begin{tabular}{l}
$\infty$ \\
\hdashline \\
\hdashline \\
\end{tabular} & $\begin{array}{l}0 \\
10 \\
0 \\
0\end{array}$ & $\overbrace{i}^{\infty}$ & i. & $\underset{\sim}{\stackrel{0}{+}}$ & 0 & 1 & 1 & 0 & 1 & 1 & 0 & 1 & & 0 \\
\hline & $\frac{x}{y}$ & 10 & $\underset{+}{\stackrel{\sim}{+}}$ & $\mid \begin{array}{l}\infty \\
\rho \\
\rho \\
p\end{array}$ & $\frac{8}{8}$ & $\stackrel{0}{\rightarrow}$ & $\underset{1}{\stackrel{8}{8}}$ & $\begin{array}{l}\wp \\
\infty \\
\infty\end{array}$ & 10 & 1 & 1 & 0 & 1 & 1 & 0 & 1 & & 0 \\
\hline 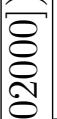 & & -1 & $\begin{array}{l}\vec{H} \\
\text { ra } \\
\stackrel{2}{\sim}\end{array}$ & $\begin{array}{l}\vec{f} \\
\infty \\
\infty \\
+1 \\
+1\end{array}$ & $\underset{1}{8}$ & $\underset{i}{\infty}$ & $\mid \begin{array}{c}8 \\
0 \\
0\end{array}$ & 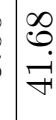 & 10 & 1 & 1 & 0 & 1 & 1 & 0 & 1 & & 0 \\
\hline 8 & $\begin{array}{c}\mathrm{H} m \\
11\end{array}$ & 28 & $\begin{array}{l}8 \\
\stackrel{1}{8} \\
8 \\
8\end{array}$ & $\begin{array}{l}\circ \\
\stackrel{2}{2} \\
\stackrel{2}{\circ}\end{array}$ & 0 & $\begin{array}{l}\infty \\
\mathscr{\Omega} \\
\mathscr{\Omega}\end{array}$ & $\mid \begin{array}{c}\mathscr{8} \\
8 \\
0 \\
\text { r. }\end{array}$ & $\left\{\begin{array}{c}8 \\
0 \\
0 \\
0\end{array}\right.$ & 10 & 0 & 0 & 0 & 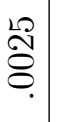 & 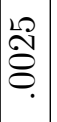 & 0 & 0 & 0 & 0 \\
\hline$\frac{\tilde{N}}{\mathcal{N}}$ & 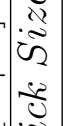 & $\stackrel{\varrho}{-1}$ & $\underset{\stackrel{\infty}{+}}{\stackrel{\infty}{0}}$ & $\begin{array}{l}\text { No } \\
\text { No } \\
\text { o. }\end{array}$ & 0 & ठै. & $\mid \begin{array}{c}\mathscr{8} \\
\mathscr{8} \\
\mathscr{8} \\
\dot{\infty}\end{array}$ & $\underset{\infty}{\stackrel{8}{O}}$ & 0 & 0 & 0 & 0 & $\begin{array}{l}\stackrel{\vec{N}}{N} \\
\overrightarrow{0} \\
0\end{array}$ & $\mid \begin{array}{l}\vec{N} \\
\stackrel{D}{0} \\
0\end{array}$ & 0 & 0 & 0 & 0 \\
\hline$\left[\begin{array}{c}11 \\
N \\
1 \\
-1 \\
2\end{array}\right.$ & 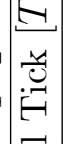 & 20 & 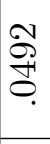 & $\begin{array}{l}1 \\
0 \\
20 \\
0\end{array}$ & 0 & $\begin{array}{l}\overrightarrow{1} \\
\infty \\
0 \\
0\end{array}$ & $\mid \begin{array}{l}\mathscr{8} \\
\mathscr{8} \\
\text { r. }\end{array}$ & $\left\{\begin{array}{l}\infty \\
\infty \\
0 \\
0 \\
\infty\end{array}\right.$ & 0 & 0 & 0 & 0 & $\left|\begin{array}{l}0 \\
+ \\
0 \\
0 \\
0\end{array}\right|$ & $\mid \begin{array}{l}0 \\
\stackrel{1}{1} \\
0 \\
0\end{array}$ & 0 & 0 & 0 & 0 \\
\hline$\left[\begin{array}{c}-1 \\
\dot{0} \\
\|\end{array}\right.$ & $\begin{array}{c}\tilde{\Xi} \\
\underset{\Xi}{二} \\
\tilde{\omega}\end{array}$ & $\rightarrow$ & 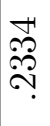 & $\begin{array}{l}0 \\
0 \\
0 \\
1\end{array}$ & 0 & $\begin{array}{l}\mathcal{I} \\
\stackrel{D}{O}\end{array}$ & $\mid \begin{array}{c}\mathscr{8} \\
\mathscr{8} \\
\dot{\mathscr{g}} \\
\dot{m}\end{array}$ & 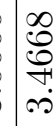 & 10 & 0 & 0 & 0 & 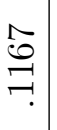 & $\mid$\begin{tabular}{l}
1 \\
0 \\
$\ddots$ \\
\hdashline
\end{tabular} & 0 & 0 & 0 & 0 \\
\hline $\begin{array}{l}80 \\
\Xi\end{array}$ & F & 20 & 0 & ஓ & $\begin{array}{l}0 \\
\stackrel{0}{8} \\
\stackrel{0}{0}\end{array}$ & $\stackrel{8}{8}$ & $\mid \begin{array}{c}0 \\
0 \\
0 \\
0 \\
\text { r. }\end{array}$ & $\left\{\begin{array}{c}0 \\
0 \\
0 \\
8 \\
\infty\end{array}\right.$ & 10 & 1 & ' & 0 & 1 & 1 & 0 & 1 & ' & 0 \\
\hline 0 & $\begin{array}{l}i \frac{N}{2} \\
\dot{v} \\
\dot{v}\end{array}$ & $\stackrel{ }{-1}$ & 0 & 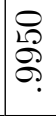 & $\begin{array}{l}0 \\
\stackrel{1}{0} \\
\stackrel{0}{0}\end{array}$ & 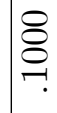 & 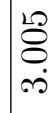 & $\mid$\begin{tabular}{c}
20 \\
\hdashline \\
\hdashline
\end{tabular} & 0 & 1 & 1 & 0 & 1 & 1 & 0 & 1 & 1 & 0 \\
\hline 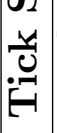 & 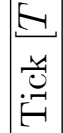 & 20 & 0 & ஓ & $\begin{array}{l}8 \\
0 \\
0\end{array}$ & $\underset{\wp}{\stackrel{8}{\varrho}}$ & $\begin{array}{l}\mathscr{8} \\
0 \\
0 \\
\ddot{\sigma} \\
\text { oj }\end{array}$ & $\begin{array}{c}\mathscr{8} \\
0 \\
0 \\
\text { i }\end{array}$ & 10 & 1 & 1 & 0 & 1 & 1 & 0 & 1 & 1 & 0 \\
\hline 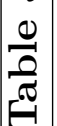 & 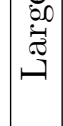 & -1 & 0 & $\begin{array}{l}8 \\
8 \\
20 \\
0 !\end{array}$ & $\begin{array}{l}8 \\
0 \\
20 \\
0\end{array}$ & 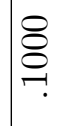 & 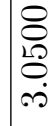 & $\left\{\begin{array}{c}0 \\
0 \\
0 \\
0 \\
\infty\end{array}\right.$ & 0 & 1 & 1 & 0 & 1 & 1 & 0 & 1 & 1 & 0 \\
\hline & & 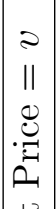 & 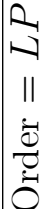 & 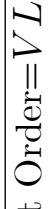 & 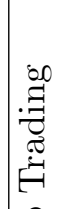 & 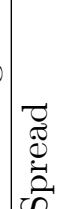 & 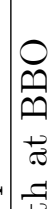 & $\mid \begin{array}{l}\frac{7}{20} \\
0 \\
0 \\
0.0\end{array}$ & 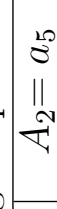 & O & 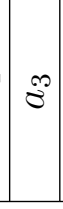 & $\mid \begin{array}{c}\tilde{Z} \\
\| \\
\| \\
-\vec{Z}\end{array}$ & $\vec{s}$ & 5 & $\begin{array}{c}\tilde{S} \\
11 \\
D^{-1}\end{array}$ & $\Xi$ & s & ט \\
\hline & & 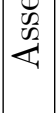 & : $\vec{a}$ & 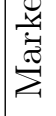 & 乙 & & ڤి & 4 & & & & & $\frac{\dot{\theta}}{0}$ & & & & & \\
\hline
\end{tabular}

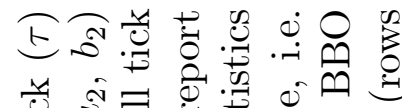

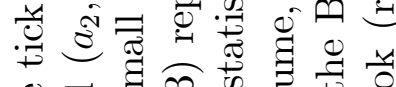
\$ తี o †

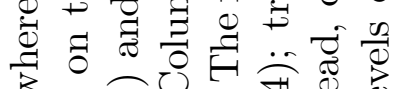

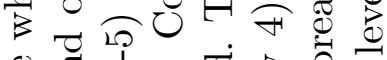

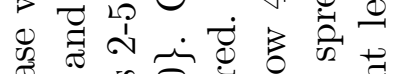
ช 0 舟 ली छี 0.0 है

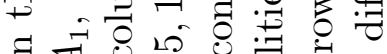

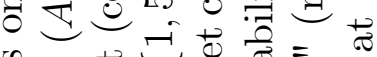

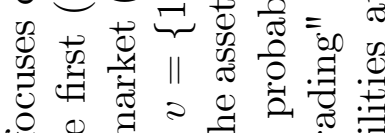

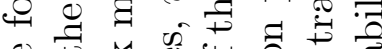

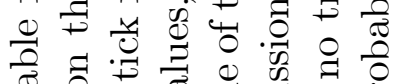
तै

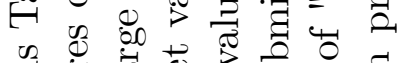

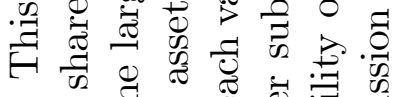

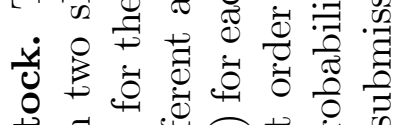

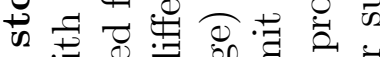

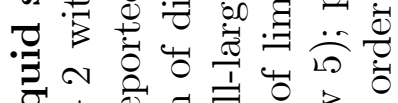
이 ।

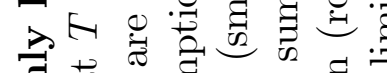
焉

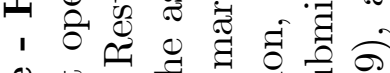

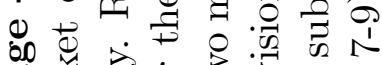
สี

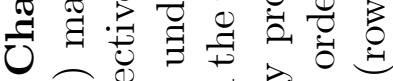

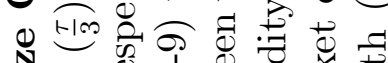
竟

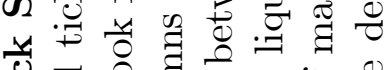
式 ॥

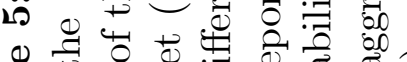

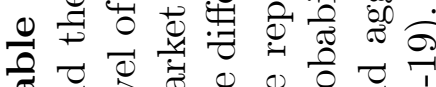

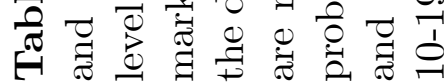




\begin{tabular}{|c|c|c|c|c|c|c|c|c|c|c|c|c|c|c|c|c|c|c|}
\hline & & ס & $\vec{\sigma}_{i}$ & - & 0 & 0 & $\tilde{\sigma}_{i}$ & $\sigma_{i}$ & 0 & 1 & 1 & 0 & 1 & 10 & 0 & ' & & 0 \\
\hline & 8 & $\stackrel{\rho}{-}$ & 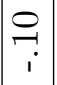 & $\stackrel{\varrho}{\rightarrow}$ & 0 & 0 & 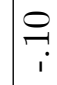 & 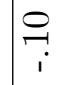 & $\underset{i}{20}$ & 1 & 1 & 0 & 1 & 10 & 0 & 1 & 1 & ${ }_{i}^{2}$ \\
\hline & $\frac{x}{y}$ & 10 & भִ & คి & 0 & 0 & คి & 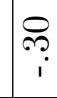 & $\stackrel{20}{\rightarrow}$ & 1 & 1 & 0 & 1 & 1 & 0 & 1 & 1 & : \\
\hline$\frac{8}{8}$ & & $\neg$ & $\mid \begin{array}{r}\stackrel{N}{N} \\
\text { oi }\end{array}$ & $\begin{array}{l}\vec{N} \\
\dot{N}\end{array}$ & 0 & $\stackrel{\mathscr{I}}{?}$ & 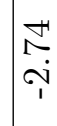 & 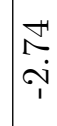 & 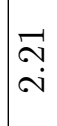 & 11 & 1 & \begin{tabular}{c}
0 \\
\multirow{1}{1}{} \\
$\stackrel{1}{1}$ \\
$T$ \\
1
\end{tabular} & 1 & 1 & 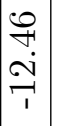 & 1 & 1 & 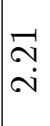 \\
\hline$\frac{8}{11}$ & {$\left[\begin{array}{c}F-10 \\
\| \\
0\end{array}\right.$} & $\stackrel{10}{\circ}$ & \begin{tabular}{|l}
2 \\
$\stackrel{2}{2}$ \\
$\stackrel{2}{0}$ \\
0
\end{tabular} & $\begin{array}{l}20 \\
0 \\
1 \\
0\end{array}$ & 0 & 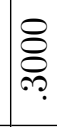 & $\begin{array}{l}20 \\
\mathscr{D} \\
0 \\
0\end{array}$ & $\begin{array}{l}20 \\
\mathscr{\Omega} \\
\mathscr{O}\end{array}$ & $\begin{array}{l}\infty \\
0 \\
0 \\
0\end{array}$ & 0 & 0 & 0 & 0 & 0 & 0 & 0 & 0 & 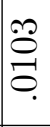 \\
\hline$\frac{8}{8}$ & 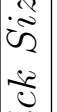 & $\stackrel{ }{=}$ & 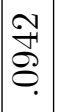 & $\begin{array}{l}\infty \\
2 \\
\stackrel{2}{8} \\
\delta\end{array}$ & 0 & $\begin{array}{l}8 \\
8 \\
\text { ?. }\end{array}$ & 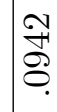 & 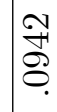 & 당 & 0 & 0 & 0 & 0 & 0 & 0 & 0 & 0 & 공 \\
\hline 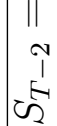 & 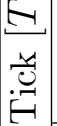 & 10 & 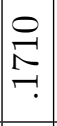 & $\begin{array}{l}\mathscr{D} \\
\stackrel{2}{2} \\
\infty\end{array}$ & 0 & @̊ & $\begin{array}{l}\varrho \\
\stackrel{I}{\nearrow}\end{array}$ & $\underset{ }{\stackrel{ }{I}}$ & $\begin{array}{l}10 \\
20 \\
08 \\
0\end{array}$ & 0 & 0 & 0 & 0 & 0 & 0 & 0 & 0 & $\mid \begin{array}{l}20 \\
20 \\
0 \\
0\end{array}$ \\
\hline $\begin{array}{l}\check{0} \\
11\end{array}$ & 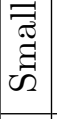 & -1 & $\begin{array}{l}2 \\
20 \\
20 \\
19\end{array}$ & $\underset{f}{\underset{f}{f}}$ & 0 & 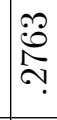 & $\begin{array}{l}0 \\
\infty \\
1 \\
1 \\
1\end{array}$ & $\begin{array}{l}0 \\
\infty \\
2 \\
10 \\
1\end{array}$ & $\stackrel{10}{\mathscr{S}}$ & 0 & 0 & 0 & $\begin{array}{l}\infty \\
\infty \\
\infty \\
0 \\
0\end{array}$ & $\left.\begin{array}{l}\infty \\
\infty \\
\infty \\
0 \\
0\end{array}\right]$ & 0 & 0 & 0 & $\stackrel{20}{8}$ \\
\hline $\begin{array}{l}1 \\
0 \\
80\end{array}$ & $\vec{F}$ & 80 & $\mid \begin{array}{l}0 \\
\stackrel{2}{0} \\
0\end{array}$ & $\begin{array}{l}+ \\
D \\
D \\
0\end{array}$ & 0 & 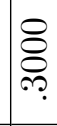 & \begin{tabular}{l}
0 \\
\multirow{1}{0}{} \\
0
\end{tabular} & 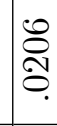 & $\begin{array}{l}2 \\
0 \\
0 \\
0\end{array}$ & ' & 1 & 0 & 1 & 1 & 0 & 1 & 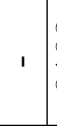 & $\begin{array}{l}\infty \\
\stackrel{0}{0} \\
\end{array}$ \\
\hline$\frac{\widetilde{\pi}}{\widetilde{\tau}}$ & $\left|\begin{array}{l}\dot{\tilde{n}} \\
\dot{\omega} \\
\dot{\sim} \\
\dot{\sim}\end{array}\right|$ & $\stackrel{ }{-1}$ & $\mid \begin{array}{l}1 \\
2 \\
8 \\
8\end{array}$ & $\underset{\infty}{\infty}$ & 0 & \begin{tabular}{l}
$\mathscr{8}$ \\
8 \\
\hdashline \\
p.
\end{tabular} & $\begin{array}{l}\mathcal{I} \\
\mathscr{2} \\
\mathscr{g}\end{array}$ & $\begin{array}{l}\mathcal{N} \\
\text { S. } \\
\delta \\
\end{array}$ & $\begin{array}{l}0 \\
\frac{1}{1} \\
0\end{array}$ & ' & 1 & 0 & 1 & I & 0 & 1 & 1 & $\begin{array}{l}0 \\
\stackrel{1}{2} \\
0\end{array}$ \\
\hline 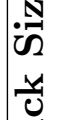 & 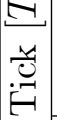 & 10 & $\begin{array}{l}\text { O } \\
\text { ㄴ } \\
-!\end{array}$ & $\begin{array}{l}0 \\
0 \\
01 \\
\infty\end{array}$ & 10 & 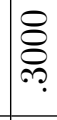 & 온 & 온 & $\begin{array}{l}\mathbb{R} \\
\infty \\
0\end{array}$ & I & 1 & 0 & 1 & 1 & 0 & 1 & 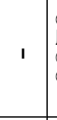 & $\begin{array}{l}\mathfrak{R} \\
\infty \\
\infty\end{array}$ \\
\hline $\begin{array}{l}E \\
0 \\
0\end{array}$ & \begin{tabular}{|l|}
0 \\
$\infty$ \\
$\dot{\tilde{T}}$ \\
$\oplus$ \\
-
\end{tabular} & $\rightarrow$ & $\begin{array}{l}\mathscr{8} \\
\mathscr{0} \\
1 \\
19\end{array}$ & 우 & 10 & $\begin{array}{l}\vec{D} \\
\stackrel{D}{N}\end{array}$ & $\begin{array}{l}\mathscr{1} \\
\mathscr{0} \\
\infty \\
1\end{array}$ & $\begin{array}{l}\mathscr{8} \\
\mathscr{0} \\
\infty \\
1\end{array}$ & $\begin{array}{l}+\infty \\
\infty \\
0 \\
-1\end{array}$ & I & 1 & $\begin{array}{l}0 \\
\stackrel{1}{1} \\
\stackrel{\sim}{-}\end{array}$ & 1 & $\$$ & $\begin{array}{l}0 \\
\stackrel{1}{\sim} \\
-1\end{array}$ & 1 & & $\begin{array}{l}\not \\
\infty \\
0 \\
\end{array}$ \\
\hline $\overrightarrow{\widetilde{\sigma}}$ & & 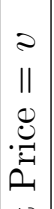 & 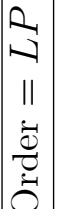 & $\begin{array}{c}-1 \\
\vdots \\
11 \\
\vdots \\
0 \\
0 \\
0 \\
0\end{array}$ & 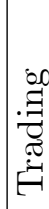 & 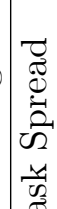 & 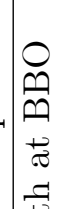 & 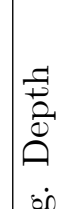 & 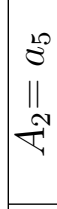 & $\vec{\sigma}^{*}$ & $\mathscr{8}$ & $\mid \begin{array}{c}\tilde{E} \\
\| \\
\| \\
\mathcal{Z}\end{array}$ & $\vec{\sigma}$ & 5 & $\begin{array}{c}\mathcal{S} \\
\| \\
D^{-1}\end{array}$ & $\infty$ & $\sigma^{H}$ & 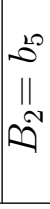 \\
\hline & & $\begin{array}{l}0 \\
0 \\
0 \\
2\end{array} \mid$ & 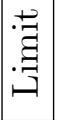 & 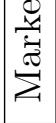 & Z & $\frac{1}{0} \cdot \frac{1}{n}$ & ญे & 4 & & & & & & & $\begin{array}{l}\dot{0} \\
\stackrel{0}{0}\end{array}$ & & & \\
\hline
\end{tabular}

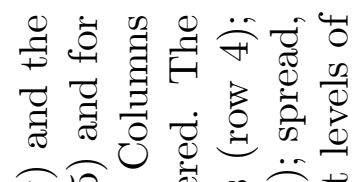

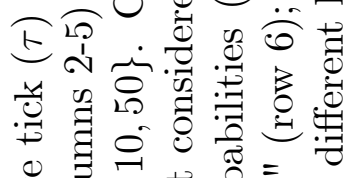

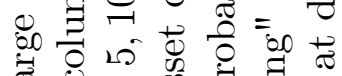

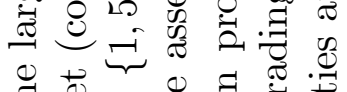

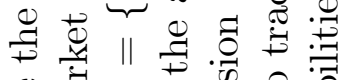
0.

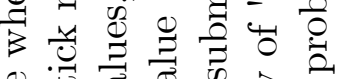
证需 क

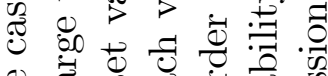

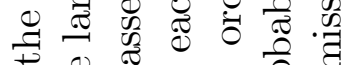

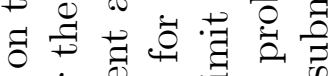
y

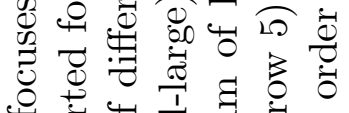

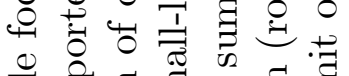

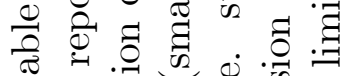
.

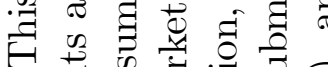

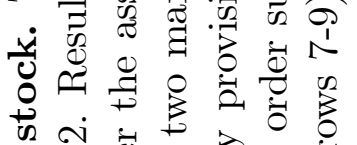
讨

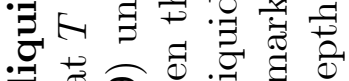

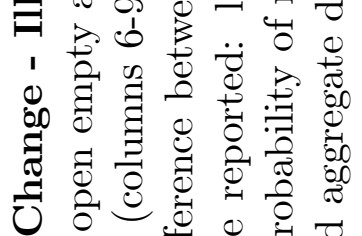
0

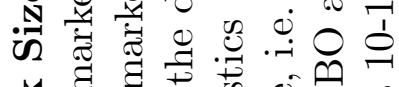

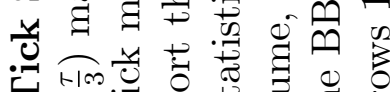

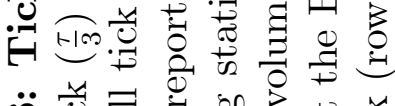

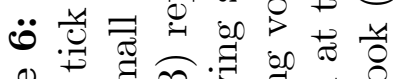

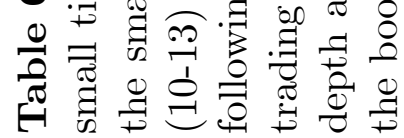




\begin{tabular}{|c|c|c|c|c|c|c|c|c|c|c|c|c|c|c|c|c|c|c|}
\hline & & $\frac{2}{2}$ & $\left.\right|_{\sigma} ^{\infty}$ & 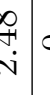 & 0 & $\ddot{\theta}_{i}$ & 0 & 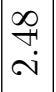 & 0 & & 1 & 0 & I & & 0 & 1 & & 0 \\
\hline $\begin{array}{c}-1 m \\
11 \\
0\end{array}$ & $\underset{8}{8}$ & $\frac{x}{\square}$ & $-1 \mid \begin{array}{l}\bar{m} \\
\end{array}$ & 年 & 0 & $\stackrel{N}{N}$ & 0 & 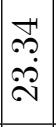 & 0 & & 1 & 0 & ' & 10 & 0 & 1 & & 0 \\
\hline 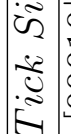 & 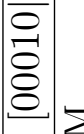 & $\subseteq$ & $\vec{a}$ & & 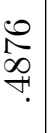 & $\begin{array}{l}\stackrel{P}{D} \\
\underset{H}{-}\end{array}$ & 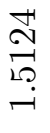 & 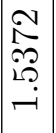 & 0 & 0 & 0 & 0 & 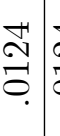 & $\begin{array}{c}\vec{J} \\
\vec{N} \\
\vec{v}\end{array}$ & 0 & 00 & 010 & 0 \\
\hline $\begin{array}{l}\ddot{\sum} \\
\ddot{\sim} \\
ت\end{array}$ & $\mid \begin{array}{l}21 \\
0 \\
\frac{0}{\sigma} \\
0\end{array}$ & ת & $-1 \mid \begin{array}{l}\vec{C} \\
\hat{\sigma}\end{array}$ & & 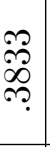 & 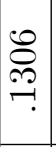 & $\begin{array}{l}1 \\
0 \\
6 \\
0 \\
-1 \\
-1\end{array}$ & $\begin{array}{l}\vec{\sigma} \\
\infty \\
\infty \\
\infty \\
-i \\
-1\end{array}$ & 0 & 0 & 0 & 0 & 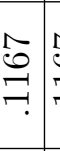 & 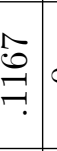 & 0 & 0.0 & 010 & 0 \\
\hline $\begin{array}{c}0 \\
\| \\
1 \\
1\end{array}$ & $\mid \begin{array}{c}11 \\
1 \\
1 \\
1 \\
5\end{array}$ & $\sum$ & $D$ & & $\begin{array}{c}0 \\
2 \\
\infty \\
\rightarrow !\end{array}$ & $\begin{array}{l}\infty \\
\infty \\
\infty \\
+ \\
\\
\end{array}$ & 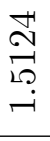 & 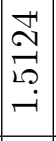 & 0 & ' & 1 & 0 & 1 & 10 & 0 & 1 & 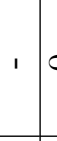 & 0 \\
\hline 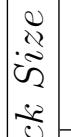 & & -1 & -10 & $0 \mid \begin{array}{l}\sigma \\
\vdots \\
\vdots\end{array}$ & 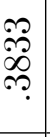 & $\begin{array}{l}\infty \\
\infty \\
\infty \\
-1 \\
-1\end{array}$ & $\begin{array}{l}\sqrt[1]{0} \\
\qquad 0 \\
0 \\
-1 \\
\end{array}$ & $\begin{array}{c}1 \\
0 \\
6 \\
0 \\
-i \\
\end{array}$ & 0 & 1 & 1 & 0 & 1 & 10 & 0 & 1 & $c$ & 0 \\
\hline$\underline{-}$ & & 2 & $P \mid \begin{array}{l}\alpha \\
g \\
\alpha\end{array}$ & $\begin{array}{l}0 \\
0 \\
0 \\
\infty\end{array}$ & 0 & 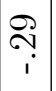 & $\begin{array}{l}\infty \\
0 \\
\infty \\
\infty\end{array}$ & $\begin{array}{c}\infty \\
0 \\
\infty \\
\infty \\
\end{array}$ & 0 & 1 & 1 & 0 & 1 & 10 & 0 & 1 & 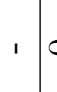 & 0 \\
\hline $\mid \begin{array}{l}3 \\
1 \\
\checkmark \\
1\end{array}$ & $\left|\begin{array}{l}8 \\
8 \\
8 \\
8 \\
\\
0\end{array}\right|<$ & $\frac{x}{\square}$ & $-\mid \begin{array}{l}\alpha \\
1 \\
b \\
v\end{array}$ & ס & 0 & 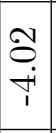 & $\begin{array}{l}\infty \\
1 \\
0 \\
10 \\
12\end{array}$ & $\mid \begin{array}{l}\infty \\
1 \\
\dot{0} \\
1 \\
1\end{array}$ & 0 & ' & 1 & 0 & 1 & 10 & 0 & 1 & 10 & 0 \\
\hline $\begin{array}{c}F-1 \\
\ddot{g} \\
.0\end{array}$ & $\left|\begin{array}{l}8 \\
8 \\
8 \\
\hdashline \\
\end{array}\right|$ & $\Sigma 10$ & 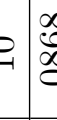 & \begin{tabular}{l|l}
0 & \\
0 & \\
0 & 2 \\
0 & \\
\end{tabular} & \begin{tabular}{l}
0 \\
0 \\
0 \\
$\stackrel{2}{9}$ \\
\hdashline
\end{tabular} & 동 & $\begin{array}{l}\infty \\
0 \\
0 \\
0 \\
0\end{array}$ & $\begin{array}{l}0 \\
0 \\
0 \\
0 \\
0 \\
\end{array}$ & 0 & 苞 & 0 & 0 & 0 & 0 & 0 & $\circ$ & $\begin{array}{c}\vec{W} \\
\stackrel{9}{O} \\
\\
\end{array}$ & 0 \\
\hline $\mid$ & $\frac{8}{8}$ & ת & $-\mid \begin{array}{l}\alpha \\
1 \\
b \\
v\end{array}$ & 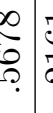 & $\begin{array}{l}\overrightarrow{0} \\
\vec{\jmath}\end{array}$ & 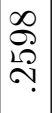 & 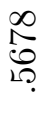 & 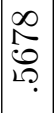 & 0 & 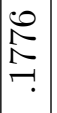 & 0 & 0 & 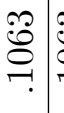 & 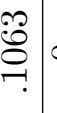 & 0 & 0 & 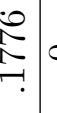 & 0 \\
\hline$\circlearrowright$ & \begin{tabular}{|c|}
11 \\
$T$ \\
$I$ \\
\end{tabular} & $\underline{\underline{e}}$ & $D \subset$ & 0 & 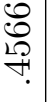 & 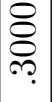 & 0 & 0 & 0 & 1 & 1 & 0 & 1 & 10 & 0 & 1 & $c$ & 0 \\
\hline 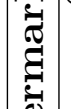 & & - & -10 & 0 & $\begin{array}{l}\overrightarrow{0} \\
\vec{\sim}\end{array}$ & 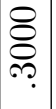 & 0 & 0 & 0 & 1 & 1 & 0 & 1 & 10 & 0 & 1 & $c$ & 0 \\
\hline $\begin{array}{l}-1 \\
\frac{0}{0} \\
\frac{0}{\sigma}\end{array}$ & & 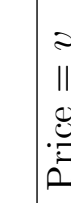 & 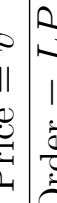 & 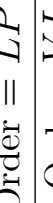 & $\begin{array}{l}-1 \\
\bar{x} \\
11 \\
\dot{0} \\
0 \\
0 \\
0\end{array}$ & 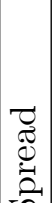 & 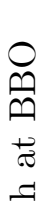 & 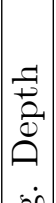 & $\begin{array}{c}0 \\
0 \\
\| \\
N \\
\mathbb{T}\end{array}$ & ठ্م) & $\tilde{\sigma}$ & $\mid \begin{array}{c}\tilde{B} \\
\| \\
\underline{\nabla} \\
\tilde{T}\end{array}$ & $\vec{\sigma}$ & 5 & $\begin{array}{c}\tilde{S} \\
\| \\
\infty \\
\sim\end{array}$ & $\infty$ & $\sigma^{+1}$ & $\begin{array}{c}\underbrace{2} \\
11 \\
0 \\
0\end{array}$ \\
\hline & & $\begin{array}{l}0 \\
0 \\
0 \\
4 \\
4\end{array}$ & 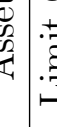 & $\exists$ & 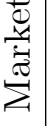 & & $\stackrel{\overrightarrow{0}}{0}$ & $\sum_{4}^{\infty}$ & & & & & & & ? & & & \\
\hline
\end{tabular}

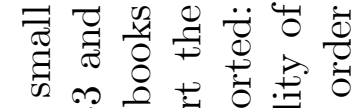

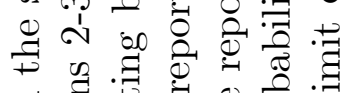
굴

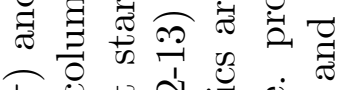

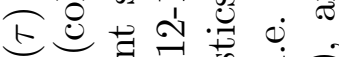
بै

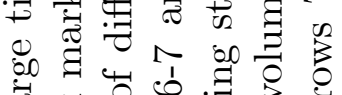
离

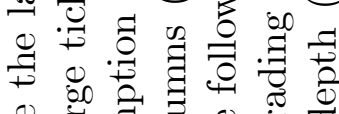

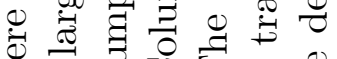

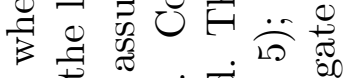
ष

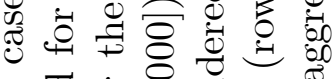
击

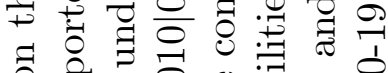

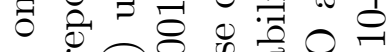
我

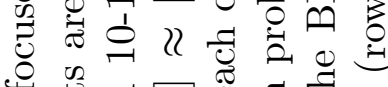
․ㅠ శ్

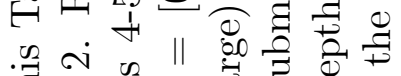
寻

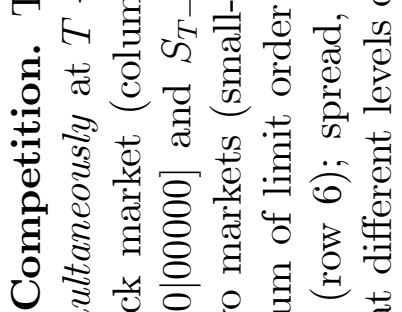
त. हूँ 幽

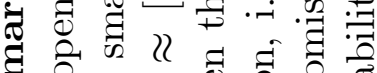

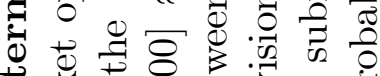
苟

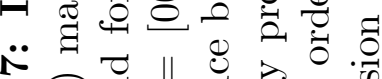
○

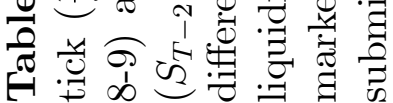


?

总

융

을

ชิำ

엉

○

‘்

118

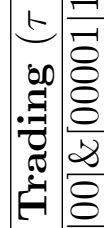

릴용

音

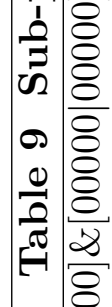

시용

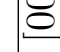

II

25

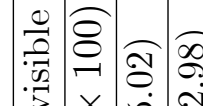

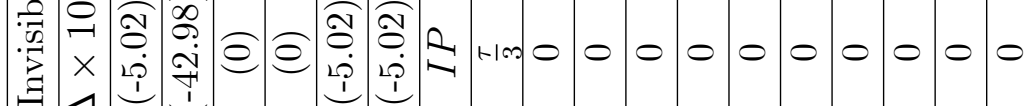

$\therefore \unlhd$

药

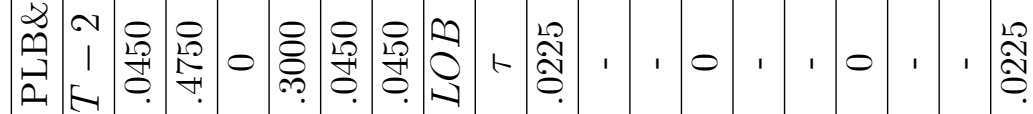

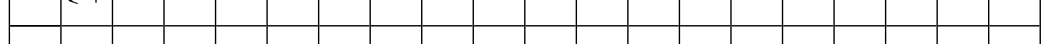

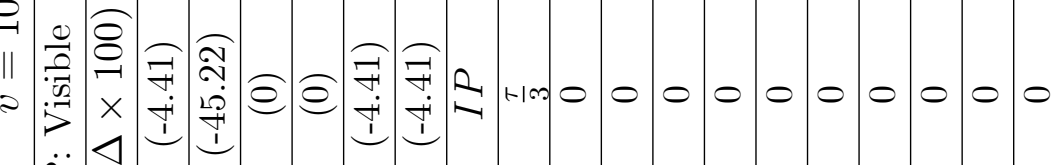

$\ddot{\theta} \unlhd$

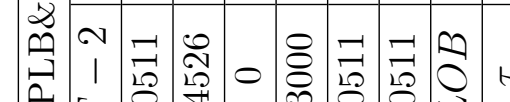

$\stackrel{5}{20}$

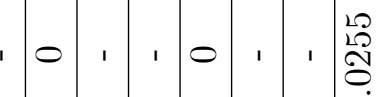

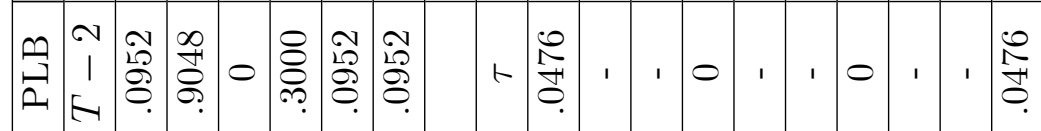

○)

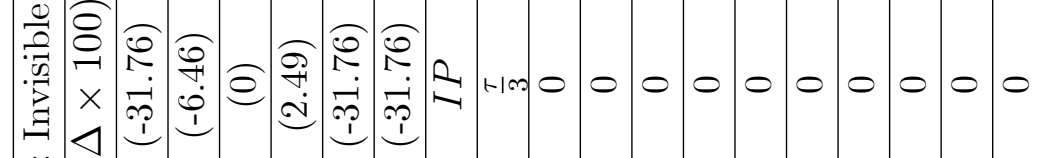

苜

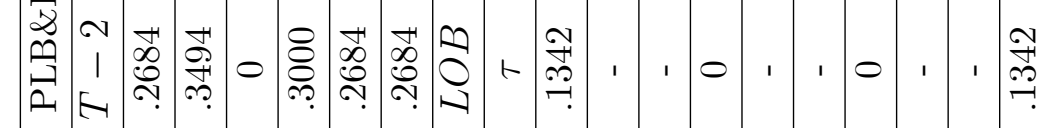

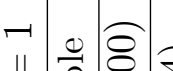

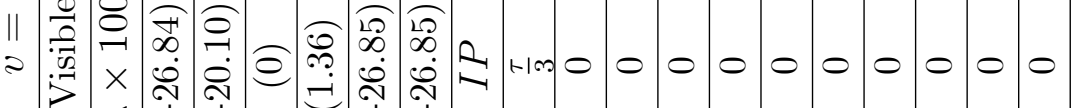
$\therefore$ ব

$\theta$

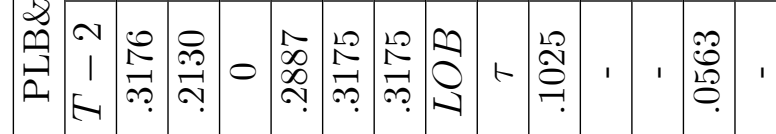

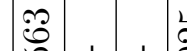

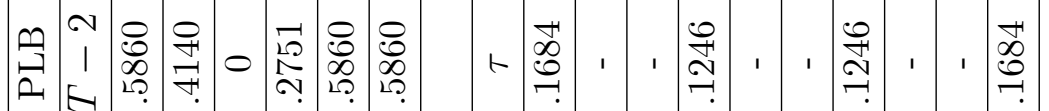

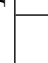

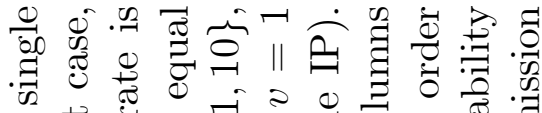

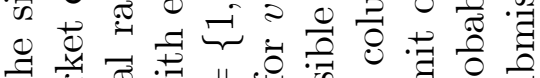

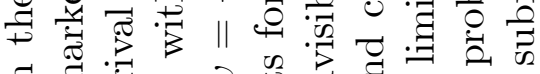

छี

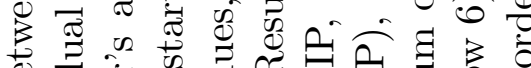

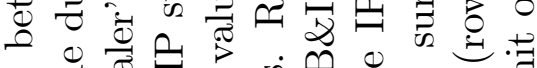

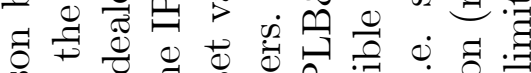

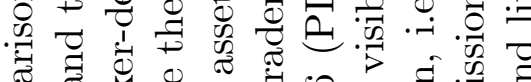

䒕

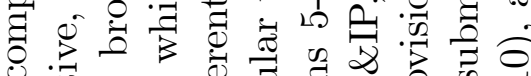

0 获

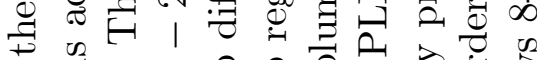

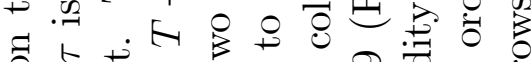

ôt.

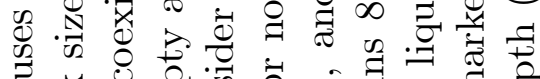

उั

फ

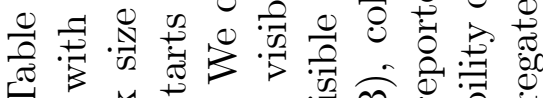

H

两要

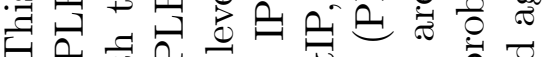

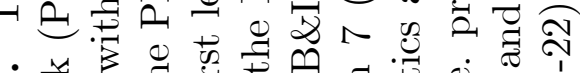

نे

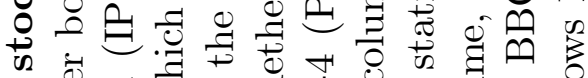

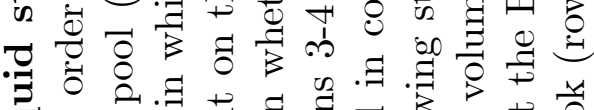

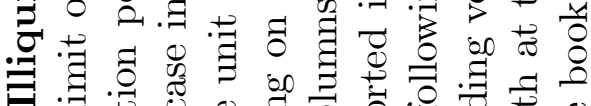

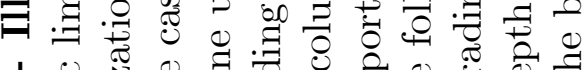

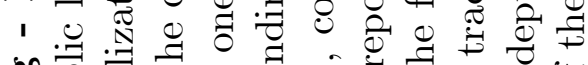

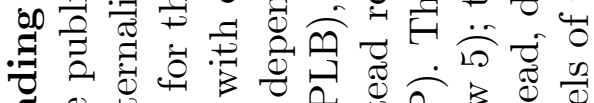

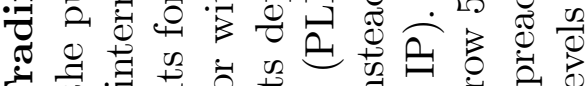

H.A

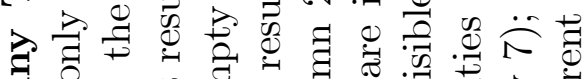

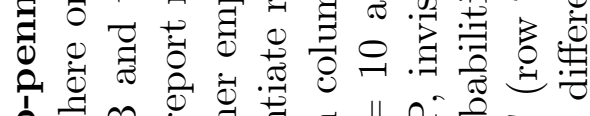

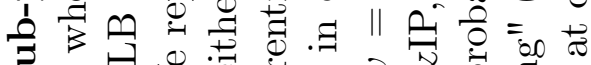

जी

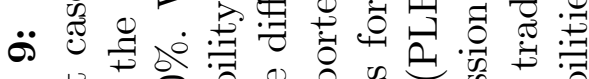

0

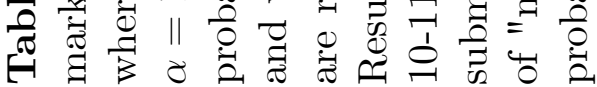




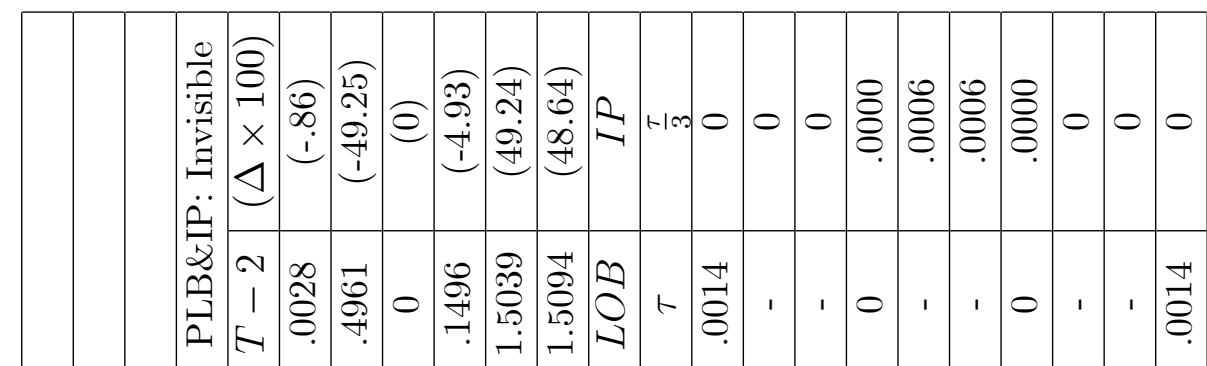

.0

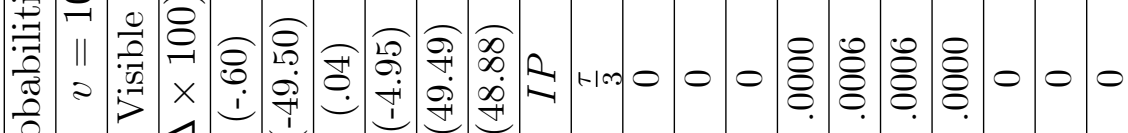
늘

(2)

$\stackrel{-}{\mathcal{O}}$

$\partial \frac{7}{\frac{1}{3}}$

官

11

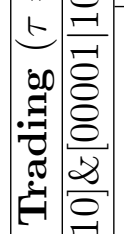

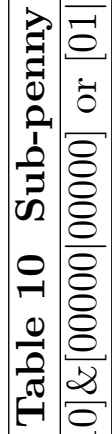

$\ddot{\theta}$

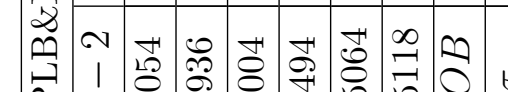

ล

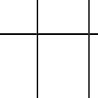

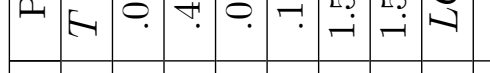

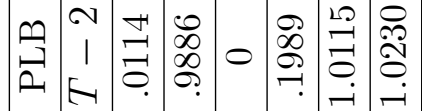

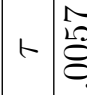

$\frac{0}{8}$

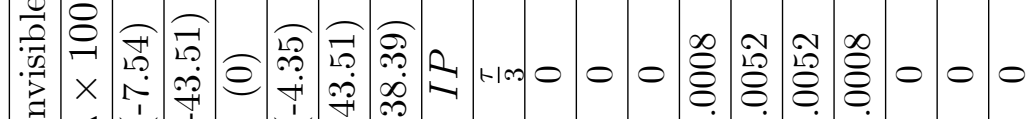

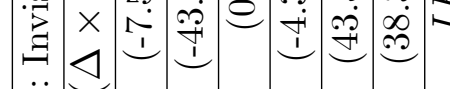

$\ddot{\theta}$

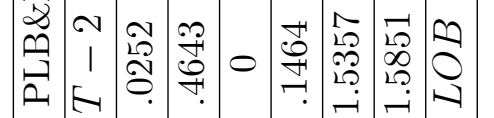

$+\mid \begin{gathered}\stackrel{0}{\vartheta} \\ \vdots \\ 0\end{gathered}$

,

10

ڤ্ণ

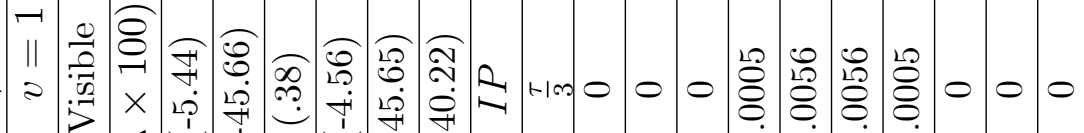

$\ddot{\theta} \unlhd$

$\frac{2}{2}$

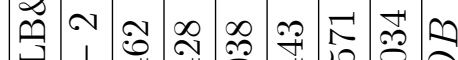

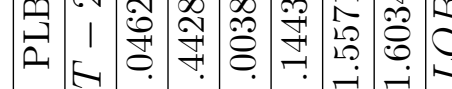

o

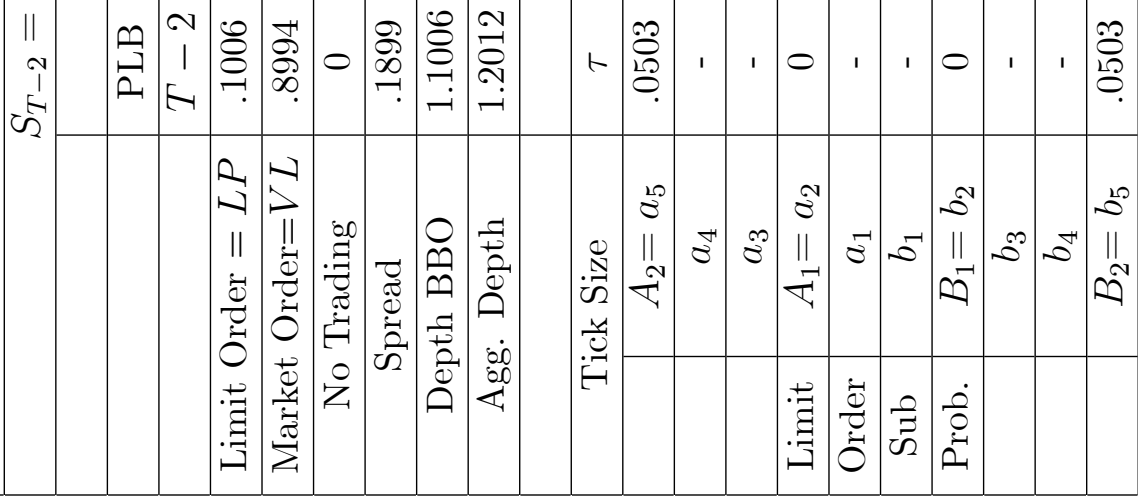

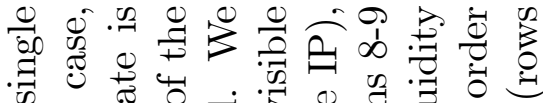

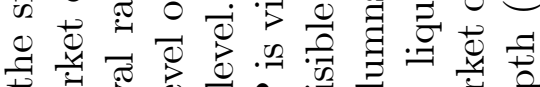

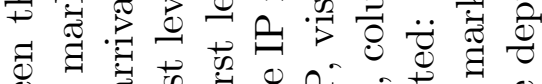

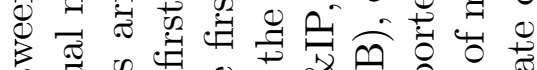

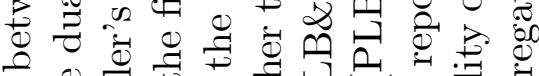

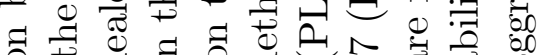

负

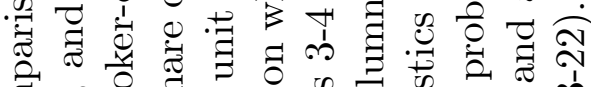

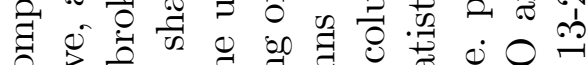

0.000 。

秀

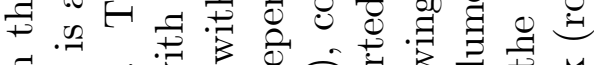

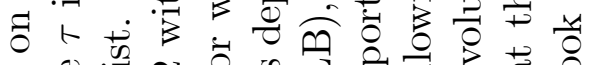

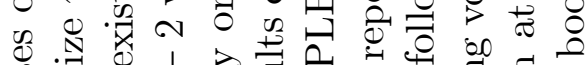

需 01 ।

ठै

फ

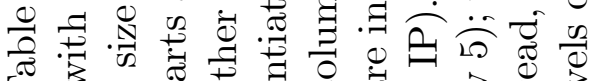

E

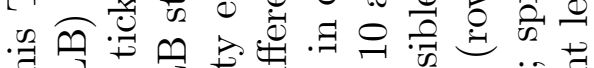
可㲧河

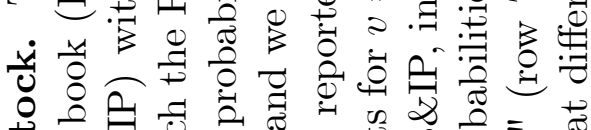

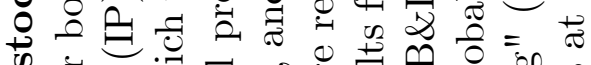
क 哥 . ,.$\exists$.

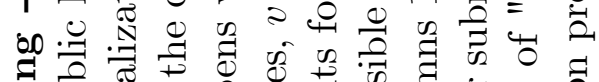

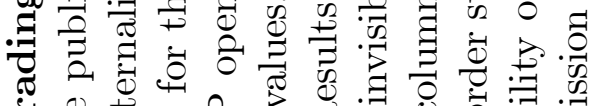
\&

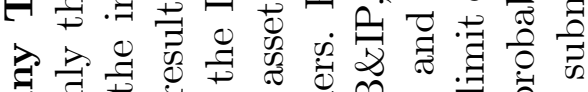
चี

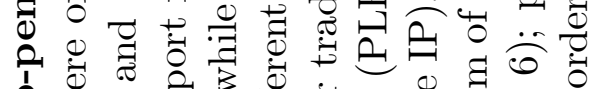

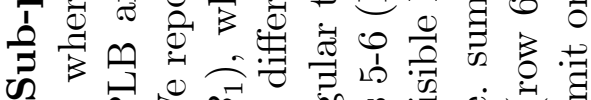
थ की

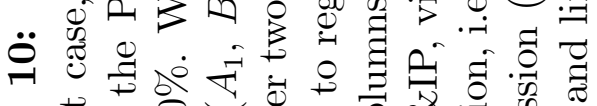

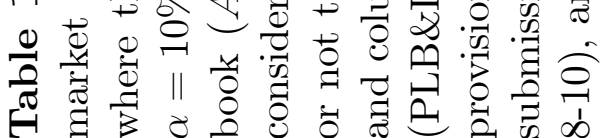

